Portland State University

PDXScholar

Dissertations and Theses

Dissertations and Theses

Summer 8-10-2016

\title{
QueF and QueF-like: Diverse Chemistries in a Common Fold
}

Adriana Bon Ramos

Portland State University

Follow this and additional works at: https://pdxscholar.library.pdx.edu/open_access_etds

Part of the Chemistry Commons, and the Enzymes and Coenzymes Commons Let us know how access to this document benefits you.

Recommended Citation

Bon Ramos, Adriana, "QueF and QueF-like: Diverse Chemistries in a Common Fold" (2016). Dissertations and Theses. Paper 3101.

https://doi.org/10.15760/etd.3098

This Dissertation is brought to you for free and open access. It has been accepted for inclusion in Dissertations and Theses by an authorized administrator of PDXScholar. Please contact us if we can make this document more accessible: pdxscholar@pdx.edu. 
QueF and QueF-like:

Diverse Chemistries in a Common Fold

\title{
by
}

\section{Adriana Bon Ramos}

A dissertation submitted in partial fulfillment of the requirements for the degree of

\author{
Doctor of Philosophy \\ in \\ Chemistry
}

Dissertation Committee:

Dirk Iwata-Reuyl, Chair

Niles Lehman

John Perona

Michael Bartlett

Portland State University

2016 


\begin{abstract}
The tunneling fold (T-Fold) superfamily is a small superfamily of enzymes found in organisms encompassing all kingdoms of life. Seven members have been identified thus far. Despite sharing a common three-dimensional structure these enzymes perform very diverse chemistries.

QueF is a bacterial NADPH-dependent oxidoreductase that catalyzes the reduction of the nitrile group of 7-cyano-7-deazaguanine (preQu) to a primary amine (preQ 1 ) in the queuosine biosynthetic pathway. Previous work on this enzyme has revealed the mechanism of reaction but the cofactor binding residues remain unknown. The experiments discussed herein aim to elucidate the role of residues lysine 80 , lysine 83 , and arginine 125 (B. subtilis numbering) in NADPH binding. The biological role of the disulfide bond between the conserved residues cysteine 55 and cysteine 99 observed in several crystal structures is also examined.
\end{abstract}

Characterization of QueF mutants K80A, K83, R125A and R125K revealed lysine 80, lysine 83 and arginine 125 are required for turnover. Further analysis of turnover rates for $\mathrm{R} 125 \mathrm{~K}$ are consistent with this residue and both lysines being involved in cofactor binding presumably by interacting with the negatively charged phosphate tail of NADPH and are therefore involved in cofactor binding. Based on bond angles and energies, the disulfide bond between Cys55 and Cys99 was characterized as non-structural. Enzyme oxidation assays were consistent with the bond serving to protect QueF against irreversible oxidation of 
Cys55, which would render the enzyme inactive. This is the only known example of a stress protective mechanism in the Tunneling-fold superfamily.

QueF-like is an amidinotransferase found in some species of Crenarchaeota and involved in the biosynthesis of archaeosine-tRNA. The work presented here is focused on the preliminary characterization of this enzyme, including the elucidation of the natural substrate as well as the source of ammonia. The structure of the enzyme was solved and is also discussed.

Substrate analysis for QueF-like indicated this enzyme is capable of binding both preQ $Q_{0}$ and preQo-tRNA and reacting to form a thioimide intermediate analogous to QueF but only the latter serves as a substrate for the reaction. This makes QueF-like the first example of a nucleic acid binding enzyme in the Tunnelingfold superfamily. Ammonia, glutamine and asparagine were tested as nitrogen sources and unlike most known amidotransferases, QueF-like can only use free ammonia to produce the archaeosine-tRNA product. The crystal structure of $P$. calidifontis QueF-like indicates the functional enzyme is a dimer of pentamers pinned together by a large number of salt bridges. The structure presents a high degree of similarity to that of QueF albeit the higher twist of the QueF-like pentamers with respect to QueF results in a more compact structure. 


\section{Dedication}

This dissertation is dedicated to my husband Aaron, who's belief in my strength and capabilities has always surpassed my own.

"Upon the subject of education, not presuming to dictate any plan or system respecting it, I can only say that I view it as the most important subject which we as a people can be engaged in."

Abraham Lincoln, First Political Announcement, March 9, 1832. 


\section{Table of Contents}

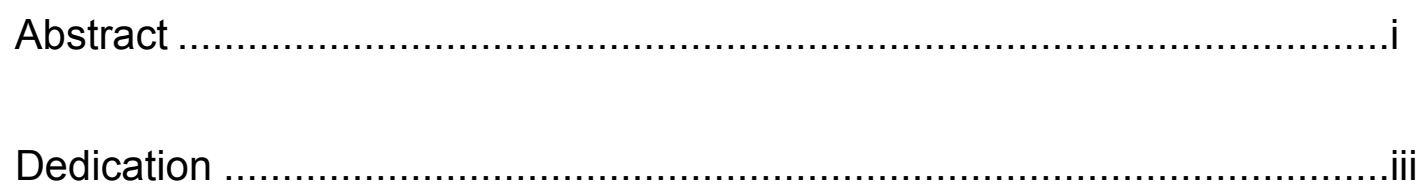



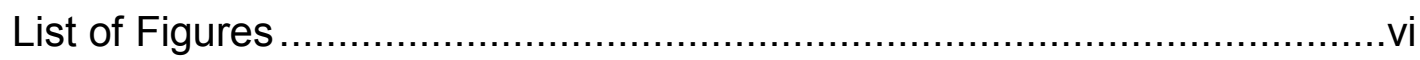

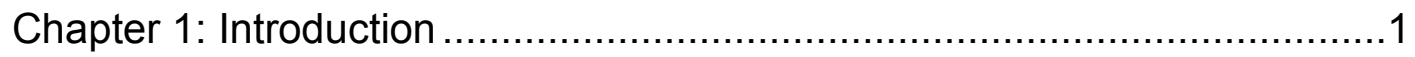

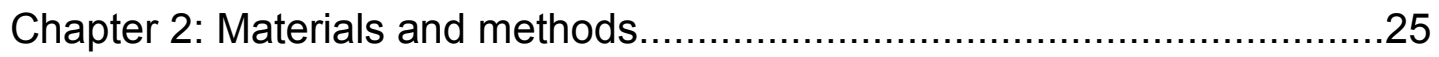

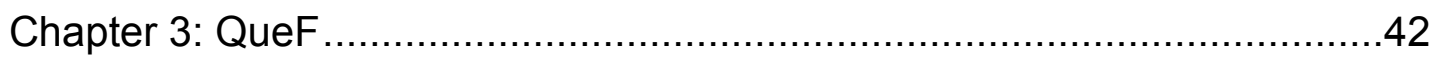

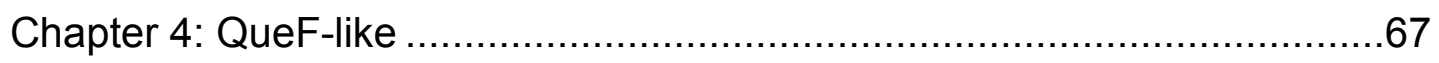

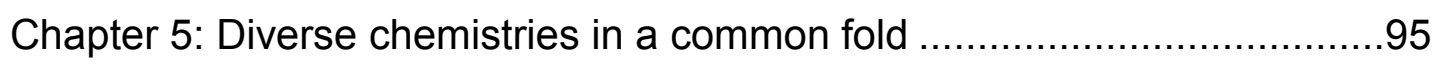



Appendix A - QueF: How to measure kinetic constants for preQo ...............110

Appendix B - QueF-like: Glutamine as a source of nitrogen for the QueFL

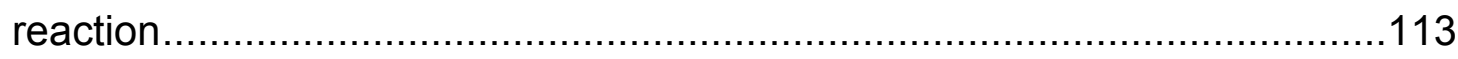




\section{List of Tables}

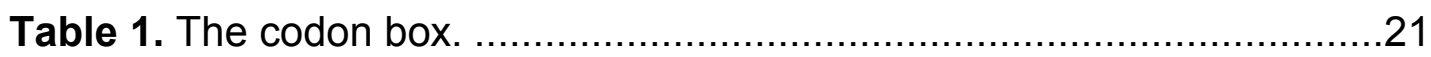

Table 2. Presence of modified nucleosides at position 37 of tRNA .............22

Table 3. Analysis of chi angles of the Cys55-Cys9g bond of QueF. ..............50 


\section{List of Figures}

Figure 1. Fold of the monomer of 7,8-dihydroneopterin epimerase...........4

Figure 2. Single subunit structures of Unimodular B. subtilis QueF (left) and bimodular V. cholerae QueF (right)..

Figure 3. Reactions catalyzed by the enzymes in the Tunneling fold superfamily .8

Figure 4. Structure of the monomers of 7,8-dihydroneopterin triphosphate epimerase, DHNA, GCYH-1B, PTPS and UOX. 9

Figure 5. Top view of the structure of the Tunneling fold enzymes.............10

Figure 6. Modified nucleosides Archaeosine (left) and Queuosine. 11

Figure 7. Depiction of the the G:C reverse Watson-Crick (W:W trans) base pair

Figure 8. Metabolic pathways to Queuosine and Archaeosine ....................15

Figure 9. Secondary $(A)$ and tertiary $(B)$ structure of tRNA .....................17

Figure 10. Modified nucleosides found in the different kingdoms of life .......18

Figure 11. Oxidation assay of QF enzymes with hydrogen peroxide...........36

Figure 12. QueF reaction mechanism. ……........................................44

Figure 13. Top view of the crystal structure of the QueF .........................45

Figure 14. Side view of the crystal structure of QueF ..............................45

Figure 15. Docking model of NADPH in QueF ...................................47

Figure 16. Cys55-Cys99 QueF disulfide bond.. ..................................48

Figure 17. Relative activity of QueF (orange) and mutants R125K (green), R125A (red), K80A (navy), K83A (black) and a blank solution (cyan)...52

Figure 18. Michaelis-Menten fit of steady-state reaction velocities for varying concentrations of NADPH with wild-type enzyme.

Figure 19. Expanded view of the formation of thioimide intermediate for wild-type QueF (black) and mutants K80A (orange), K83A (maroon), R125A (green) and R125K (blue).... 
Figure 20. Steady-state reaction velocities for wild-type enzyme with varying concentrations of NADPH..

Figure 21. Steady-state velocities reactions of mutant enzyme R125K with varying concentrations of $\mathrm{NADPH}$.

Figure 22. Continuous monitoring of NADH consumption in the WT QueF reaction.

Figure 23. Reversible and irreversible oxidation of thiols 60

Figure 24. Activity of wild-type QueF (black), mutants C99A (red) and C99S (blue).

Figure 25. Inactivation of QueF upon treatment with hydrogen peroxide.....62

Figure 26. Recovery of wild-type enzyme activity upon treatment with thioredoxin. 63

Figure 27. Activity recovery after $60 \mathrm{~min}$ treatment with thioredoxin .64

Figure 28. Archaeosine-tRNA biosynthetic pathway. 68

Figure 29. Conservation of archaeosine metabolism enzymes in Archaea. 70

Figure 30. Possible biosynthetic routes from PreQ 0 to archaeosine-tRNA ..72

Figure 31. Sequence alignment of Unimodular (uni) and bimodular (BiC) QueF and QueF-like (QueFL). .73

Figure 32. Modeled QueF-like structure superimposed on QueF B. subtilis structure. .74

Figure 33. SDS-PAGE analysis of QueF-like purification. .........................76

Figure 34. SDS-PAGE analysis of MjTGT purification.............................77

Figure 35. Urea-PAGE purification of in vitro transcribed M.

Thermoautotrophicus tRNA ${ }^{\text {Gln }}$ .78

Figure 36. Loss of radiolabeled guanine during the MJTGT exchange reaction. .79

Figure 37. HPLC analysis of digested PreQo-tRNA. .80

Figure 38. UV-Vis spectroscopy of PreQo addition to QueF-like. 81 
Figure 39. Increase in $376 \mathrm{~nm}$ absorbance as a function of PreQ concentration

Figure 40. UV-Vis spectroscopy of PreQo-tRNA addition to QueF-like (inset)

Figure 41. Loss of thioimide intermediate absorbance as a function of reaction time.

Figure 42. Loss of thioimide absorbance at $376 \mathrm{~nm}$ for the reaction of QueF-like with PreQo-tRNA and ammonium chloride (solid), glutamine (dashed) and asparagine (dotted) respectively.

Figure 43. Loss of thioimide absorbance when PreQo-tRNA and ammonium chloride are used as substrates for archaeosine formation.

Figure 44. HPLC of digested tRNA from the reaction between QueFL, preQo-tRNA and ammonium chloride.

Figure 45. Absorbance spectrum of HPLC peaks at $31 \mathrm{~min}$ (left) and $32 \mathrm{~min}$ (right) for the product of the reaction between QueFL, PreQo-tRNA and $\mathrm{NH}_{4} \mathrm{Cl}$.

Figure 46. ESI-MS analysis of the digested tRNA product from the reaction between QueF-like, PreQo-tRNA ${ }^{\text {Gln }}$ and ammonium chloride. 89

Figure 47. Top (left) and side (right) view of the QueF-L homodecamer. ....91

Figure 48. Formation of thioimide intermediate in QueF-like .92

Figure 49. Structural comparison of $V$. cholereae QueF (A), B. subtilis (B), and $P$. calidifontis QueF-like $(\mathrm{C})$. .97

Figure 50. Proposed mechanism for the QueF-like reaction .99 


\section{Chapter 1. Introduction}

\subsection{Protein superfamilies and folds}

Understanding the global relationships between protein sequence, structure and function is essential to predicting the function of newly discovered proteins and engineering new enzymes. Currently, classifications of protein families and superfamilies are based on their function and/or structure ${ }^{1,2}$. Ultimately, the goal is to be able to determine the relationship between the presence of an amino acid in a protein sequence and its effect on the function and/or structure of the protein. That is, a protein equivalent of the codon box. ${ }^{3-5}$

When methods capable of determining the structure of proteins were first developed in the 1970s, it became increasingly clear that protein structure is more highly conserved than sequence ${ }^{6,7}$. Currently, over 100,000 structures have been solved and reported in the PDB database ${ }^{8}$. Structural data provides information on the evolutionary processes that have led to increasingly complex protein domain combinations, resulting in the diversity of phenotypes observed ${ }^{9}$.

As evolution takes place, proteins derived from a common ancestor (homologs) can undergo large changes to their sequences through mutations or substitutions of residues, as well as insertions, deletions, and inversions. This gives rise to families of proteins that have very low sequence similarities but may share functionalities. In other cases, relatives possess no significant sequence or function similarity but they share structural features (analogs) $)^{5,6}$. 
The term "superfamily" was coined in 1965 by Margaret Dayhoff, who early on recognized the extent of sequence variation observed within families of proteins. We now use the term to define families of evolutionarily related proteins which may have low sequence similarities but share structural features ${ }^{10,11}$. While others have included functionality as part of the superfamily grouping, ${ }^{12}$ we will not do so here.

We can further classify superfamilies as specificity diverse or mechanistically diverse. The first includes homologous enzymes that catalyze the same overall reaction with different substrate specificities, such as the serine proteases. Mechanistically diverse proteins catalyze different reactions with different substrate specificities, but typically share a common mechanistic attribute such as the same partial reaction, common intermediates or shared transition states. ${ }^{12-14}$ Examples of mechanistically diverse superfamilies include the enolase, nudix, haloacid dehalogenase, crotonase, amidohydrolase, nacetylneuraminate lyase, and terpene cyclase superfamilies. ${ }^{15,16}$

In general, mechanistic diversity is the result of differential placement of catalytic residues that are not conserved throughout the family while substrate diversity results from variations in loops and accessory binding domains. ${ }^{17-19}$ In a review of 31 superfamilies based on structure, Thornton et al. found the conservation of reaction chemistry to be far more prevalent than the conservation of substrate binding. ${ }^{13}$ They also identified semi-conserved superfamilies in which enzyme members use a common chemical strategy in the context of 
different overall transformations. Typically, it is the initial catalytic step that is conserved while the reaction paths vary, illustrating the versatility of folds. ${ }^{13,20}$

As of 2005, 1 million protein sequences from 150 completed genomes were known. Of those, approximately 50,000 have been assigned to families. Less than $15 \%$ of protein families found in a genome were found in other genomes or kingdoms. Therefore, two thirds of the protein families are unique to an organism and/or kingdom. Whether these sequences are truly "stand alone" or the product of divergent evolution is unknown. ${ }^{21-23}$

Topology or fold describes the orientations of secondary structures in three dimensions and the manner in which they are connected. Despite the growing number of unique protein sequences, only $\sim 850$ folds are predicted to exist. ${ }^{24} \mathrm{~A}$ very small percentage (about $10,<0.1 \%$ ) of these folds accounts for nearly $40 \%$ of all sequence families in the PDB and are adopted by several superfamilies. These are: TIM barrel fold, $\alpha \beta$-barrel, Rossmann fold, three-layer, $\alpha \beta$-sandwich, $\alpha \beta$-plait, and two layer $\alpha \beta$-sandwich. ${ }^{2}$ 


\subsection{The T-fold superfamily}

The tunneling fold ( $T$-fold) superfamily is a structural superfamily of proteins with diverse functions that bind planar pterin and purine substrates. The T-fold domain can be described by an antiparallel beta sheet of four strands, with two antiparallel helices layered on the concave side of the beta sheet, between the second and third strands (Figure 1). These assemble into homo oligomers to form a $\beta_{2 n} \alpha_{n}$ barrel, with 2 barrels joining in a head-to-head orientation to form a tunnel-like center ${ }^{25,26}$



Figure 1. Fold of the monomer of $7,8-$ dihydroneopterin epimerase. The $\beta$ strands and $\alpha$ helical regions are shown in blue and red, respectively. The connecting loops are shown in yellow.Figure reproduced from Ploom et al ${ }^{47}$

The active sites of all T-fold enzymes are located at the interface of several subunits (at least two), with residues from each monomer contributing to the global architecture of the active site. Furthermore, the active site has a conserved glutamine or glutamate, which anchors the substrate, along with other conserved interactions. The T-fold superfamily has two structural subfamilies, a unimodular subfamily, with proteins formed by subunits containing a single $\mathrm{T}$-fold domain repeat and a bimodular subfamily composed of proteins formed by subunits with tandem T-fold domains (Figure 2) ${ }^{26}$ 

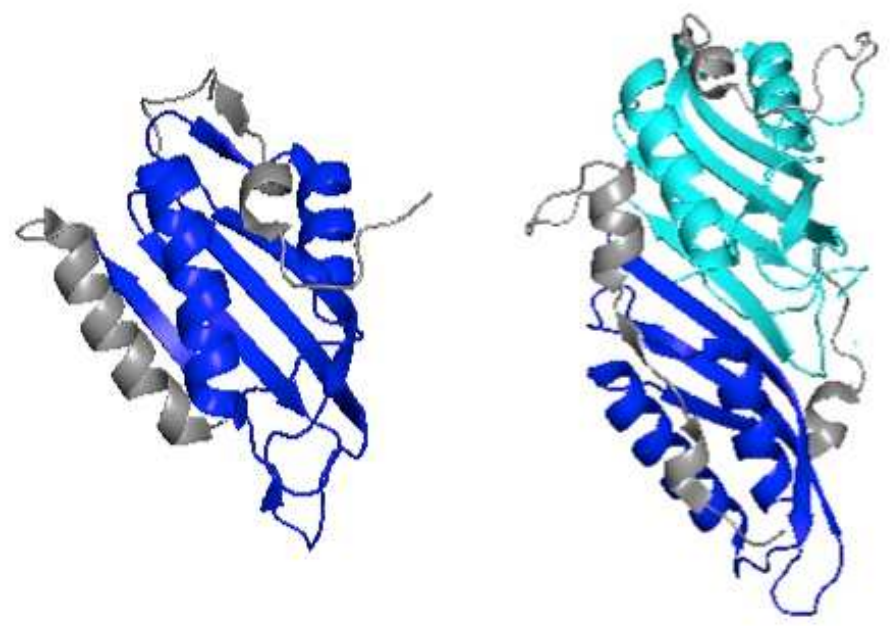

Figure 2. Single subunit structures of Unimodular B. subtilis QueF ${ }^{27}$ (left) and bimodular $V$. cholerae QueF $^{28}$ (right). The Tunneling fold motif is highlighted in blue for $B$. subtilis. Tandem motifs are shown in blue and cyan for $V$. cholerae.

To date, the T-fold superfamily has 6 known members: Guanosine cyclohydrolase 1A/B (GCYH-1A/B), ${ }^{29,30}$ QueD (previously ykvK) ${ }^{31}$, 7-cyano-7deazaguanine reductase (QueF), 27,32 7,8-dihydroneopterin triphosphate epimerase $^{33}$, 6-pyruvoyl tetrahydropterin synthase (PTPS) ${ }^{34}$, Urate oxidase $(\mathrm{UOX})^{35}$ and Dihydroneopterin aldolase (DHNA) ${ }^{36}$. GTP cyclohydrolase (GCYH-I) catalyzes the first step of the de novo tetrahydrofolate biosynthetic pathway in bacteria and plants, the 7-deazapurine (Queuosine and Archaeosine) biosynthetic pathways in Bacteria and Archaea, ${ }^{37}$ and the biopterin biosynthetic pathway in Eukarya. ${ }^{38}$ GCYH-I converts GTP to 7,8-dihydroneopterin triphosphate (Figure $3 \mathrm{~A}$ ) via the nucleophilic attack of C8 in GTP by a zinc activated water molecule. Two classes of GCYH-I exist, A (unimodular) and B (bimodular). ${ }^{39}$

6-pyruvoyl tetrahydropterin synthase (PTPS) is a unimodular ${ }^{40}$ zinc dependent enzyme that catalyzes the second step of the three-step biosynthesis 
of the essential cofactor tetrahydrobiopterin $\left(\mathrm{BH}_{4}\right)$ from GTP in mammals. PTPS converts dihydroneopterin triphosphate into 6-pyruvoyl tetrahydropterin in vertebrates. (Figure 3B). ${ }^{41}$

QueD is a homolog of PTPS that catalyzes the conversion of dihydroneopterin triphosphate to 6-carboxy-5,6,7,8- tetrahydropterin $\left(\mathrm{CPH}_{4}\right)$. E.coli QueD can also convert $\mathrm{PPH}_{4}$ and sepiapterin to $\mathrm{CPH}_{4}{ }^{42}$ (Figure $3 \mathrm{C}$ )

Dihydroneopterin aldolase (DNHA) catalyzes the conversion of 7,8dihydroneopterin (DHNP) to 6-hydroxymethyl-7,8-dihydropterin (HP) in the folate biosynthetic pathway in Bacteria and plants ${ }^{43,44}$ (Figure 3D). While mammals utilize folates, they cannot synthesize them because they lack the first three enzymes in the biosynthetic pathway, therefore, these enzymes are attractive targets for antibiotic development. ${ }^{45,46}$

7,8-dihydroneopterin triphosphate epimerase catalyzes the epimerization of carbon 2 of dihydroneopterin triphosphate $\left(\mathrm{H}_{2} \mathrm{NTP}\right)$ to dihydromonapterin triphosphate $\left(\mathrm{H}_{2} \mathrm{MTP}\right)$ in Bacteria (Figure 3E). The biological role of this enzyme and reaction product remains unclarified. ${ }^{33,47}$

Urate oxidase $(\mathrm{UOX})$ is a bimodular T-fold enzyme responsible for the conversion of uric acid to allantoin (Figure 3F) ${ }^{48}$ It catalyzes the oxidative ring opening of the purine ring in the purine degradation pathway. This enzyme is present in most fish, amphibian and mammalian species but lacking in humans. The absence in humans is considered an evolutionary advantage as uric acid provides antioxidant defense, often linked to decreased cancer rate. ${ }^{35,49}$ 
QueF is an NADPH-dependent oxidoreductase that catalyzes the reduction of the nitrile group of 7-cyano-7-deazaguanine (PreQ0) to a primary amine (preQ 1 , Figure 3G). ${ }^{32}$ Both unimodular and bimodular QueF enzymes exist.

Three T-fold enzymes, GCYH-1A/B, QueD and QueF are found in the Queuosine and Archaeosine biosynthetic pathways. 
A

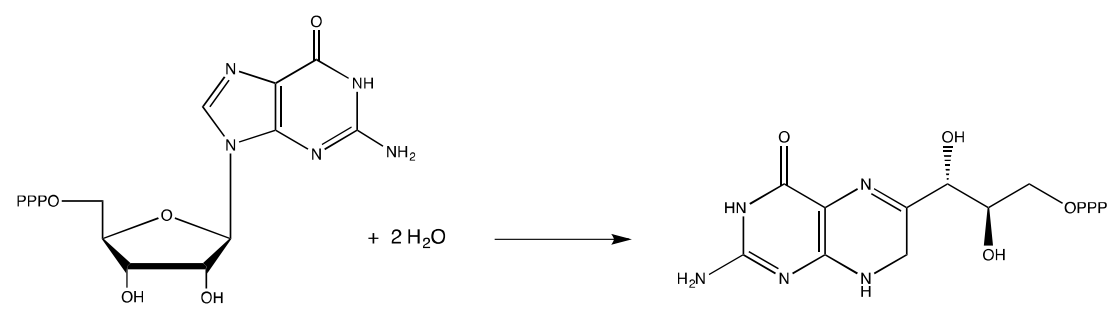

B<smiles>CC(=O)C(=O)c1cnc2c(n1)C(O)[C@H](C)C(N)=N2</smiles>

C

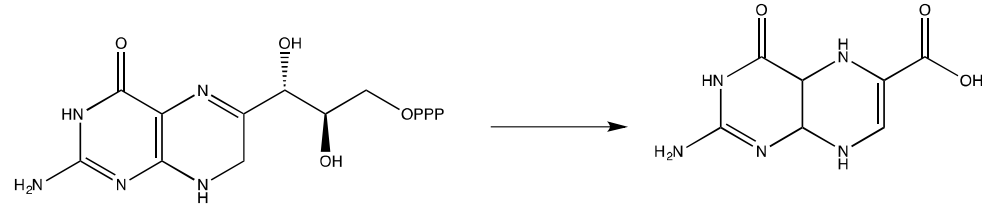

D<smiles>CN=C1NC2=C(N=C(CO)CN2)C(O)N=C1N</smiles>

E<smiles>COC[C@H](O)[C@H](O)C1=NC2=C(NC1)NC(N)=NC2O</smiles>

$\mathbf{F}$<smiles>CC1(C)C(=O)C(=O)N=C2N=C(O)NC21C</smiles>

G<smiles>N#Cc1c[nH]c2nc(N)[nH]c(=O)c12</smiles>

Figure 3. Reactions catalyzed by the enzymes in the Tunneling fold superfamily. A) GCYH-1A, B) PTPS, C) QueD, D) DHNA, E) Dihydroneopterin epimerase, F) UOX, G) QueF. 
All members of the T-fold superfamily share high structural or topological homology (Figure 4) while presenting low sequence identity. ${ }^{26}$

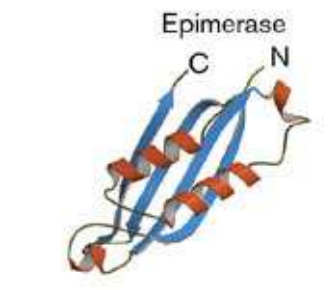

PTPS



DHNA



บ01

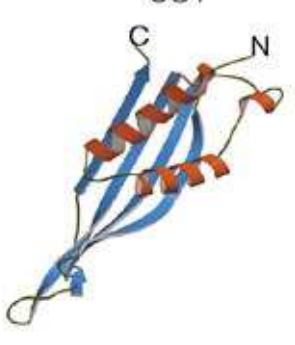

GTP CH-I
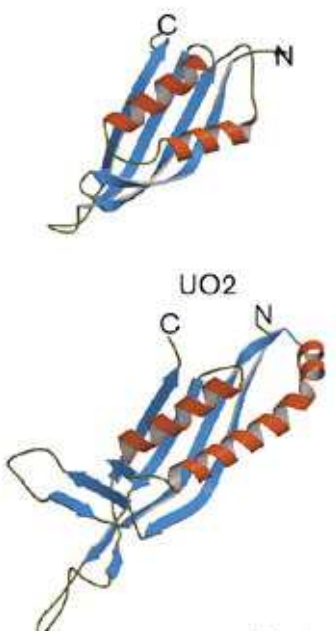

Figure 4. Structure of the monomers of 7,8-dihydroneopterin triphosphate epimerase, DHNA, $\mathrm{GCYH}-1 \mathrm{~B}, \mathrm{PTPS}$ and UOX. Figure reproduced from Ploom et al. ${ }^{47}$

The functional T-fold enzymes differ in size and number of monomers that constitute the functional protein. GCYH-1A is a homodecamer (Dimer of pentamers, Figure $5 \mathrm{~A}$ ), GCYH-1B is a homotetramer, DNHA (Figure $5 \mathrm{~B}$ ) and dihydroneopterin epimerase (Figure 5C) are homooctamers (dimers of tetramers), PTPS is a homohexamer (dimer of trimers, Figure 5D), and UOX is a homotetramer (Figure 5E) $31,35,47,50$. 

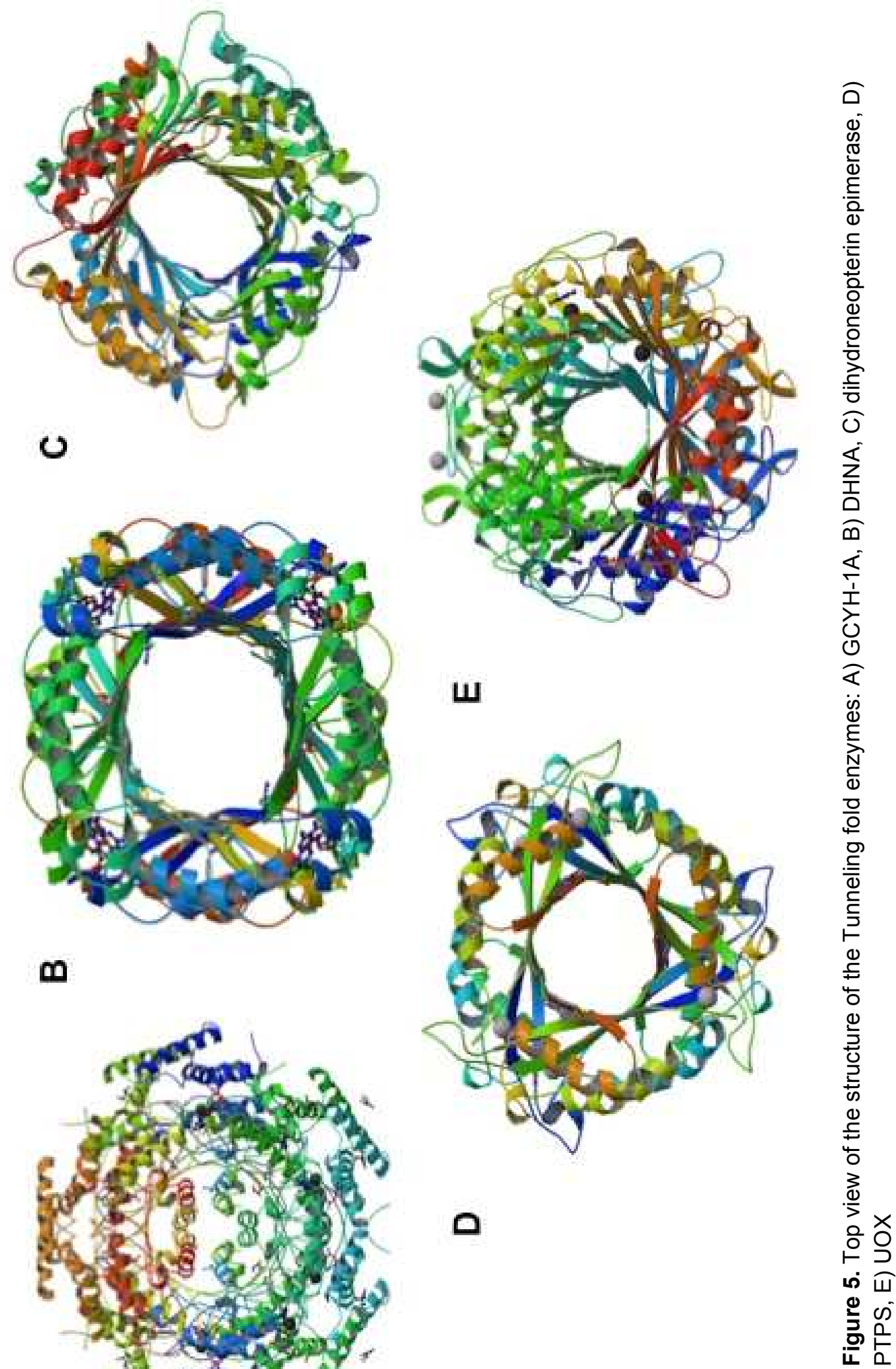

$\infty$
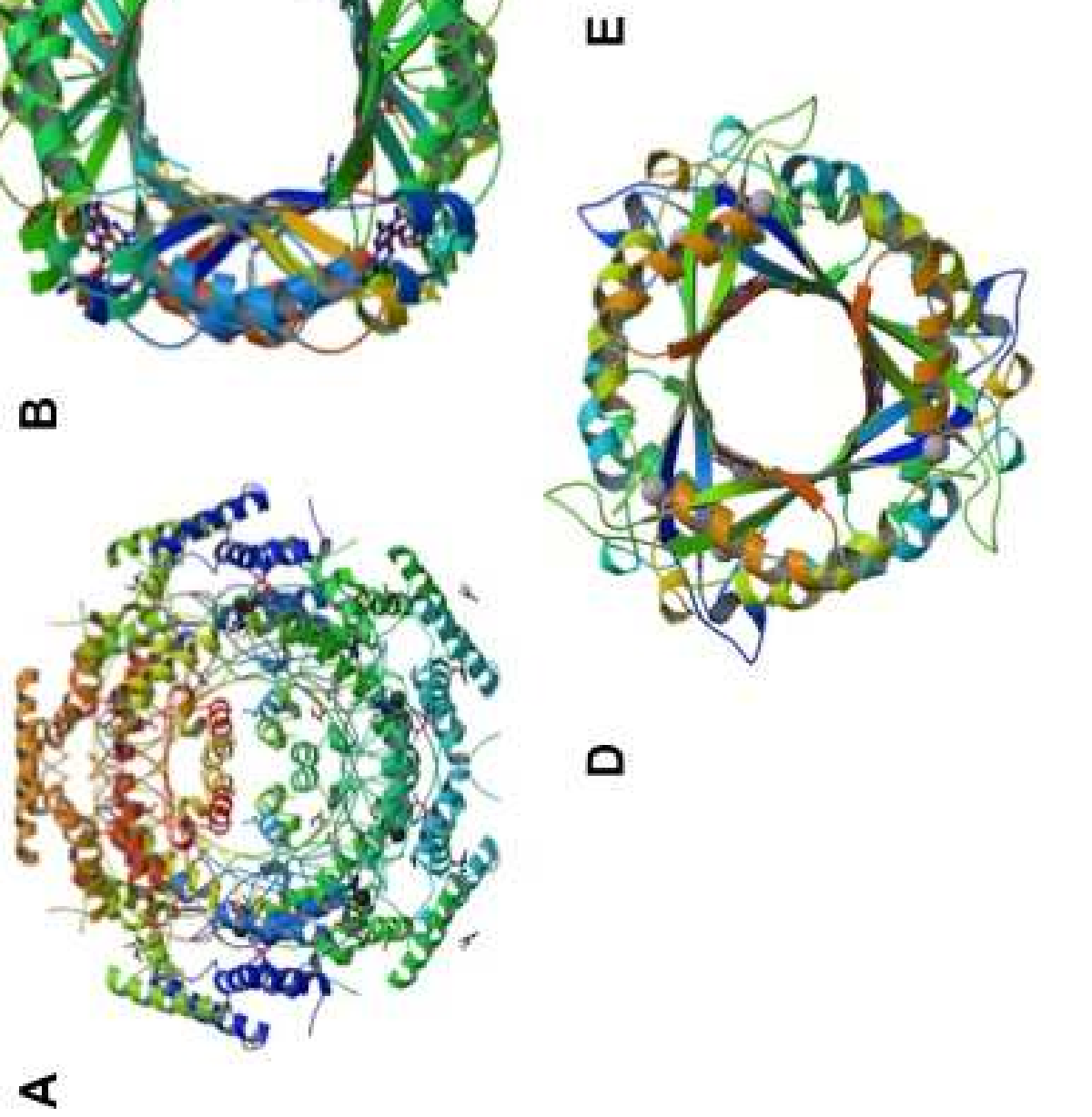


\subsection{Queuosine and Archaeosine}

The 7-deazaguanosine nucleosides queuosine $(\mathrm{Q})$ and archaeosine $\left(\mathrm{G}^{+}\right)$ are two of the most highly modified nucleosides found in tRNA (Figure 6). They share the 7-deazaguanosine core, but differ in the extent of modification of the ring and their location in the tRNA. Moreover, queuosine is found in Bacterial and Eukaryal tRNAs, whereas archaeosine is present exclusively in Archaeal tRNAs. ${ }^{51,52}$
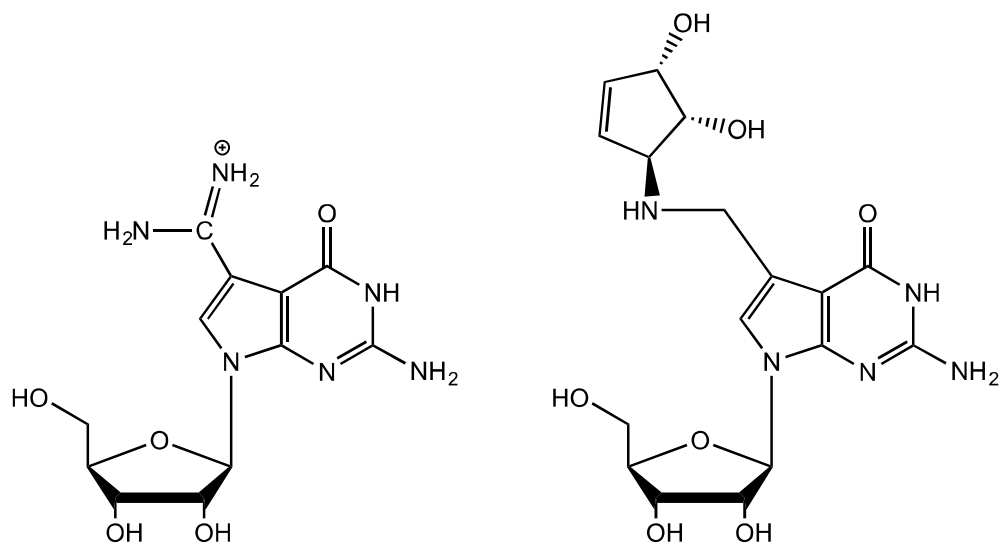

Figure 6. Modified nucleosides Archaeosine (left) and Queuosine (right).

Queuosine contains a cyclopentenediol ring appended to an aminomethyl group at position 7 . In some mammals, this position can be further modified by glycosylation with galactose in tyrosyl tRNA, or mannose in aspartyl tRNA. ${ }^{53,54}$ Eubacterial species do not produce sugar modified queuosine but in these species, cyclopentene hydroxyl groups of aspartyl tRNA can be modified by the addition of glutamic acid at the C4" or C5" position. ${ }^{55}$ Archaeosine possesses an amidine functional group at position 7 of the deazaguanosine core. 
Queuosine is ubiquitous in bacteria and eukarya and is located at position 34 (wobble position) of a subset of tRNAs containing a $\mathrm{G}_{34} \mathrm{U}_{35} \mathrm{~N}_{36}$ anticodon sequence (where $\mathrm{N}$ is any base) and include tyrosine, aspartate, asparagine and histidine. ${ }^{56}$ These decode the dual synonymous codons NAU and NAC. ${ }^{57,58}$ Its location at position 34 of the tRNA suggests queuosine has a role in modulating translational fidelity and/or efficiency, and physiological studies are consistent with such a role. ${ }^{58-60}$

Archaeosine $(\mathrm{G}+)$ is found quasi-universally in Archaeal tRNAs at position 15 of the dihydrouridine loop (D-loop), a position that isn't modified in eukaryotic or bacterial tRNA (Figure 3, left and center). G+ contains an imidino side chain on the $\mathrm{C} 7$ atom of the 7 -deazaguanine core. ${ }^{61}$

Archaeosine is proposed to play a critical role in the maintenance of the tertiary structure of Archaeal tRNAs. Position 15 of the tRNA, always a purine, base pairs with a pyrimidine at position 48 (Levitt base pair, Figure 7). The Levitt base pair involves a G:C reverse Watson-Crick interaction between the D-loop and the T-loop in tRNA ${ }^{62}$ and this interaction has been shown to constitute a general conserved mechanism for stabilization of the L-shape of tRNA. ${ }^{63}$ This is attributed to a stabilization of the correct $15-48$ base pairing interaction. Archaeosine is thought to act through electrostatic interactions between the positively charged amidino group and the negatively charged phosphates in an interaction that mimics magnesium metal coordination. 


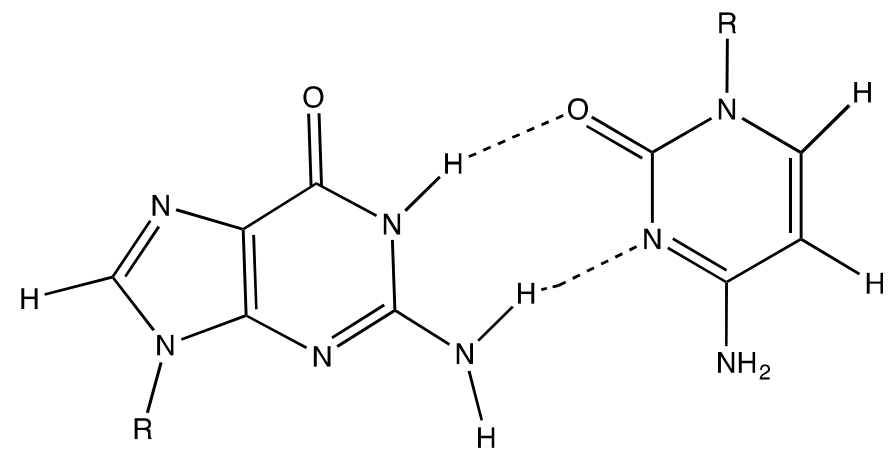

Figure 7. Depiction of the the G:C reverse Watson-Crick (W:W trans) base pair, also known as Levitt base pair. ${ }^{62}$

\subsection{Biosynthesis of Queuosine and Archaeosine}

Only bacteria are capable of de novo synthesis of queuosine. Eukaryotes must acquire queuosine or its free nucleobase, queuine, from the diet or the gut flora ${ }^{64,65}$. Both cytosolic and mitochondrial tRNA species are modified with queuosine. ${ }^{66}$

GTP cyclohydrolase I, the first biosynthetic enzyme in the folate/biopterin pathways, is also the first enzyme in the $\mathrm{Q} / \mathrm{G}^{+}$pathways. ${ }^{67} \mathrm{GCYH}-1 \mathrm{~A}$ is followed by 6-carboxytetrahydropterin synthase (QueD), ${ }^{42}$ 7-carboxy-7-deazaguanine synthase (QueE) $)^{68}$ and 7-cyano-7-deazaguanine synthase (QueC) ${ }^{69}$ enzymes, both in Bacteria and Archaea, to produce the common intermediate 7-cyano-7deazaguanine or preQ. ${ }^{46,70}$

In Bacteria, preQo is reduced to 7-aminomethyl-7-deazaguanine (preQ1) by the oxidoreductase 7-cyano-7-deazaguanine reductase $\mathrm{QueF}$. $\mathrm{preQ}_{1}$ is then inserted into the tRNA by a bacterial tRNA-guanine transglycosylase (bTGT). preQ1 modified tRNA is further processed by $S$-adenosylmethionine:tRNA 
ribosyltransferase-isomerase (QueA) and epoxyqueuosine reductase (QueG) ${ }^{71}$, to form queuosine. In Archaea, preQo is inserted directly into tRNA by archaeal tRNA-guanine transglycosylase or arcTGT (EC 2. 4.2.29) ${ }^{72}$. Archaeosine synthase (arcS), an ATP-independent amidotransferase, catalyzes the conversion of preQo-tRNA to $\mathrm{G}^{+}$-tRNA in the last step of the reaction in Euryarcheota $^{73}$ (Figure 8). 


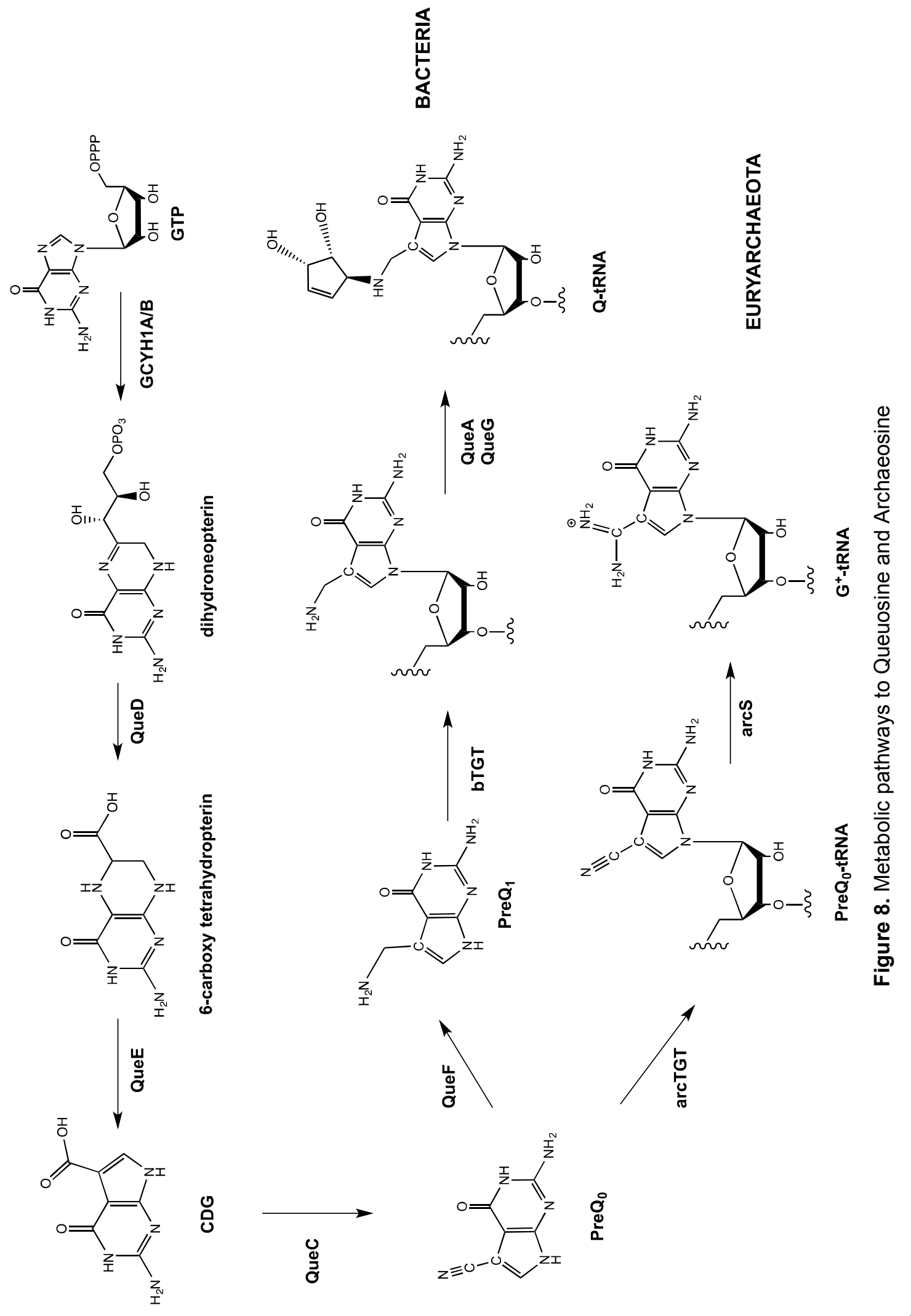




\section{5. tRNA structure and function}

Transfer ribonucleic acid (tRNA) is the information adapter molecule between messenger RNAs (mRNAs) and the elongating peptide chains of newly formed proteins. It serves as an interface for the amino-acid sequence of the protein and the genetic information encoded in deoxyribonucleic acid (DNA). tRNAs have a central role in the decoding process and interact with most of the components that form the translation apparatus. Most tRNAs are about 75-90 nucleotides in length and contain four arms and three loops. The acceptor, D (dihydrouridine), T $\Psi \mathrm{C}$ (T-pseudouridine-C) and anticodon arms are double helical and produce the cloverleaf structure of tRNA (Figure 9A). The cloverleaf undergoes further folding to form a compact L-shaped structure held together the stacking of the acceptor arm onto the TYC arm and the stacking of the $D$ arm onto the anticodon arm, yielding the acceptor and anticodon stems respectively (Figure 9B). The D, T $\Psi \mathrm{C}$ and anticodon loops are conserved in all canonical tRNAs but the size of the variable loop changes. ${ }^{74,75}$ 
A

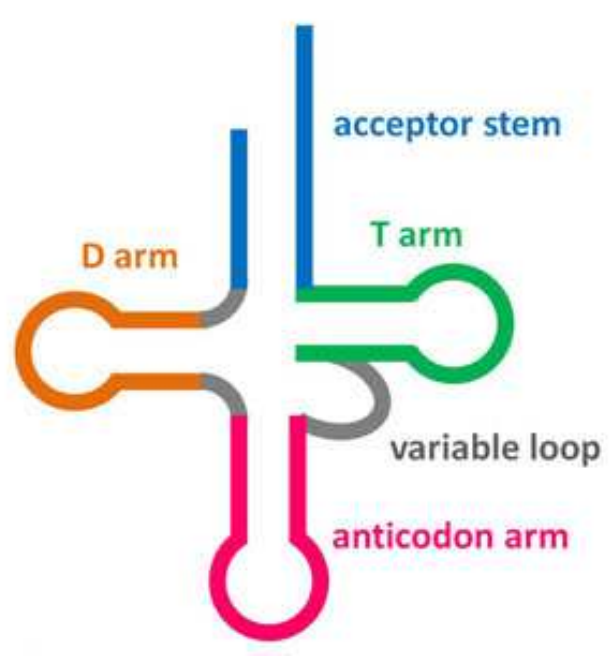

B

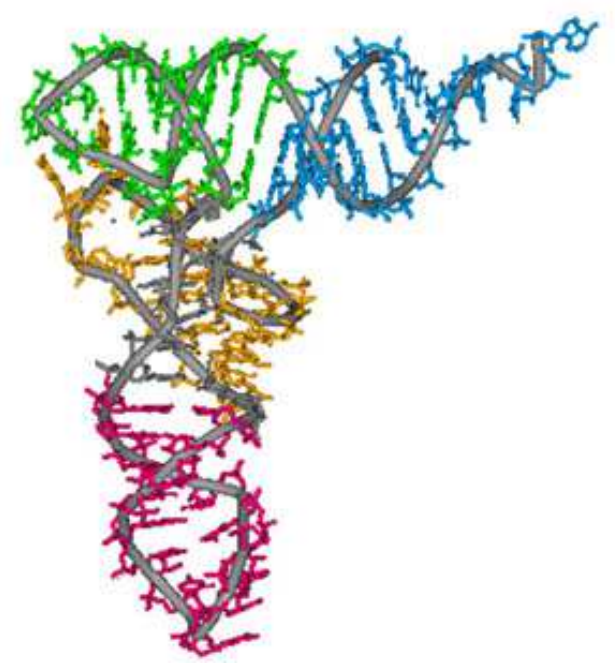

Figure 9. Secondary (A) and tertiary (B) structure of tRNA. ${ }^{76}$

In protein biosynthesis, tRNA is aminoacylated by one of the 20 different aminoacyl tRNA synthetases. Then the aminoacyl tRNA is carried into the ribosome in a complex with the appropriate elongation factor, where it interacts with a number of ribosomal proteins. Once the amino acid has been transferred to the growing polypeptide chain the tRNA is released from the ribosome. ${ }^{74,77}$

Transfer RNAs can also perform additional functions such as regulation of metabolic and cellular processes. For example, uncharged tRNAs regulate global gene expression in response to changing amino acid concentrations in the cell. Aminoacylated tRNAs are implicated in cell wall formation, labeling of proteins for degradation, modification of phospholipids in the cell membrane, and antibiotic biosynthesis. ${ }^{78-80}$ 


\section{6. tRNA modification}

tRNA molecules are primarily composed of the four canonical ribonucleosides incorporated during transcription: adenosine $(A)$, guanosine $(G)$, cytidine $(\mathrm{C})$ and uracil $(\mathrm{U})$. However, posttranscriptional modification of tRNA produces a large number of structurally diverse modified nucleosides (Figure 10). By 2011, 109 modified nucleosides had been reported and collected in the RNA modification database. ${ }^{81}$ The extent of such modification in plants and mammals can be as high as $25 \%$, whereas modification in homologous bacterial tRNAs is lower $(2-15 \%){ }^{82}$ It is estimated that 1 to $10 \%$ of the genes in a given genome encode for tRNA modification enzymes, highlighting the importance of such modifications. ${ }^{83}$

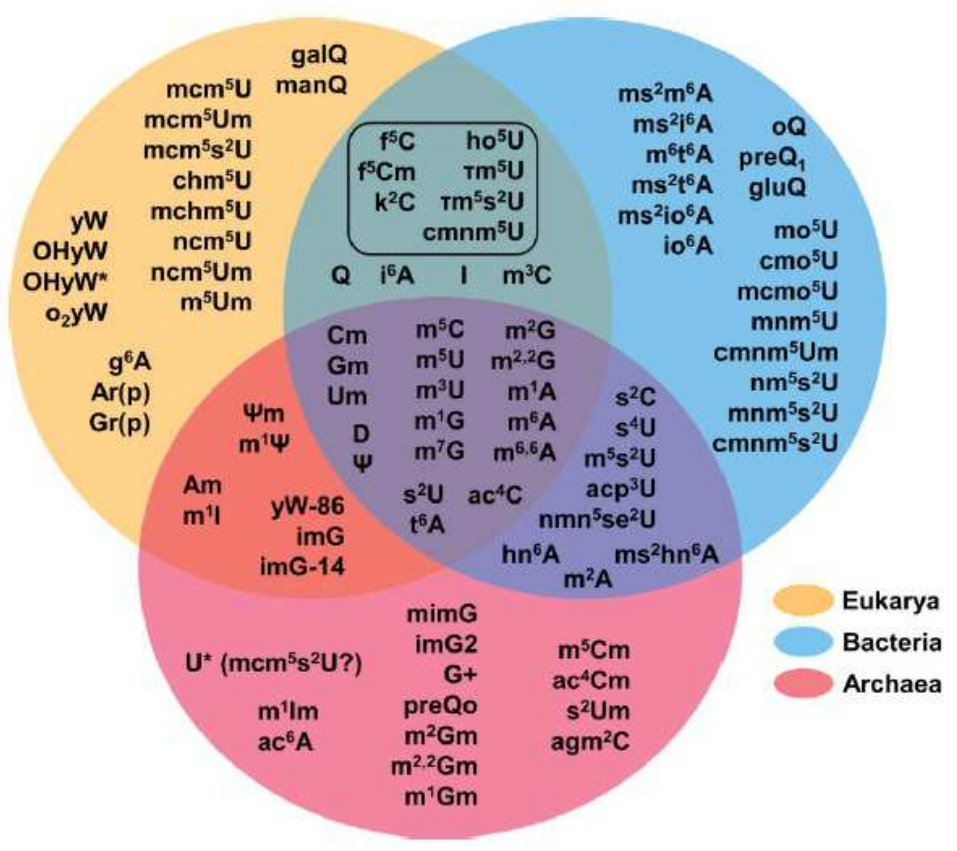

Figure 10. Modified nucleosides found in the different kingdoms of life. Figure reproduced from Jackman et al. ${ }^{84}$ 
Every position of a purine or pyrimidine ring in tRNA can be posttranscriptionally modified. Single modifications are most common and include methylation, hydroxymethylation, deamination, transglycosylation, acetylation, reduction, thiolation, oxidation, ribosylation, isomerization and selenation. Hypermodification involves extensive changes that may require several enzymatic steps. ${ }^{82}$

Some modified nucleosides are universally conserved in type and location in tRNA and they have become part of the nomenclature associated with tRNA structure. The most relevant examples are dihydrouridine $(D)$, ribothymidine $(T)$ and pseudouridine $(\Psi)$, which give name to the tRNA arms and loops and are required for proper tRNA folding. ${ }^{85}$

\subsection{Function of modified nucleosides.}

In general, modifications positioned outside the loop are thought to maintain the structural integrity of the tRNA molecule and act as determinants for tRNA-protein interaction, whereas those in the anticodon often contribute to the fidelity and/or efficiency of protein synthesis. ${ }^{86}$

Modifications found at the core of the folded tRNA can either rigidify the overall structure or make it more flexible. Increased rigidity may occur as a result of pseudouridine modification, which favors the 3'-endo sugar pucker associated with A-form RNA helices. In contrast, dihydrouridine promotes the opposing 2'endo sugar pucker, which gives conformational flexibility to the tRNA. Maintenance of optimal tRNA structure requires contributions from both types of 
modifications. Recent evidence suggests that lack of modifications that reinforce the structural core of the tRNA leads to non-functional tRNAs in vivo. ${ }^{87-89}$

In organisms that experience extreme temperature environments, the level of modification generally correlates with the need for tRNA stability and has been observed to change with growth temperature..$^{90}$

The translation decoding system is heavily dependent on the presence of modified bases. The universal genetic code has 61 codons for 20 standard amino acids and three stop signals (Table 1). Therefore, the genetic code is degenerate and most amino acids are encoded by more than one codon, some as many as six. Decoding relies on the interaction between mRNA's codon triplet and the three anticodon bases of the cognate aminoacyl-tRNA (numbered 34, 35 and 36 in the anticodon stem loop). Because there are only 40 distinct tRNA genes and 61 possible codons, amino acid specific tRNAs must recognize coding triplets that differ in the third letter. ${ }^{86}$

This notion gave rise to the Wobble Hypothesis, proposed by Francis Crick in $1966^{91}$. Crick proposed that non-standard base-pairing might occur between the nucleotide base in the 5' position of the anticodon and the $3^{\prime}$ position of the codon. Wobbling allows some tRNAs to decode different sets of codons which code for the same aminoacid, and some codons to be recognized by more than one anticodon sequence..$^{92}$ We now know that $30-40 \%$ of all codon recognition is accomplished through the tRNA wobble recognition of more than one codon. ${ }^{92}$ 


\begin{tabular}{|c|c|c|c|c|c|c|c|}
\hline Lut & Phe & UCU & Ser & UAL & Tyr. & UGU & Cys \\
\hline L10 & Phe & UCC & Ser & UAC & Tyr. & $1 \mathrm{GO}$ & Cys \\
\hline IUIA & leu & UCA & Ser & UAA & Stop & $U G A$ & Stop \\
\hline 110 & Leu & UCG & Ser & UAG & Stop & UGG & Trp \\
\hline CUU & Leu & $\mathrm{CCU}$ & Pro & CAU. & His & CGU & Arg \\
\hline CUC & Leu & CCC & Pro & CAC & His & CGC & Arg \\
\hline CUA & Leu & CCA & Pro & CAA & Gin & CGA & Arg \\
\hline CUG & Leu & CCG & Pro & CAG & Gin & CGG & Arg \\
\hline ALUI & lle & $\mathrm{ACU}$ & Thr & AAU & Asn & AGU & Ser \\
\hline AULC. & lle & ACC & Thr & AAC & Asn & $A G C$ & Ser \\
\hline ALIA & lle & ACA & Thr & AAA & lys & AGA & Arg \\
\hline AUG & Met & ACG & Thr & $A A G$ & lys & AGG & Arg \\
\hline GUU & Val & GCU & Ala & GAU & Asp & GGU & Gly \\
\hline GUC & Val & GCC & Ala & GAC & Asp & GGC & Gly \\
\hline GUA & Val & GCA & Ala & GAA & Giu & GGA & Gly \\
\hline GUG & Val & GCG & Ala & GAG & Glu. & GGG & Gly \\
\hline
\end{tabular}

Table 1. The codon table ${ }^{86}$

The modified Wobble hypothesis, proposed in $1991^{93}$, suggests that some modifications pre-form the anticodon structure, reducing its conformational space and dynamics, rather than the ribosome inducing a correct fit for the anticodon to fit the decoding site. Thus, modifications that occur at the Wobble position and adjacent to the anticodon are of particular interest. ${ }^{86,93}$ The chemistry and structure of the anticodon loop has evolved to achieve optimal presentation of the anticodon as a recognition determinant for a single cognate aminoacyl-tRNA synthetase, as well as accurate and efficient binding to cognate and wobble codons on the ribosome. ${ }^{94}$ 
In most tRNAs, position 37 is a purine that is almost always modified and the modifications present influence the decoding capacity of the tRNA and shown in Table 2.

\begin{tabular}{|c|c|c|c|c|c|}
\hline \multicolumn{3}{|c|}{ Codon } & \multicolumn{3}{c|}{ Modifications at position 37 } \\
\hline $1 s t$ & $2^{\text {nd }}$ & $3^{\text {rd }}$ & Eukarya & Bacteria & Archaea \\
\hline$U$ & $N$ & $N$ & $\begin{array}{c}y W, \mathrm{O}^{2} \mathrm{yW} \\
\mathrm{i}^{6} \mathrm{~A}, \mathrm{~m}^{1} \mathrm{G}\end{array}$ & $\begin{array}{c}\mathrm{ms}^{2} \mathrm{i}^{6} \mathrm{~A}, \mathrm{i}^{6} \mathrm{~A}, \\
\mathrm{~ms}^{2} \mathrm{i} \mathrm{o}^{6} \mathrm{~A}, \mathrm{~m}^{1} \mathrm{G}\end{array}$ & $\mathrm{m}^{1} \mathrm{G}$ \\
\hline $\mathrm{C}$ & $\mathrm{N}$ & $\mathrm{N}$ & $\mathrm{m}^{1} \mathrm{G}$ & $\mathrm{m}^{1} \mathrm{G}, \mathrm{m}^{2} \mathrm{~A}$ & $\mathrm{~m}^{1} \mathrm{G}$ \\
\hline $\mathrm{A}$ & $\mathrm{N}$ & $\mathrm{N}$ & $\begin{array}{c}\mathrm{t}^{6} \mathrm{~A}, \mathrm{mt}^{6} \mathrm{~A} \\
\mathrm{~ms} \mathrm{t}^{6} \mathrm{~A}\end{array}$ & $\begin{array}{c}\mathrm{t}^{6} \mathrm{~A}, \mathrm{mt}^{6} \mathrm{~A}, \\
\mathrm{~m} 6 \mathrm{~A}, \mathrm{~ms}^{2} \mathrm{t} \mathrm{A}\end{array}$ & ${ }^{6} \mathrm{~A}$ \\
\hline $\mathrm{G}$ & $\mathrm{N}$ & $\mathrm{N}$ & $\mathrm{m}^{1} \mathrm{G}, \mathrm{m}^{1} \mathrm{I}$ & $\mathrm{m}^{2} \mathrm{~A}, \mathrm{~m}^{6} \mathrm{~A}$ & $\mathrm{~m}^{1} \mathrm{G}$ \\
\hline
\end{tabular}

Table 2. Presence of modified nucleosides at position 37 of tRNA (Adapted from Bjork et al. ${ }^{95}$ )

Modifications at position 37 help maintain an open loop conformation blocking Watson-Crick pairing ${ }^{96}$ with neighboring nucleotides on the other side of the loop, especially position 33 , which aids in the formation of the canonical Uturn structure, essential for anticodon-codon pairing during decoding. ${ }^{84}$

Modifications at the Wobble position also influence the decoding capacity of the tRNA. Several tRNAs, particularly tRNA ${ }^{G l n}$, tRNA $A^{\text {Glu }}$ and tRNA ${ }^{\text {Lys }}$ contain a uracil at position 34 . This base typically undergoes $s^{2} U$ thiolation and in some cases further modification at position $\mathrm{C}_{5}$ of the pyrimidine ring. Modifications at $\mathrm{C}_{5}$ commonly include methylations and acetylations and in some cases hypermodification by addition of sugars. The presence of $s^{2} U$ imparts a distinct 
conformation that allows for the preferential recognition of $A$ but not $G$ or $U$ in NAA/G codons where $\mathrm{N}$ can be $\mathrm{C}, \mathrm{A}$ or $\mathrm{G} .{ }^{76,97}$

Since modifications have a direct role in maintaining tRNA structure and function, their loss creates an error-prone translational system. ${ }^{98}$ There are very few cases in which the lack of a modification leads directly to cell death ${ }^{99,100}$. There is evidence however, that some modifications whose absence leads to apparently innocuous effects may be crucial to viability under changing environmental conditions. ${ }^{101,102}$

The presence of modifications is key to the viability of tRNA in the cell. Hypomodified tRNAs are targeted for specific degradation pathways and therefore modification is crucial to the maintenance of the tRNA pool. ${ }^{103-105}$

\subsection{Research objective}

The work presented here aims to expand the information available on two enzymes, QueF and QueF-like. Prior work has established the mechanism for QueF, the only nitrile reductase known in biology, but the residues responsible for the binding of the cofactor are yet to be elucidated. QueF-like is a newly discovered enzyme involved in the biosynthesis of the tRNA modification archaeosine. QueF-like serves the same function as arcS, which is not a Tunneling-fold enzyme. The substrate, ammonia sources and mechanism of QueF-like are unknown.

The goal of the work discussed in Chapter 3 is to determine the role of residues lysine 80 , lysine 83 and arginine 125 of QueF in the binding of NADPH 
and general catalysis as well as to establish the possible biological function of the disulfide bond between cysteine 55 and cysteine 99 (B. subtilis numbering).

The work presented in Chapter 4 focuses on the preliminary characterization of QueF-like. This includes the elucidation of the primary substrate and source of nitrogen in the biosynthesis of archaeosine-tRNA. 


\section{Chapter 2. Materials and methods}

\section{1. Chemicals and reagents}

Buffers, salts and reagents (highest quality grade available) and gel filtration molecular weight standards and rNTPs, were purchased from Sigma (St. Louis, MO) unless otherwise stated. DEPC (diethylpyrocarbonate) treated water was used in the preparation of all solutions for RNA related assays. Dithiothreitol (DTT), isopropyl- $\beta$-D-thiogalacto-pyranoside (IPTG), kanamycin sulfate, $\beta$ NADPH ( $\beta$-Nicotinamide adenine dinucleotide phosphate), $\beta$-NADP ${ }^{+}$, DEPC and

ampicillin were purchased from RPI Corporation (Chicago, IL). $\left[8-{ }^{14} \mathrm{C}\right]-$ guanine was obtained from Perkin Elmer (Waltham, MA). PEI cellulose TLC plates, Amicon Ultra 15 and 0.5 centrifugal filter units as well as NovaBlue Singles competent cells were acquired from EMD Millipore (Billerica, MA). Nickelnitrilotriacetic acid agarose $\left(\mathrm{Ni}^{2+}-\mathrm{NTA}\right.$ agarose), silica TLC plates, Whatman GFB PVDF syringe filters and SnakeSkin dialysis tubing were purchased from Fisher Scientific (Pittsburgh, PA). GeneJet Plasmid Miniprep kits, Klenow enzyme and PageRuler pre-stained protein ladder were purchased from Fermentas (Glen Burnie, MD). Custom oligonucleotides were obtained from Integrated DNA Technologies (San Diego, CA). All reagents for sodium dodecyl sulfate polyacrylamide gel electrophoresis (SDS-PAGE) were purchased from BioRad (Hercules, CA). SDS-PAGE analysis was carried out using $12 \%$ gels and visualized with Coomassie Brilliant Blue. DNA sequencing was carried out at the "The DNA Services Core" at Oregon Health and Sciences University (OHSU), Portland, OR. 


\subsection{Instrumentation}

PCR was carried out on a 2720 Applied Biosystems cycler (Thermo, San Jose, California). UV-Vis spectroscopy was performed with a Varian Cary 100 spectrophotometer equipped with a thermostated cell holder. Fluorescence spectroscopy was carried out on a LS55 Fluorescence Spectrometer from Perkin Elmer (Waltham, MA). HPLC was carried out using a Agilent 1100 with photodiode array detector, and controlled via the Agilent Chemstation software, Agilent (Santa Clara, CA). Centrifugation was carried out on a bench-top Eppendorf 5430 R (Hamburg, Germany) or a Sorvall 5C+ (Thermo, San Jose, CA). SDS-PAGE was carried out on a mini Protean III system from BioRad (Hercules, CA). Small molecule mass spectrometry was performed on an Orbitrap mass spectrometer (Thermo Electron, San Jose, CA) equipped with an electrospray ionization (ESI) source at the the Department of Chemistry at Portland State University. Radioactivity was quantified with a Hidex 300 SL liquid scintillation counter (Turku, Finland). An Amersham Biosciences Typhoon Trio + variable mode imager (Amersham, United Kingdom) with ImageQuant LT software was used for phosphorimaging. NMR was carried out in a Bruker 400 $\mathrm{MHz}$ Spectrometer (Bruker, Billerica, MA) and the data was processed using MestreNova (Santiago de Compostela, Spain).

\section{3. Strains, media and growth conditions}

$\mathrm{DH} 5 \alpha\left(\mathrm{F}^{-}\right.$$\varphi 80 / a c Z \Delta \mathrm{M} 15 \Delta($ lacZYA-argF)U169 recA1 endA1 hsdR17(rk-, mk+) phoA supE4 thi-1 gyrA96 relA1 tonA) (Invitrogen), NovaBlue (endA1 
hsdR17 $\left(\mathrm{r}_{\mathrm{K} 12^{-}} \mathrm{m}_{\mathrm{K} 12^{+}}\right)$supE44 thi-1 recA1 gyrA96 relA1 lac $\mathrm{F}^{\prime}\left[p r o A^{+} B^{+}\right.$ laclaZ $\square$ M15::Tn10 $\left.\left(\operatorname{Tet}^{\mathrm{R}}\right)\right]$ (EMD Millipore, Billerica, MA), BL21 (DE3) $\mathrm{F}^{-}$ompT gal dcm lon hsd $S_{\mathrm{B}}\left(\mathrm{r}_{\mathrm{B}^{-}} \mathrm{m}_{\left.\mathrm{B}^{-}\right)}\right) \lambda(\mathrm{DE} 3$ [lacl lacUV5-T7 gene1 ind1 sam7 nin5]) (EMD Millipore, Billerica, MA) were used for plasmid propagation or protein overproduction, and were routinely grown in LB medium at $37{ }^{\circ} \mathrm{C}$. Growth media were solidified with $15 \mathrm{~g} / \mathrm{L}$ agar for the preparation of plates. Transformation of E. coli was performed following standard procedures, Ampicillin (amp, 100 $\mu \mathrm{g} / \mathrm{mL}$ ) and Kanamycin (kan, $50 \mu \mathrm{g} / \mathrm{mL}$ ), were used as needed.

\subsection{Enzymes}

Bacterial alkaline phosphatase, Nuclease $\mathrm{P}_{1}$ from Penicillium citrinum, snake venom phophodiesterase I and DNase were purchased as lyophilized powders from Sigma and stored in $50 \%$ glycerol with the appropriate buffer at the recommended temperature. PfuUltra ${ }^{\mathrm{TM}}$ DNA polymerase was obtained from Agilent (Santa Clara, CA). Restriction enzymes were purchased from Fermentas (Glen Burnie, MD) and New England Biolabs (Ipswich, MA). Lysozyme was purchased from RPI Corporation (Mount Prospect, IL)

\section{5. PreQo preparation}

PreQ0 was synthesized as previously described by Klepper (yield $12 \%$, purity $98 \%$ ). ${ }^{106,107}$ The product was purified by HPLC using a Luna C18 semipreparative column (250 x $10 \mathrm{~mm}, 5$ micron) from Phenomenex (Torrance, CA). 
The product eluted at 12 minutes using a gradient of ammonium acetate $(25 \mathrm{mM}$, $\mathrm{pH} 6.5$ ) and acetonitrile (0 to $50 \%$ ACN over 30 minutes). 


\subsection{Expression and purification of recombinant enzymes}

\subsubsection{Expression and purification of bacterial proteins: wild type His6-QueF,}

His6-QueF K80A, K83A, R125A and R125K mutants and T7 polymerase.

Recombinant QueF was expressed in E. coli BL 21(DE3) cells with the plasmid $\mathrm{pET} 30-\mathrm{ykvM}{ }^{32}$ or mutant plasmids pET30-ykvMK80A, pET30ykvMK83A, pET30-ykvMR125K, pET30-ykvMR125A in LB/kanamycin medium (1 mM). The frozen cell stock was used to streak a plate of LB/kanamycin agar. A single colony was then used to inoculate a $3 \mathrm{~mL} L B /$ kanamycin medium. After 12 hours of incubation at $37^{\circ} \mathrm{C}$, a $200 \mu \mathrm{L}$ aliquot was removed and used to inoculate $500 \mathrm{~mL}$ of $\mathrm{LB} /$ medium in a $2 \mathrm{~L}$ flask. The cultures were incubated at $37{ }^{\circ} \mathrm{C}$ and 250 rpm for 12 hours (overnight). When an $\mathrm{OD}_{600}$ of 2-3 was reached, the cultures were harvested by centrifugation at $9000 \mathrm{rcf}$ for $20 \mathrm{~min}$ and subsequently resuspended in $500 \mathrm{~mL}$ of fresh LB/kanamycin medium. After $1 \mathrm{hr}$ of incubation at $37{ }^{\circ} \mathrm{C}$, protein over-expression was induced by the addition of IPTG to a final concentration of $0.5 \mathrm{mM}$. The cell cultures were grown for an additional 4 hours at which time the cells were collected by centrifugation at $11000 \mathrm{rcf}$ for 20 minutes at $4{ }^{\circ} \mathrm{C}$ and frozen with liquid nitrogen. Typically $15-20 \mathrm{~g}$ of cells were obtained from $2 \mathrm{~L}$ of media. The cells were stored at $-80{ }^{\circ} \mathrm{C}$ until further use. The expression of the mutants K80A, K83A, R125A, and R125K was carried out identically. T7 polymerase was expressed from pT7-911Q in E. coli as described for the QueF wild-type protein. 
All proteins were purified as follows: The frozen cells were thawed and resuspended to $250 \mathrm{mg} / \mathrm{mL}$ in $50 \mathrm{mM}$ Tris- $\mathrm{HCl}(\mathrm{pH} 8.0), 100 \mathrm{mM} \mathrm{KCl}, 2 \mathrm{mM}$ $\beta M E, 1 \mathrm{mM}$ imidazole, and $1 \mathrm{mM}$ PMSF (lysis buffer). Lysozyme was added to a final concentration of $250 \mu \mathrm{g} / \mathrm{mL}$ and the cells incubated at $37^{\circ} \mathrm{C}$ for 30 minutes, followed by 3 intervals of freeze-thaw cycles. DNase was added to a final concentration of $10 \mu \mathrm{g} / \mathrm{mL}$ and the cells were left at $37{ }^{\circ} \mathrm{C}$ for an additional 30 minutes. The cell lysate was centrifuged at $12000 \mathrm{xg}$ for 30 minutes after which it was filtered through a low protein binding $0.45 \mu \mathrm{m}$ PVDF filter to remove any present particulate. The cell free extract was loaded onto a $5 \mathrm{~mL}$ column containing $\mathrm{Ni}^{2+}-\mathrm{NTA}$ agarose equilibrated in lysis buffer. The column was washed with 10 column volumes of lysis buffer. Non-specifically bound proteins were eluted with $20 \mathrm{mM}$ imidazole in lysis buffer containing no PMSF. The recombinant protein of interest was eluted with $200 \mathrm{mM}$ imidazole in lysis buffer containing no PMSF. All buffers used were filtered through a $0.22 \mu \mathrm{m}$ PVDF filter. The collected eluate was concentrated to about $2 \mathrm{~mL}$ using the Amicon Ultra YM10 and dialyzed overnight against $4 \mathrm{~L}$ of lysis buffer without PMSF, then stored at $-80{ }^{\circ} \mathrm{C}$ as a $50 \%$ glycerol stock in aliquots of $100 \mu$ l.

To remove the His tag, Factor Xa $(10 \mu \mathrm{g})$ was added to $20 \mathrm{mg}$ of purified QueF WT and mutant proteins and the digestion was carried out in the presence of $100 \mathrm{mM}$ Tris- $\mathrm{HCl}(\mathrm{pH} 8.0), 100 \mathrm{mM} \mathrm{KCl}, 1 \mathrm{mM} \mathrm{CaCl} 2$, and $1 \mathrm{mM} \beta M E$, for 20 hours at room temperature after which the digest was loaded onto a $\mathrm{Ni}^{2+}-\mathrm{NTA}$ agarose column that had been equilibrated in $100 \mathrm{mM}$ Tris- $\mathrm{HCl}(\mathrm{pH} 8.0), 100 \mathrm{mM}$ $\mathrm{KCl}$, and $1 \mathrm{mM} \beta \mathrm{ME}$ (elution buffer). The cleaved wild type protein was eluted 
with 10 column volumes of elution buffer. The protein was concentrated as previously described and stored in aliquots of appropriate volumes at $-80{ }^{\circ} \mathrm{C}$ in the presence of $50 \%$ glycerol. Typical yields were $20 \mathrm{mg}$ of protein per liter of cultured media.

\subsubsection{Expression and purification of archaeal proteins: wild type His6-MJTGT and His6-QueF-like.}

Recombinant His6-MJTG protein and His6-QueFL was expressed in $E$. coli BL21(DE3) cells at $37{ }^{\circ} \mathrm{C}$ in LB/kanamycin medium. LB/kanamycin medium ( $3 \mathrm{~mL}$ ) was inoculated with a single colony of the cells and after 12 hours of incubation at $37{ }^{\circ} \mathrm{C}$ a $1 \mathrm{~mL}$ aliquot was used to inoculate $100 \mathrm{~mL}$ of LB/kan medium. The cultures were incubated at $37{ }^{\circ} \mathrm{C}$ and $250 \mathrm{rpm}$ for 12 hours and a 5 $\mathrm{mL}$ aliquot was taken and used to inoculate $500 \mathrm{~mL}$ of $\mathrm{LB} / \mathrm{kan}$ medium. When an $\mathrm{OD}_{600}$ of 0.9 was reached protein over-expression was induced by the addition of IPTG to a final concentration of $0.25 \mathrm{mM}$. The cell cultures were grown for an additional 4-5 hours when the cells were collected by centrifugation at 7,500 $\mathrm{g} g$ for 15 minutes and frozen with liquid nitrogen. The cells were stored at $-80{ }^{\circ} \mathrm{C}$ until further use.

The cells were resuspended to a density of $250 \mathrm{mg} / \mathrm{mL}$ in $50 \mathrm{mM}$ Tris- $\mathrm{HCl}$ (pH 8.0), $300 \mathrm{mM} \mathrm{KCl,} 2 \mathrm{mM} \beta M E$, and $1 \mathrm{mM}$ PMSF (lysis buffer). Lysozyme was added to a final concentration of $250 \mu \mathrm{g} / \mathrm{mL}$ and the cells incubated at $37^{\circ} \mathrm{C}$ for 30 minutes, followed by 3 intervals of freeze-thaw cycles. DNase was added to a final concentration of $10 \mu \mathrm{g} / \mathrm{mL}$ and the cells were left at $37{ }^{\circ} \mathrm{C}$ for an 
additional 30 minutes. The cell lysate was centrifuged at $26,000 \times g$ for 30 minutes. The CFE was heated up to $80{ }^{\circ} \mathrm{C}$ for 15 minutes and centrifuged at 26000x g for 20 minutes. The resulting CFE was filtered using a low proteinbinding $0.45 \mu \mathrm{m}$ PVDF syringe filter, then loaded onto $5 \mathrm{~mL}$ of $\mathrm{Ni}^{2+}-\mathrm{NTA}$ agarose resin equilibrated in lysis buffer The column was washed with 5 column volumes of buffer A followed by 5 column volumes of lysis buffer with $20 \mathrm{mM}$ imidazole and no PMSF. The recombinant protein was eluted with 7 column volumes of buffer B containing $200 \mathrm{mM}$ imidazole then concentrated to about $2 \mathrm{~mL}$ using the Amicon Ultra YM-10k and dialyzed overnight against $4 \mathrm{~L}$ of lysis buffer with no PMSF at $4{ }^{\circ} \mathrm{C}$. Both proteins were cleaved by Factor $\mathrm{Xa}$ and purified as previously described. The cleaved protein was stored in 50\% glycerol in $100 \mu \mathrm{L}$ aliquots at $-80^{\circ} \mathrm{C}$.

\subsubsection{Expression of Selenomethionine labeled QueF-like}

Expression of QueF-like labeled with Selenomethionine was perfomed as previously described ${ }^{108}$ using selenomethionine solutions of $50 \mathrm{mg} / \mathrm{mL}$ added to the minimal media solution ${ }^{109}$ at $1 \mathrm{uL}$ per $\mathrm{mL}$ of media. The methionine auxotrophic strain of E.coli B834 [genotype F- ompT hsdSB(rB - mB -) gal dcm met (DE3)] was a gift from Dr. Kelly Chacón (Reed College, Portland, OR).

\subsubsection{Size exclusion chromatography}

Size exclusion chromatography was used to determine the quaternary structure of QueF and QueF-like like using a BioSep-Sec-4000 column (Phenomenex, Torrance, CA) with an isocratic mobile phase of $25 \mathrm{mM}$ 
phosphate ( $\mathrm{pH} 7.2), 25 \mathrm{mM} \mathrm{KCl}$, at a flow rate of $1 \mathrm{~mL} / \mathrm{min}$. The protein was monitored for a change in retention time upon addition of PreQo. For that purpose, the protein was pre-incubated with $\mathrm{PreQ}_{0}$ at least $15 \mathrm{~min}$ and the presence of the thioimide intermediate was assessed by UV-vis spectroscopy prior to gel filtration analysis. A standard curve was determined using the Sigma Molecular weight filtration kit MWGF200 which includes: Blue Dextran (2000 kDa), Albumin (66 kDa), Alcohol Dehydrogenase (150 kDa), $\beta$-amylase (200 $\mathrm{kDa})$, carbonic anhydrase $(29 \mathrm{kDa})$ and Cytochrome C (12.4 kDa).

\subsection{Mutagenesis $P C R$}

Mutagenesis was performed as described by the Quickchange mutagenesis kit from Agilent Technologies according to manufacturer instructions (Santa Clara, CA, USA). The primers used were the following:

R125K, Forward primer: 5' - GGG GCA AAT TCA CGC CAA AAG GCG GAA TTT CCA - 3'

R125K, Reverse primer: 5' - TGG AAA TTC CGC CTT TTG GCG TGA ATT TGC $\mathrm{CCC}-3^{\prime}$

R125A, Forward primer: 5' - GGC AAA TTC ACG CCA GGA GGC GGA ATT TCC - 3'

R125A, Reverse primer: 5' - GGA AAT TCC GCC TCC TGG CGT GAA TTT GCC - 3' 


\subsection{NADPH 7-cyano-7-deazaguanine oxidoreductase}

\subsubsection{Substrate titration studies}

Titrations of QueF with preQo were monitored in the absence of NADPH. PreQo (3 mM in DMSO) was titrated into a solution of wild-type QueF or QueF mutants $(20 \mu \mathrm{M})$ containing $100 \mathrm{mM}$ tris $(\mathrm{pH}$ 7.5), $100 \mathrm{mM} \mathrm{KCl}$ and $1 \mathrm{mM}$ DTT, while monitoring the absorbance from 230 to $450 \mathrm{~nm}$. The titration was continued until there was no further increase in absorbance. The concentration of DMSO did not exceed $5 \%$ of the total volume.

\subsubsection{Steady-state kinetic measurements}

\section{NADPH dependent kinetics}

Changes in absorbance at $340 \mathrm{~nm}$ as a result of $\mathrm{NADPH}$ consumption were monitored using a Cary 100 spectrophotometer equipped with a temperature controller. Using a quartz microcuvette, $200 \mu \mathrm{L}$ reactions containing 800 nM wild-type, K80A (80 uM), K83A (80 uM), R125A (80 uM) or R125K (8 uM) and $100 \mathrm{mM}$ phosphate (pH 6.5), $50 \mathrm{mM} \mathrm{KCl}, 20 \mathrm{mM} \mathrm{MgCl}_{2}, 1 \mathrm{mM}$ DTT, 20 $\mu \mathrm{M}$ preQ $Q_{0}$ and varying concentrations of NADPH were incubated at $37^{\circ} \mathrm{C}$ for 15 min. The data was linearly fitted and the slope was used to calculate the velocity of the reaction.

\section{PreQo dependent kinetics}

Reactions $300 \mu \mathrm{L}$ in volume containing $400 \mathrm{nM}$ wild-type or $4 \mu \mathrm{M}$ mutant QueF enzyme, $100 \mathrm{~mm}$ phosphate $(\mathrm{pH} 6.5), 50 \mathrm{mM} \mathrm{KCl}, 20 \mathrm{mM} \mathrm{MgCl}_{2}, 1$ 
mM DTT, $180 \mu \mathrm{M}$ NADPH, and varying concentrations of PreQo were incubated at $37^{\circ} \mathrm{C}$ and $50 \mu \mathrm{L}$ aliquots were taken at varying times and quenched with an equivalent volume of $\mathrm{HCl}$. After 10 minutes, a $50 \mu \mathrm{L}$ aliquot of the quenched reaction was taken and treated with $200 \mu \mathrm{L}$ of $\mathrm{NaOH}$ and allowed to develop in the dark for at least 3 hours. A standard curve was generated with varying concentrations of $\mathrm{NADP}^{+}$in the presence of the same NADPH concentrations used in the reactions. The standards were treated identically to the reaction samples taken.

Both samples and standards were analyzed using a Perkin Elmer L55 fluorometer. The excitation wavelength used was $360 \mathrm{~nm}$ and the emission was scanned from $430-520 \mathrm{~nm}$. If necessary, the slit opening was varied for each NADPH concentration to ensure sufficient signal and prevent saturation. After a slit change, a standard set was re-analyzed to recalculate the fit (concentration $\mathrm{NADP}^{+}$vs. RFU).

\subsection{3. $\mathrm{H}_{2} \mathrm{O}_{2}$ oxidation of wild-type and C99A/S enzymes}

Oxidation of wild-type QueF and mutants C99A/S (generated by Spencer Cohen) was performed as depicted in Figure 11. A stock enzyme solution containing $100 \mathrm{mM}$ phosphate $(\mathrm{pH} 6.5), 50 \mathrm{mM} \mathrm{KCl}, 20 \mathrm{mM} \mathrm{MgCl}_{2}$, and $36 \mathrm{uM}$ protein was prepared and a $20 \mathrm{uL}$ aliquot was taken. To this, $5 \mathrm{uL}$ of a solution of $1 \mathrm{mM}$ hydrogen peroxide was added to the enzyme solution and was allowed to react for $0,15,30,45,60$ or 75 seconds. At each timepoint, a 20 uL aliquot was removed from the reaction and added to a solution containing 12 units of 
catalase and $1 \mathrm{mM}$ DTT and mixed thoroughly to achieve full quenching of the hydrogen peroxide. The quenched solution was then transferred to a $200 \mathrm{uL}$ microcuvette and PreQo and NADPH were added to a were added to a final concentration of $36 \mu \mathrm{M}$ and $180 \mu \mathrm{M}$ respectively, to initiate turnover. The absorbance of the reaction at $340 \mathrm{~nm}$ was monitored over a period of $20 \mathrm{~min}$ to determine the initial velocity ${ }^{110}$.
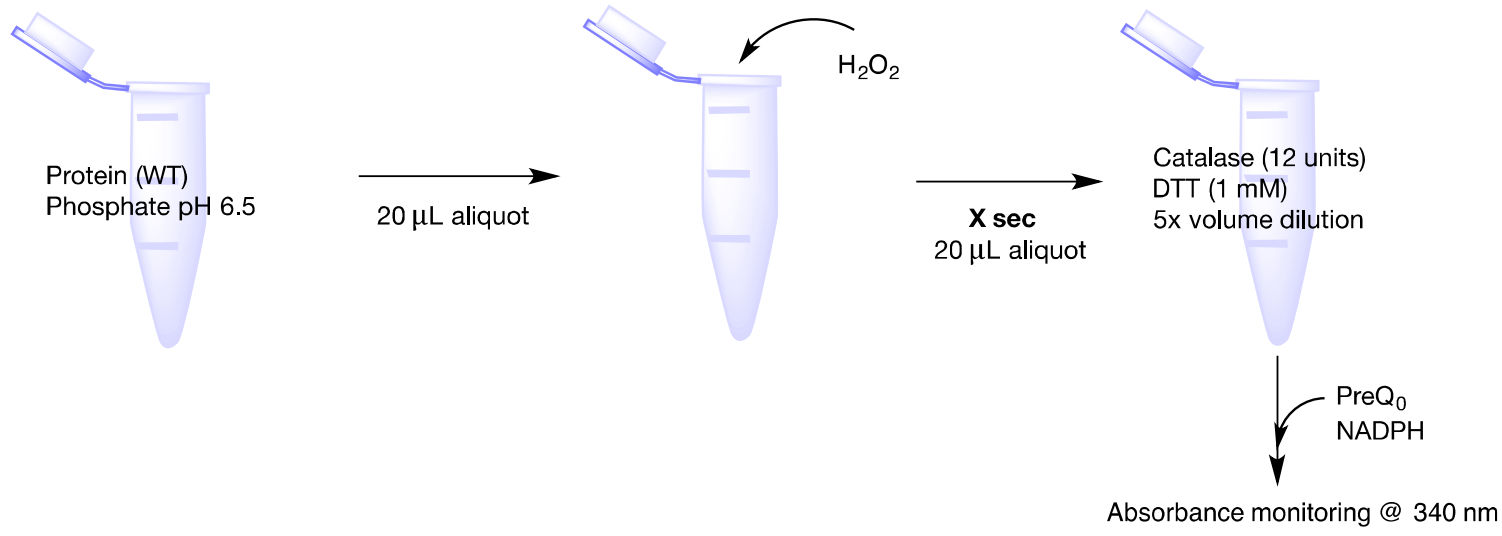

Figure 11. Oxidation assay of QF enzymes with hydrogen peroxide

\subsubsection{Activity recovery of oxidized QF enzymes}

Wild type and C99A/S mutant enzymes of QueF were oxidized for 45 seconds prior to rescue treatment. To ensure accurate measurement of recovered activity, a control experiment was performed in which the activity of each enzyme was measured after oxidation as described in the prior section. Non control samples were subject to oxidation and quenched with a solution containing 12 units of catalase and either $10 \mathrm{mM}$ DTT or 5 equivalents of 
thioredoxin. After 60 minutes, the solution was transferred to a microcuvette and PreQ $Q_{0}$ and NADPH were added to a final concentration of $100 \mu \mathrm{M}$ and $180 \mu \mathrm{M}$ respectively, to initiate turnover. The absorbance of the reaction at $340 \mathrm{~nm}$ was monitored over a period of 20 min to determine the initial velocity ${ }^{110}$

\section{9. QueF-like}

\subsection{1. tRNA transcription and modification}

In Vitro transcription of $M$ thermo tRNA ${ }^{\text {Gln }}$

Duplex DNA templates for in vitro transcription were synthesized from two single-stranded oligodeoxynucleotides containing a complementary overlap duplex region, as previously described..$^{111}$

The oligonucleotide sequences used were:

$5^{\prime-}$

GCAGTAATACGACTCACTATAGGTCCCGTGGGGTAGTGGTAATCCTGCTG GGCTTTG- 3'

5'TGGTAGTCCCGAGCGGAGTCGAACCGCTGTCGCCGGGTCCAAAGCCCA GC- 3'

The underlined region represents the T7 RNA polymerase promoter sequence. Milligram quantities of each tRNA were transcribed with the Del(172173) variant of T7 RNA polymerase. Transcription reactions were performed as 
previously described, ${ }^{111}$ loaded onto a Urea-PAGE gel and after electrophoresis (80W, $60 \mathrm{~min}$ ), the band was excised and extracted overnight in $100 \mathrm{mM}$ ammonium acetate ( $\mathrm{pH}$ 6.5) containing 1 mM EDTA. The gel was then discarded and the RNA precipitation from the remaining solution with ethanol, and resuspended in $100 \mathrm{mM}$ succinate $(\mathrm{pH} 5.5), 1 \mathrm{mM}$ EDTA at $-20{ }^{\circ} \mathrm{C}$ to be used in the preQo-tRNA exchange reaction described below. Alternatively the tRNA was stored dried at $-80^{\circ} \mathrm{C}$.

\section{Preparation of PreQo-tRNA}

PreQo was inserted into the tRNA transcript using recombinant wild-type M. jannaschii arcTGT. A solution of tRNA in succinate buffer (100 mM, pH 5.5) was refolded before use. ${ }^{112}$ An aliquot of MJTT $(10 \mu \mathrm{M})$ was added to a $1 \mathrm{~mL}$ solution containing $50 \mathrm{mM}$ succinate (pH 5.5), $20 \mathrm{mM} \mathrm{MgCl}$, $100 \mathrm{mM} \mathrm{KCl,} 2 \mathrm{mM}$ DTT, $100 \mu \mathrm{M}$ M. Thermo tRNA ${ }^{\mathrm{Gln}}$, and $1 \mathrm{mM}$ preQo. After 45 minutes at $80{ }^{\circ} \mathrm{C}$, the reaction was terminated by the addition of one-tenth volume of $2 \mathrm{M} \mathrm{NaOAc}$ $(\mathrm{pH} 4.0)$ followed by one volume of water-saturated phenol and one fifth volume chloroform:isoamyl alcohol (49:1). After vortexing for 20s, the solution was centrifuged in a fixed angle rotor at $9000 x g$ for 1 minute. The aqueous phase was recovered and mixed with an equal volume of chloroform:isoamyl alcohol. After vortexing for $20 \mathrm{~s}$, the solution was centrifuged in a fixed angle rotor for 1 $\min$ at $9000 \mathrm{xg}$. The aqueous phase was recovered and concentrated using an Amicon Ultra4 centrifugal concentrator. Subsequently, the preQo-tRNA ${ }^{\text {Gln }}$ was precipitated from the eluate by the addition of 3 volumes of ethanol and cooling at $-20{ }^{\circ} \mathrm{C}$ for 2 hours. The solution was centrifuged at $20,000 \times \mathrm{g}$ for 20 minutes at 
$4{ }^{\circ} \mathrm{C}$, the supernatant removed, and the RNA pellet washed with $70 \%$ cold ethanol. After centrifugation again at $20,000 \times \mathrm{g}$ the supernatant solution was removed and the preQo-tRNA was resuspended in $3 \mathrm{mM}$ sodium citrate $(\mathrm{pH} \mathrm{6.3)}$ and stored at $-20^{\circ} \mathrm{C}$.

\subsubsection{Guanine incorporation assay}

In order to quantify preQo incorporation into tRNA ${ }^{\mathrm{Gln}}$, a control reaction was run in which $\left[8-{ }^{-14} \mathrm{C}\right]$-guanine $(50 \mathrm{mCi} / \mathrm{mmol} ; 1.85 \mathrm{GBq} / \mathrm{mmol})$ was first loaded into the tRNA using $M$. jannaschii arcTGT under the same conditions described above (section 2.9.1). Aliquots of the reaction can be taken every five minutes to show the rate of incorporation over time. The reactions were terminated by the addition of one-tenth volume of $2 \mathrm{M} \mathrm{NaOAc}(\mathrm{pH} 4.0)$ followed by one volume of water-saturated phenol and one fifth volume chloroform:isoamyl alcohol (49:1). chloroform:isoamyl alcohol (49:1). After vortexing for 20 s, the solution was centrifuged in a swinging bucket rotor at $700 \times g$ for 20 minutes and the tRNA was pipetted into Whatman GF/B glass filters. The filters were then sandwiched in between larger filters (to secure them) and washed with cold ethanol in a vacuum filtration system so as to remove any unbound radioactive material. Once dry, the filters were placed in $7 \mathrm{~mL}$ scintillation vials with the appropriate scintillation cocktail and the radioactivity was measured by scintillation counting. 


\subsubsection{Substrate titration studies}

Titrations of QueF with preQo or preQo-tRNA were monitored in the absence of a nitrogen donor. PreQ $(3 \mathrm{mM}$ in DMSO) or preQo-tRNA $(20 \mu \mathrm{M})$ was titrated into a solution of QueF-like $(20 \mu \mathrm{M})$ containing $100 \mathrm{~mm}$ phosphate (pH 6.5), $50 \mathrm{mM} \mathrm{KCl}, 20 \mathrm{mM} \mathrm{MgCl}_{2}$, and $1 \mathrm{mM} \mathrm{DTT}$, while monitoring the absorbance from 230 to $450 \mathrm{~nm}$. The concentration of DMSO did not exceed $5 \%$ of the total volume.

\subsubsection{Amidinotransferase assays}

Assays of amidinotransferase activity were carried out using QueF-like (20 $\mu \mathrm{M})$ in $100 \mathrm{mM}$ phosphate (pH 6.5), $50 \mathrm{mM} \mathrm{KCl}, 20 \mathrm{mM} \mathrm{MgCl}_{2}$, and $1 \mathrm{mM} \mathrm{DTT}, 1$ $\mathrm{mM}$ preQ or $10 \mu \mathrm{M}$ preQo-tRNA in the presence of $\mathrm{NH}_{4} \mathrm{Cl}(100 \mathrm{mM})$, glutamine $(1 \mathrm{mM})$ or asparagine $(1 \mathrm{mM})$. QueF-like was incubated with preQo for 15 minutes at $37^{\circ} \mathrm{C}$. The solution was then filtered through a centrifugal concentrator (Amicon) in a fixed angle rotor at $8500 \mathrm{rcf}$ for 10 minutes to remove excess preQo. The remaining solution was reconstituted with buffer and $\mathrm{NH}_{4} \mathrm{Cl} /$ glutamine/asparagine was added while monitoring the loss of covalent thioimide adduct at $376 \mathrm{~nm}$.

QueF-like and preQo-tRNA were incubated in the presence of $\mathrm{NH}_{4} \mathrm{Cl}$ for 1 $\mathrm{hr}$ at $37^{\circ} \mathrm{C}$ and the tRNA was then precipitated using ethanol and digested using Nuclease P1, snake venom phosphodiesterase and alkaline phosphatase and the nucleoside products of the reaction were analyzed by HPLC as previously described ${ }^{73,113}$, using a Phenomenex Gemini 5 uM C18 $110 \mathrm{~A} 250 \times 2 \mathrm{~mm}$, with a 
mobile phase comprised of a linear gradient from $100 \% 25 \mathrm{mM} \mathrm{NH}_{4} \mathrm{OAc}(\mathrm{pH} 6.3)$ to $85 \% 5 \mathrm{mM} \mathrm{NH}{ }_{4} \mathrm{OAc} / 15 \%$ acetonitrile developed over 30 minutes up to $50 \%$ acetonitrile at $45 \mathrm{~min}$. Flow was maintained at $0.3 \mathrm{~mL} / \mathrm{min}$. LCMS analysis of nucleosides was performed on an Orbitrap-LTQ mass spectrometer (Thermo Electron, San Jose, CA) utilizing electrospray ionization (ESI). The ESI interface was operated in the positive mode using the following settings: end plate offset $-500 \mathrm{~V}$, capillary voltage $-4500 \mathrm{~V}$, nebulizer gas $1.6 \mathrm{bar}$, dry gas $4 \mathrm{~L} / \mathrm{min}$, dry temperature $200^{\circ} \mathrm{C}$, funnel $1 \mathrm{RF} 350 \mathrm{Vpp}$, funnel $2 \mathrm{RF} 350 \mathrm{Vpp}$, hexapole RF $400 \mathrm{Vpp}$, collision energy $10 \mathrm{eV}$ and collision RF $300 \mathrm{Vpp}$.

\subsubsection{Amidinotransferase activity with radiolabeled glutamine}

$\left[5-{ }^{14} \mathrm{C}\right]$-L-glutamine $(1.85-2.22 \mathrm{GBq} / \mathrm{mmol})$ was tested as a substrate in reactions containing $1 \mathrm{mM}$ DTT, $20 \mathrm{mM} \mathrm{MgCl} 2,100 \mathrm{mM}$ phosphate $\mathrm{pH} 6.5,10$ $\mu \mathrm{M}$ QueF-like, 10 um preQo-tRNA, $19 \mu \mathrm{M}{ }^{14} \mathrm{C}$-glutamine in a total volume of 20 $\mu \mathrm{L}$. The reactions were incubated at $37^{\circ} \mathrm{C}$ and $2 \mu \mathrm{L}$ aliquots were taken at 30,60 , 120, 180. 300 and $420 \mathrm{~min}$ and then quenched with $4 \mu \mathrm{L}$ of $8 \mathrm{M}$ ammonium acetate. A pre-wetted PEI cellulose TLC was used to separate $2 \mu \mathrm{L}$ spots of the quenched reactions and analyzed as previously described. ${ }^{114}$ 


\section{Chapter 3: Characterization of 7-cyano-7-deazaguanine, QueF}

\subsection{Introduction}

QueF is an NADPH-dependent oxidoreductase that catalyzes the reduction of the nitrile group of 7-cyano-7-deazaguanine (preQ0) to a primary amine (preQ 1$) .32$ The discovery of the QueF family of enzymes expanded the chemistry of known nitrile metabolizing enzymes, which at that point included, hydrolysis, oxidation and cleavage ${ }^{115}$. It was also a new addition to a group of enzymes classified as $N A D(P)^{+}$dependent four-electron-transfer dehydrogenases, which includes UDP-glucose-dehydrogenase, histidinol dehydrogenase and 3-hydroxy-3-methylglutaryl-coenzyme-A reductase. ${ }^{116-118}$

Sequence and structural analysis of QueF revealed that this enzyme belongs to the Tunneling fold (T-fold) superfamily. As previously discussed, the T-fold superfamily has two structural subfamilies, a unimodular subfamily, with proteins formed by subunits with a single T-fold domain, and a bimodular subfamily composed of proteins formed by subunits with tandem $\mathrm{T}$-fold domains. ${ }^{26}$ The QueF family includes both unimodular and bimodular enzymes. ${ }^{119}$

The unimodular family is represented by the Bacillus subtilis enzyme, and it contains a signature QueF motif $(E(S / L) K(S / A) h K(L / Y)(Y / F / W))$, where $h$ is an hydrophobic amino acid, bracketed on the $\mathrm{N}$ - and C-terminal sides by an invariant Cys and Glu, respectively. This cysteine is also universally conserved in the guanosine cyclohydrolase family ${ }^{29}$ where it serves as a ligand for the required 
zinc/manganese cofactor, while the glutamate is characteristic of the entire T-fold superfamily. ${ }^{26}$

The bimodular family is represented by the Escherichia coli enzyme and it contains two tandem T-fold domains. In this case, the QueF motif and the Cys and Glu residues are spatially separated and located in the homologous $\mathrm{N}$ - and C- terminal T-fold domains, respectively. ${ }^{28}$

The predicted mechanism ${ }^{119}$ of the reaction begins with the binding of preQo to the enzyme, followed by nucleophilic attack of the thiol of Cys55 (B. subtilis numbering) on the nitrile group of preQ, forming a thioimide intermediate (Figure 12). Subsequently, NADPH binds to the enzyme and reduces the intermediate rendering a new covalent adduct, the thiohemiaminal. The first NADPH molecule is then released, a second NADPH cofactor molecule binds, and collapse of the thiohemiaminal followed by reduction, yields the preQ 1 product. Mutation of the Cys55 residue to alanine or serine results in complete loss of activity. These experiments support the key role of this residue in catalysis. ${ }^{119}$ His96 and Asp 62 are the acid/base catalytic residues proposed to participate in the reaction. ${ }^{119}$

The crystal structure of the $B$. subtilis QueF reveals a nonsymmetric homodecamer of two head-to-head facing pentamers (a dimer of pentamers), which comprise the classic T-fold architecture (PDB ID 4F8B, Figures 13 and 14). ${ }^{27}$ The active site encompasses three subunits, two from adjacent subunits in the same pentamer and one from the opposite pentamer. 

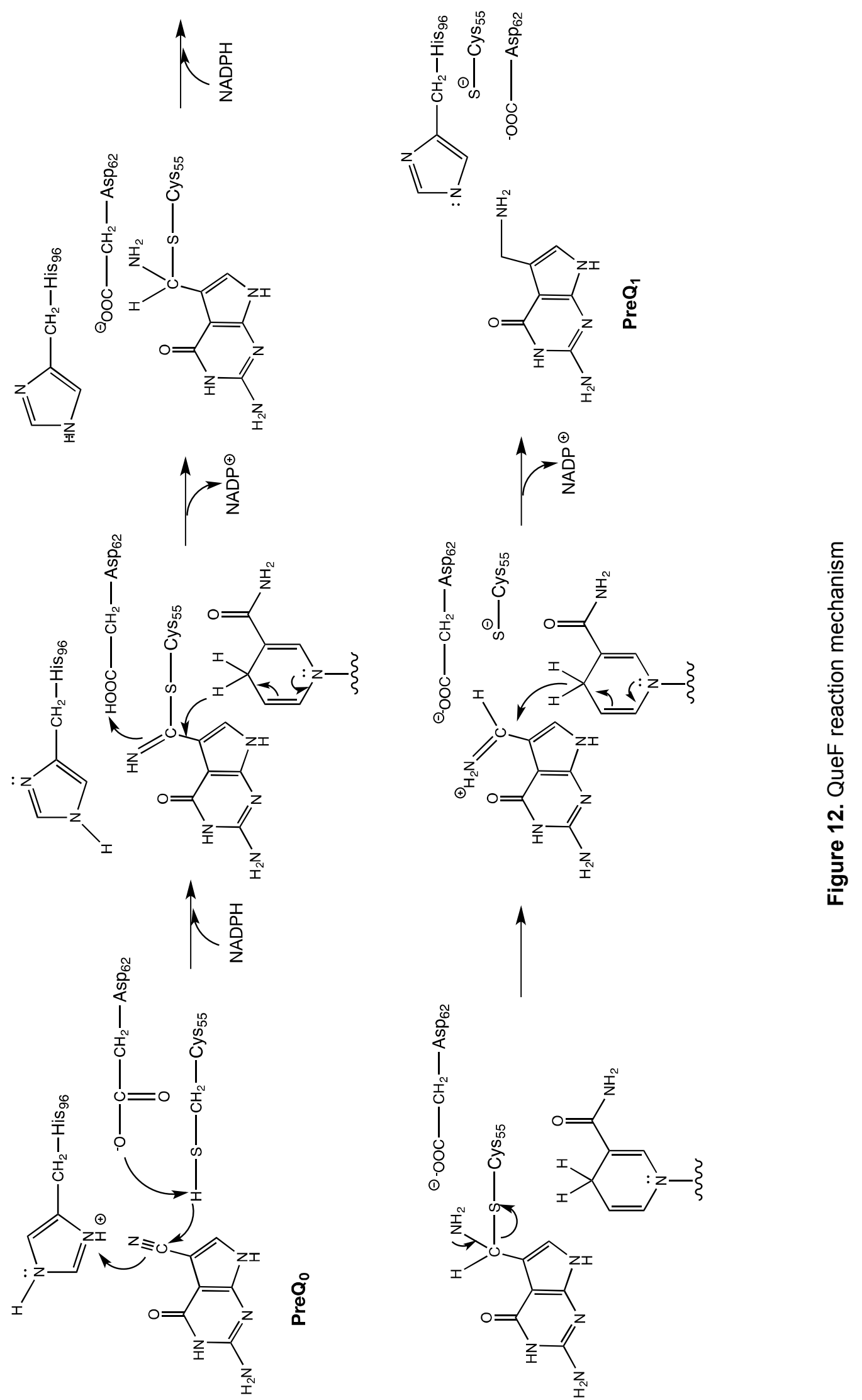


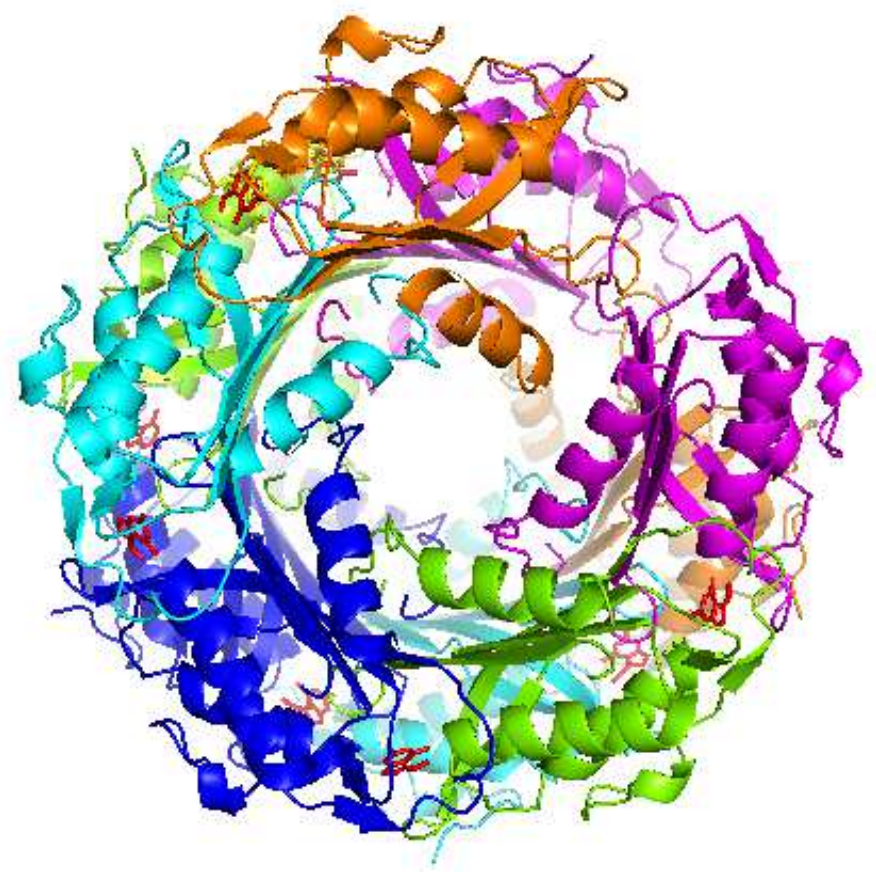

Figure 13. Top view of the crystal structure of the QueF. ${ }^{27}$ Subunits are color coded A (orange), $B$ (cyan), C (blue), D (green), E (magenta). Substrate PreQ $Q_{0}$ is depicted in red.



Figure 14. Side view of the crystal structure of the QueF. ${ }^{27}$ Coloring as in Figure 13. 
The location of the QueF motif suggests that the residues in this motif are involved in binding NADPH and a docking model generated by Manal Swairjo (Figure 15, unpublished) shows a single NADPH molecule (pink) binding at the interface of four subunits, two from each pentamer, spanning two active sites. Moreover, the NADPH diphosphates are within close proximity to $\operatorname{Arg} 125$, Lys80 and Lys83 (orange), coming from two subunits, one from each pentamer. 


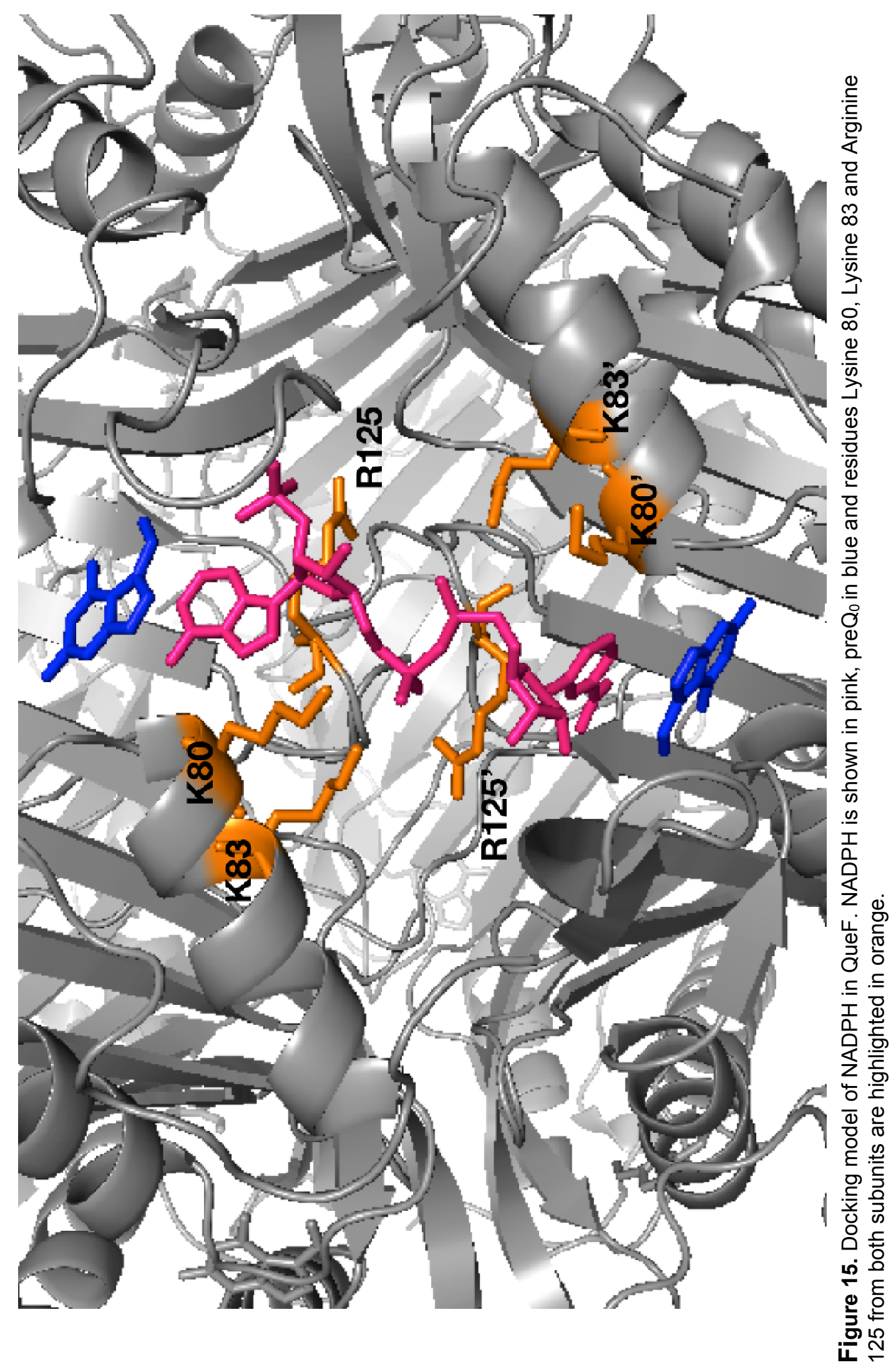




\subsubsection{Non-structural disulfide bonds}

A disulfide bridge was observed in crystal structures of the QueF mutant E78A, between Cys55 and Cys99 (Figure 16, Manal Swairjo, unpublished data). Cys99 is located in the alpha helix at the bottom of the active site and is conserved throughout the QueF family, suggesting selection pressure to retain it.

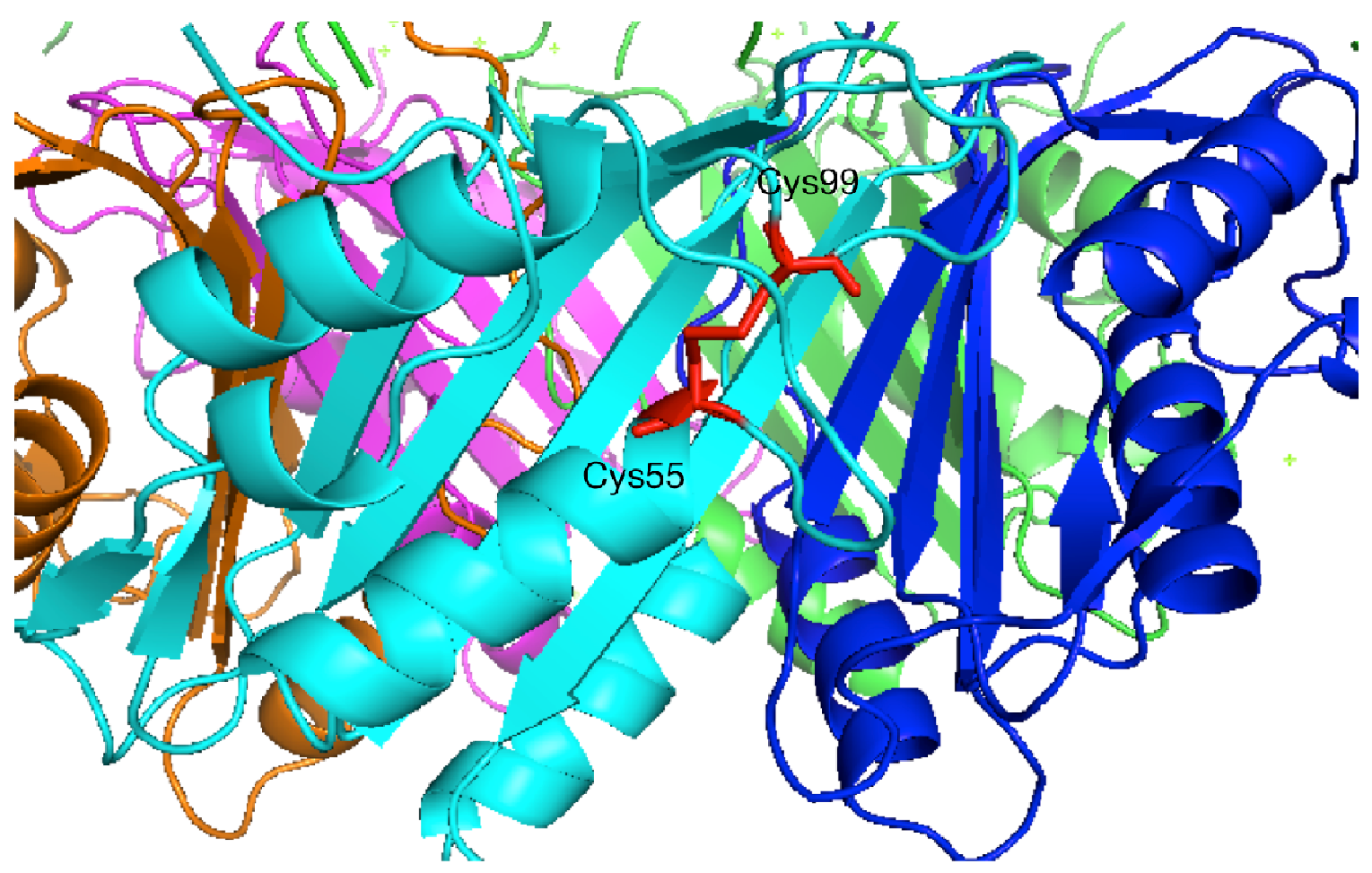

Figure 16. Cys55-Cys99 QueF disulfide bond.

Disulfide bonds in proteins can be considered structurally as involving six atoms linking the two $\alpha$-carbons of the cysteine residues: $\mathrm{C} \alpha-\mathrm{C} \beta-\mathrm{S} y-\mathrm{S} \gamma^{\prime}-\mathrm{C} \beta^{\prime}-\mathrm{C} \alpha^{\prime}$. Rotation about the bonds linking these six atoms defines five chi $(\chi)$ angles, which can be positive or negative, resulting in 20 possible disulfide bond 
configurations. By convention, there are 3 basic types of disulfide bonds: Spirals, hooks, and staples. Further characterization as right- or left-handed is a function of whether $\chi_{3}$ is positive or negative. ${ }^{120,121}$

The -LHSpiral (left handed) configuration is the most common and has the lowest dihedral strain energy, making it the primary structural disulfide. Most catalytic disulfides that have been structurally characterized have a -/+ RHHook (right handed) $\left(\chi_{1}, \chi_{2}, \chi_{3}, \chi_{2}^{\prime}, \chi_{1}^{\prime}\right.$, are,,,,+-++- respectively) configuration whereas allosteric disulfides are typically $-\mathrm{RHStaple},\left(\chi_{1}, \chi_{2}, \chi_{3}, \chi_{2}^{\prime}, \chi_{1}^{\prime}\right.$, are -,-,+,-,+ respectively) or -LHHook $\left(\chi_{1}, \chi_{2}, \chi_{3}, \chi_{2}^{\prime} 2, \chi_{1}^{\prime} 1\right.$ are,,,,,---+- , respectively). ${ }^{120}$ These bonds have a higher potential energy and are more easily cleaved than bonds with lower stored energy, which is consistent with their functional role. ${ }^{122-124}$

A defining feature of both catalytic and allosteric bonds is the close proximity of the $\alpha$-carbon atoms of the two cysteine residues. These are $4.3 \AA$ apart on average vs. the $5.6 \AA$ mean for all disulfides ${ }^{121}$. This shorter bond is the result of linking secondary structures. About $60 \%$ of $-\mathrm{RHStaple}$ bonds link adjacent strands in the same $\beta$-sheet. The proximity of the strands causes them to pucker in order to accommodate the bond, adding strain to it. ${ }^{123,125}$

Analysis of the chi angles of the five bonds comprising the QueF Cys55Cys99 disulfide present shows that four of the five bonds had measurements consistent with the -LHHook configuration $(-,-,-,+,--;$ Table 3). 


\begin{tabular}{|c|c|c|c|c|c|c|c|c|}
\hline $\begin{array}{c}\text { Subunit } \\
\text { containing } \\
\text { Cys55- } \\
\text { Cys99 }\end{array}$ & $\mathrm{X}$ & $\mathrm{X} 2$ & $\mathrm{X} 3$ & $\begin{array}{c}\text { Distance } \\
(\mathrm{A})\end{array}$ & $\mathrm{X} 2^{\prime}$ & $\mathrm{X}^{1}$ & $\begin{array}{c}\text { Disulfid } \\
\text { e Strain } \\
\text { Energy } \\
\mathbf{( k J / m o l )}\end{array}$ & $\begin{array}{c}\text { Bond } \\
\text { class }\end{array}$ \\
\hline $\mathrm{A}$ & -53.64 & -130.82 & -104.16 & 2.05 & 173.30 & -65.06 & 14.67 & -LHHook \\
\hline $\mathrm{B}$ & -107.05 & 138.74 & 96.37 & 2.06 & 74.64 & -106.34 & 40.93 & -RHSpiral \\
\hline $\mathrm{C}$ & -56.22 & -129.79 & -104.29 & 2.04 & 167.78 & -67.52 & 15.45 & -LHHook \\
\hline $\mathrm{D}$ & -51.38 & -133.63 & -97.82 & 2.05 & 167.94 & -71.56 & 14.52 & -LHHook \\
\hline $\mathrm{E}$ & -51.13 & -124.15 & -100.67 & 2.00 & 173.17 & -76.26 & 17.11 & -LHHook \\
\hline
\end{tabular}

Table 3. Analysis of chi angles of the Cys55-Cys99 bond of QueF.

These results indicate four out of five disulfide bonds present in QueF can be classified as allosteric whereas one of them is consistent with a structural role. The latter however, corresponds to an unstructured part of the crystal structure and the results were not taken into consideration.

\subsubsection{Objective}

The work described in this chapter aims to test the hypothesis that the residues lysine 80, lysine 83 and arginine 125 in QueF are involved in binding of NADPH as well as to establish the possible biological function of the disulfide bond between cysteine 55 and cysteine 99. 


\subsection{Results and discussion}

\subsubsection{Binding of NADPH}

The model for NADPH binding into QueF (Figure 16) shows residues Arg125, Lys80 and Lys83 in close proximity to the cofactor, suggesting they are involved in its binding. To test this model site directed mutagenesis was therefore performed to test if these residues were important for binding of NADPH.

Arginine 125 was mutated both to alanine and lysine and lysines 80 and 83 were both mutated to alanine. Those mutants were then tested for turnover by monitoring the change in NADPH concentration as a function of time (as described in Chapter 2). This was achieved by continuously measuring the absorbance of reaction solutions containing the wild-type or one of the mutants, at $340 \mathrm{~nm}$.

Figure 17 presents a sample plot of absorbance over time for a control reaction (blank) and reactions each containing either K80A $(80 \mu \mathrm{M}), \mathrm{K} 83 \mathrm{~A}(80$ $\mu \mathrm{M}), \mathrm{R} 125 \mathrm{~A}(80 \mu \mathrm{M}), \mathrm{R} 125 \mathrm{~K}(8 \mu \mathrm{M})$, or the wild-type enzyme $(800 \mathrm{nM})$. The traces for mutants K80A, K83A and R125A overlap with that of the control, indicating no significant activity was observed for these mutant proteins. Note that in these experiments the mutant enzyme concentrations were present at 100-1000 fold higher than the wild-type enzyme. Mutant R125K however, demonstrated significant activity as compared to the control. While these results are consistent with impaired NADPH binding, mutagenesis can also compromise the 3D structure of the enzyme, which in turn would prevent turnover. 


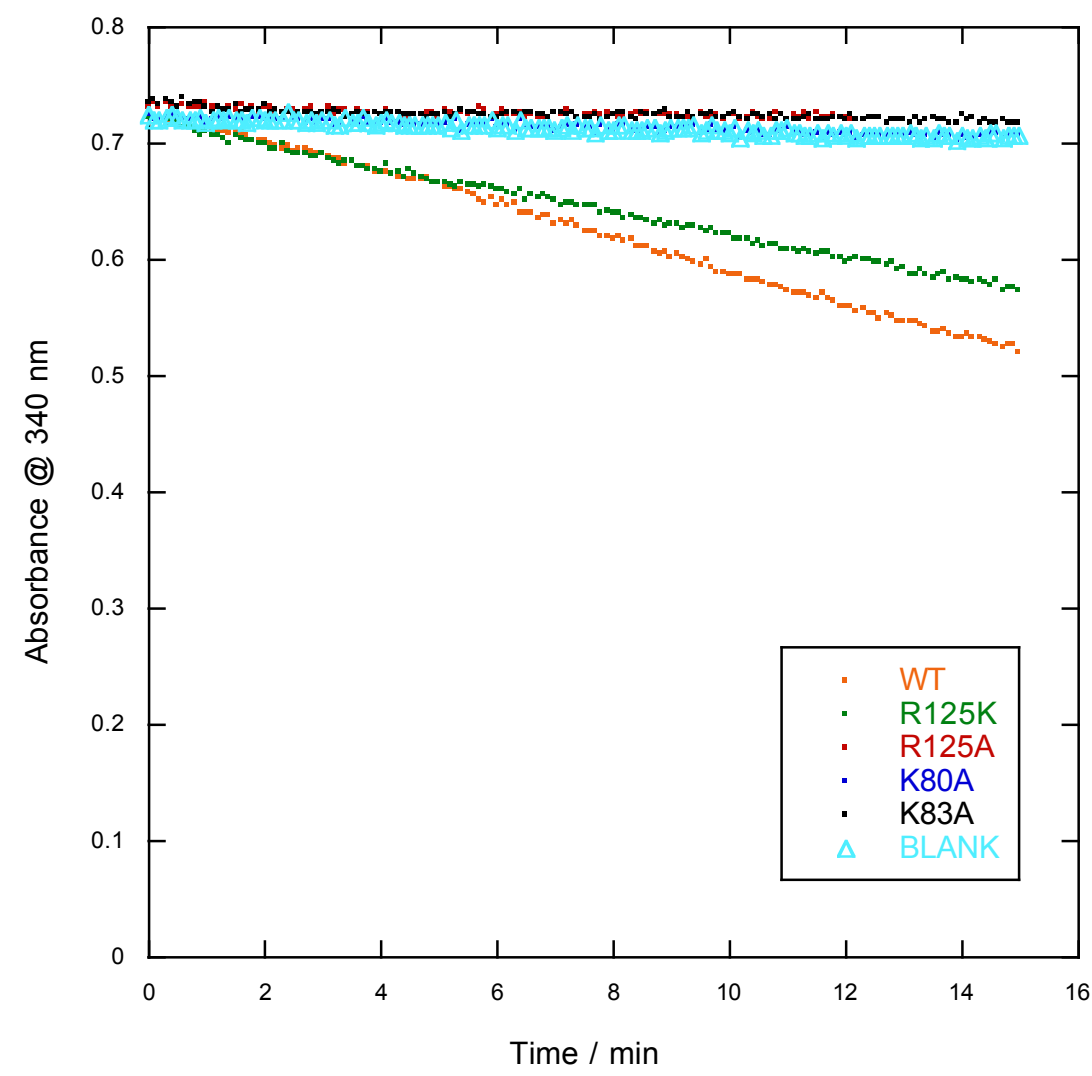

Figure 17. Relative activity of QueF (orange) and mutants R125K (green), R125A (red), K80A (navy), K83A (black) and a blank solution (cyan).

In order to determine if the mutant enzymes are capable of forming the active homodecamer they were analyzed for their ability to undergo reaction with preQ $Q_{0}$ and form the covalent thioimide intermediate. Enzymes with the correct structure will bind preQ to form a thioimide intermediate between the thiol of Cys55 and the nitrile group of the substrate. This intermediate possesses a 
characteristic absorbance at $376 \mathrm{~nm}(\varepsilon=4400)$ and can be monitored by UV-Vis spectroscopy. ${ }^{119}$

The data for the thioimide assays are presented in Figure 18, where absorbance at wavelengths $230-450 \mathrm{~nm}$ is depicted. The region of the graph around the thioimide absorbance maxima has been expanded for clarity in Figure 19. The concentration of wild-type QueF and all QueF mutants was $20 \mu \mathrm{M}$ and preQo was present at $100 \mu \mathrm{M}$.

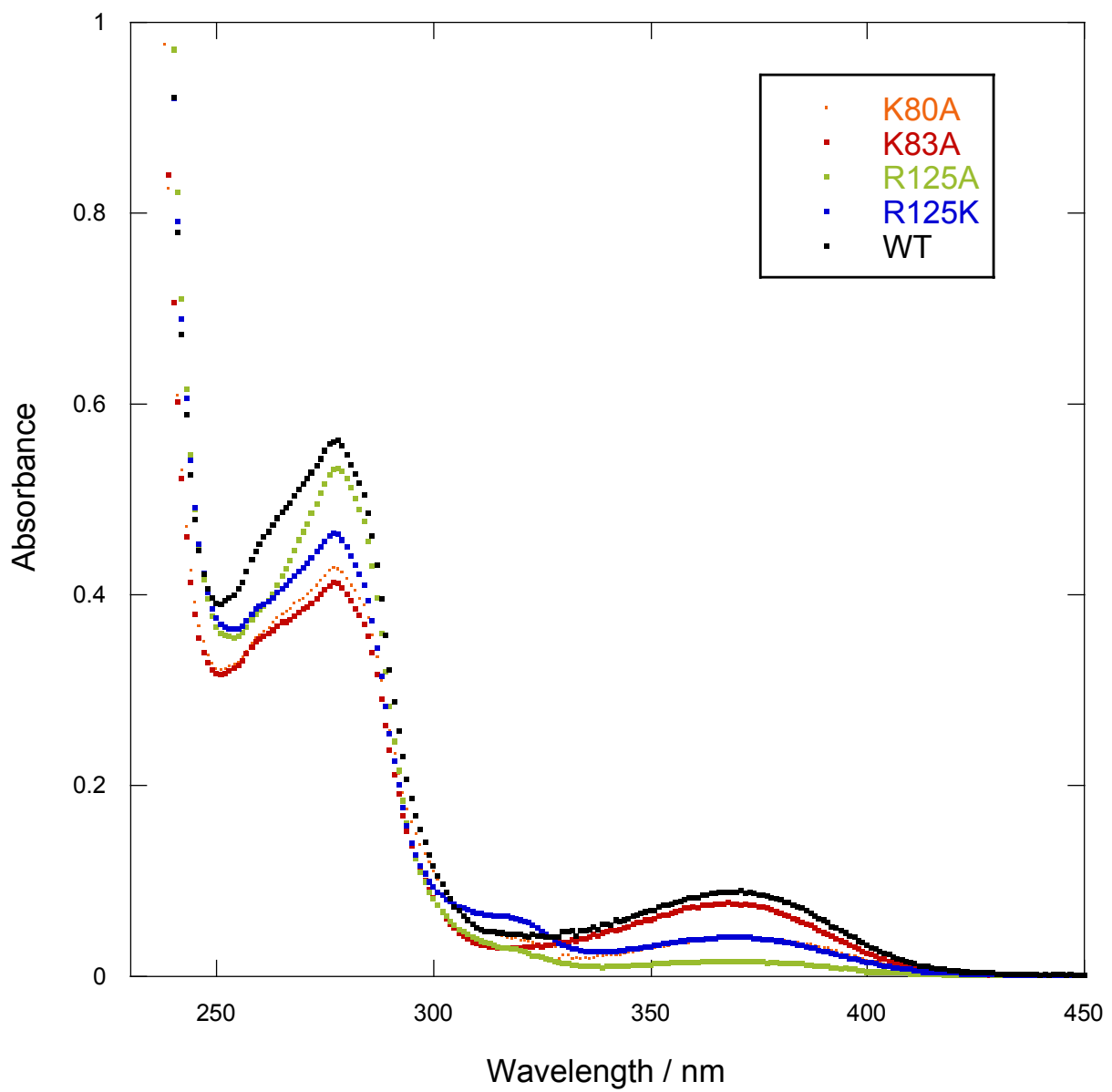

Figure 18. Formation of thioimide intermediate for wild-type QueF and mutants K80A (orange), K83A (maroon), R125A (green) and R125K (navy). 




Figure 19. Expanded view of the formation of thioimide intermediate for wild-type QueF (black) and mutants K80A (orange), K83A (maroon), R125A (green) and R125K (blue).

The characteristic thioimide absorbance peak was observed in mutants $\mathrm{K} 80 \mathrm{~A}, \mathrm{~K} 83 \mathrm{~A}, \mathrm{R} 125 \mathrm{~A}$, and R125K. Differences in the relative absorbance are consistent with different preQo binding affinities for each mutant. These results demonstrate that all mutant enzymes are capable of binding the substrate to form the thioimide intermediate and therefore have the correct tertiary structure. Thus, 
the absence of turnover for the K80A, K83A and R125A mutants is consistent with disruption of cofactor binding and/or the reaction.

The results obtained from the thioimide formation and substrate specificity assays indicate that loss of activity upon introduction of the mutations $\mathrm{K} 80 \mathrm{~A}$, K83A and R125A can be directly attributed to the loss of specific residues required for catalysis. This result is consistent with the notion that both lysines 80 and 83 and arginine 125 are required for the proper binding of NADPH.

Mutant R125K displayed significant levels of activity with respect to the wild type. Mutation of arginine to lysine reduces the length of the amino acid lateral chain but maintains the basic nature of it. It can then be inferred that a basic residue is required at this position to maintain catalytic activity.

The effect of this mutation on catalysis can be quantitatively measured. To do so, $k_{c a t}$ and $K_{M}$ for both preQo and $\mathrm{NADPH}$ were determined under steady state conditions for both the wild type and R125K and then compared to one another.

To determine the $k_{c a t}$ and $K_{M}$ for NADPH activity assays were carried out by monitoring NADPH oxidation at $340 \mathrm{~nm}$. The results obtained for the wild-type enzyme are shown in Figure 20. Reaction velocities in $\mathrm{nM} / \mathrm{min}$ units are plotted against $\mu \mathrm{M}$ concentrations of NADPH. Error bars indicate the standard deviation for triplicate repeats of reactions with the same NADPH concentration. 
The data obtained can subsequently be fitted to the Michaelis-Menten equation in order to obtain $\mathrm{k}_{\mathrm{cat}}$ and $\mathrm{K}_{\mathrm{M}}$ values as shown in Figure 18. From this fit it was determined that $\mathrm{V}_{\max }=1.2 \pm 0.4 \mu \mathrm{M} / \mathrm{min}, \mathrm{K}_{\mathrm{M}}=59.7 \pm 5.2 \mu \mathrm{M}$, $\mathrm{k}_{\text {cat }}=1.44$ $\mathrm{sec}^{-1}, \mathrm{k}_{\mathrm{cat}} / \mathrm{K}_{\mathrm{M}}=0.024 \mu \mathrm{M} / \mathrm{sec}$. These values are consistent with the previously published constants. ${ }^{119}$

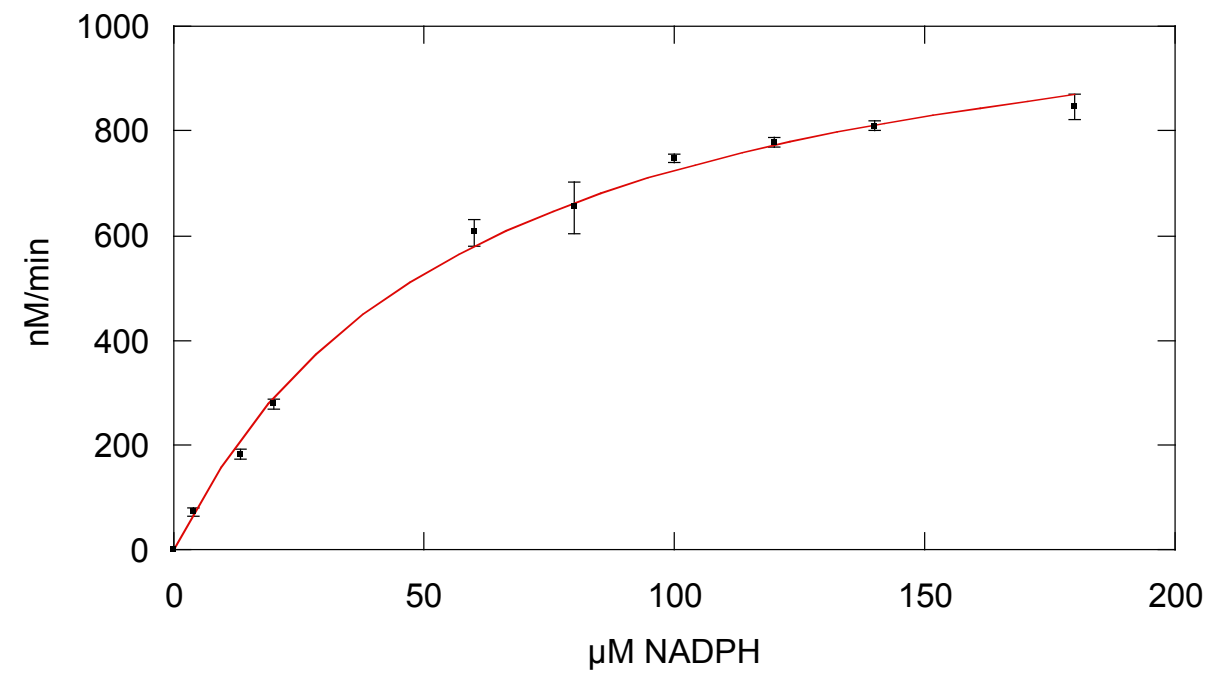

Figure 20. Steady-state reaction velocities for wild-type enzyme with varying concentrations of $\mathrm{NADPH}$. Consumption of substrate in $\mathrm{nM} / \mathrm{min}$ is plotted against $\mu \mathrm{M}$ concentrations of NADPH and Michaelis-Menten fit is shown in red.

The same experiment was performed for the mutant protein $\mathrm{R} 125 \mathrm{~K}$ but in this case the mutant concentration was 10 -fold that of the wild-type to ensure velocities for low concentrations of NADPH were within the detection limit of the instrument. The triplicate results with standard deviation values are summarized in Figure 21. The data obtained was fit to a Michaelis-Menten equation and the resulting values were $\mathrm{V}_{\max }=5.2 \pm 0.4 \mu \mathrm{M} / \mathrm{min}$ and $\mathrm{K}_{\mathrm{M}}=189 \pm 12 \mu \mathrm{M}$, and $\mathrm{k}_{\text {cat }}=$ $0.65 \mathrm{sec}^{-1}, \mathrm{k}_{\mathrm{cat}} / \mathrm{K}_{\mathrm{M}}=0.0034 \mu \mathrm{M} / \mathrm{sec}$. 


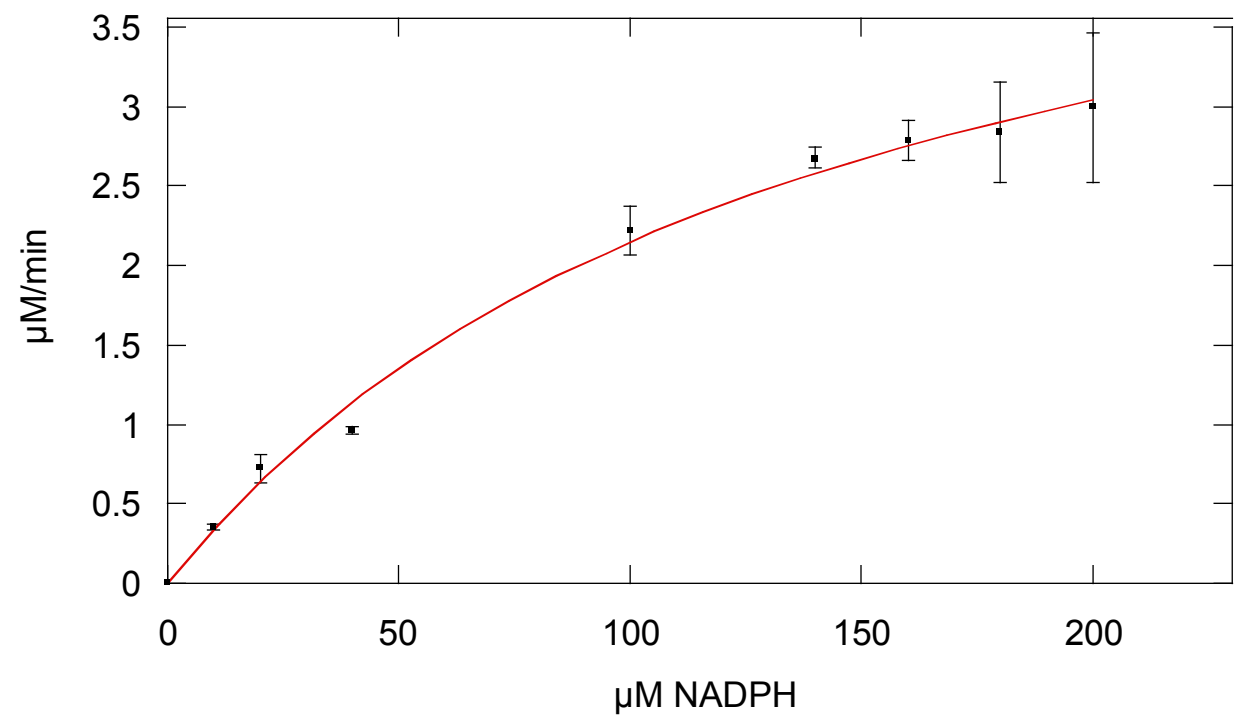

Figure 21. Steady-state velocities reactions of mutant enzyme R125K with varying concentrations of NADPH. Consumption of substrate in $\mu \mathrm{M} / \mathrm{min}$ is plotted against $\mu \mathrm{M}$ concentrations of NADPH and Michaelis-Menten fit is shown in red.

Kinetic constants for preQo must be determined by an indirect method due to the lack of any distinctive and measurable substrate properties such as fluorescence or absorbance. Additionally in order to achieve velocities near $V_{\max }$, the concentration of NADPH has to be kept at approximately 10 fold the $\mathrm{K}_{\mathrm{M}}$. Under these conditions the absorbance of the solution is too high to accurately measure small changes in NADPH concentration via the continuous assay and we employed an indirect fluorescence assay instead. The results obtained however were inconsistent with previously reported values and they are reported in the appendix. 


\subsubsection{Cofactor specificity}

The binding model for NADPH shows lysine 80 , lysine 83 and arginine 125 in close proximity to the phosphates of the cofactor, and while the mutants $\mathrm{K} 80 \mathrm{~A}, \mathrm{~K} 83 \mathrm{~A}$ and $\mathrm{R} 125 \mathrm{~A}$ are capable of binding preQ $\mathrm{Q}_{0}$ to form a thioimide intermediate, the lack of turnover is consistent with impaired binding of NADPH. Because NADH lacks a 2'-phosphate but is otherwise identical to NADPH we hypothesized that it might be able to substitute for NADPH in these mutants. To test this, NADH was used as the cofactor in reactions containing the wild-type or mutant QueF and turnover was monitored at $340 \mathrm{~nm}$ and compared to a control reaction containing no enzyme (Figure 22). Neither the wild-type nor the mutant enzymes demonstrated any significant catalytic activity with $\mathrm{NADH}$, indicating it is not a suitable cofactor for the QueF reaction. 


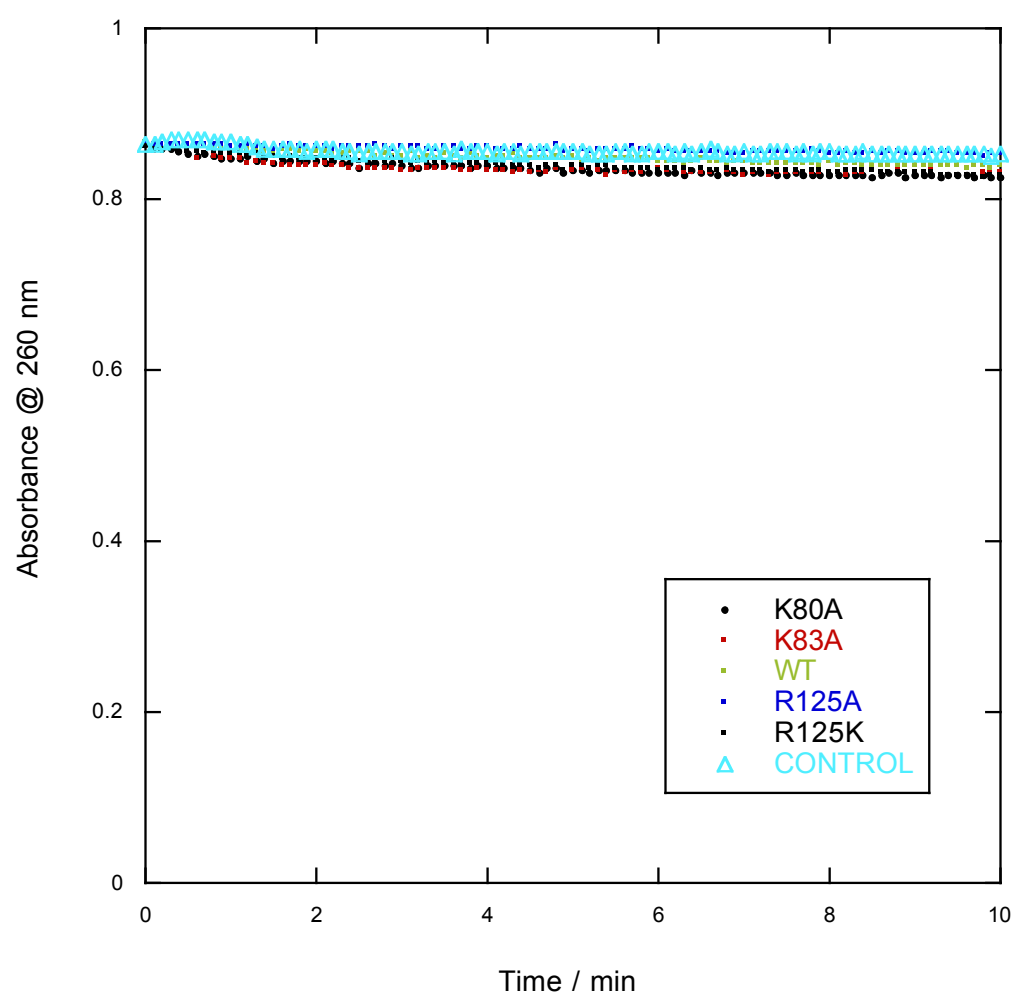

Figure 22. Continuous monitoring of NADH consumption in the WT QueF reaction. Absorbance of NADH at $260 \mathrm{~nm}$ is measured as a function of time.

\subsubsection{Functional disulfides}

Analysis of bond lengths and angles for QueF Cys55-Cys99 observed in the structure of the $\mathrm{E} 78 \mathrm{Q}$ mutant of QueF are indicative of a non-structural disulfide. As previously shown, ${ }^{27}$ Cys55 is required to bind preQo and therefore loss or inactivation of this residue results in loss of activity of the enzyme. 
Oxidative stress is common in the cellular environment and as shown in Figure 23 , when a single cysteine is present, the thiol can be successfully oxidized to a sulfenic acid, sulfinic acid and sulfonic acid. The latter two are irreversible under cellular conditions. However, when two cysteines are present, oxidation can lead to the reversible formation of a disulfide bond.


REVERSIBLE

Figure 23. Reversible and irreversible oxidation of thiols. 
To determine the role of Cys99 in catalysis, this residue was mutated to both alanine and serine. The change in NADPH absorbance as a function of time was monitored for C99A and C99S and both enzymes displayed catalytic activity of a comparable magnitude to that of the wild-type (Figure 24). This indicates Cys99 is not required for turnover. We then hypothesized the role of the disulfide bond to be the protection of Cys55 against irreversible oxidation.



Figure 24. Activity of wild-type QueF (black), mutants C99A (red) and C99S (blue) 
To test this hypothesis, the enzyme was treated with hydrogen peroxide and the oxidation was subsequently quenched using catalase. QueF was then tested to determine remaining activity. About $90 \%$ of activity is lost within 15 seconds of treatment and the enzyme is essentially inactive after one minute (Figure 25), demonstrating that it is sensitive to oxidative conditions.

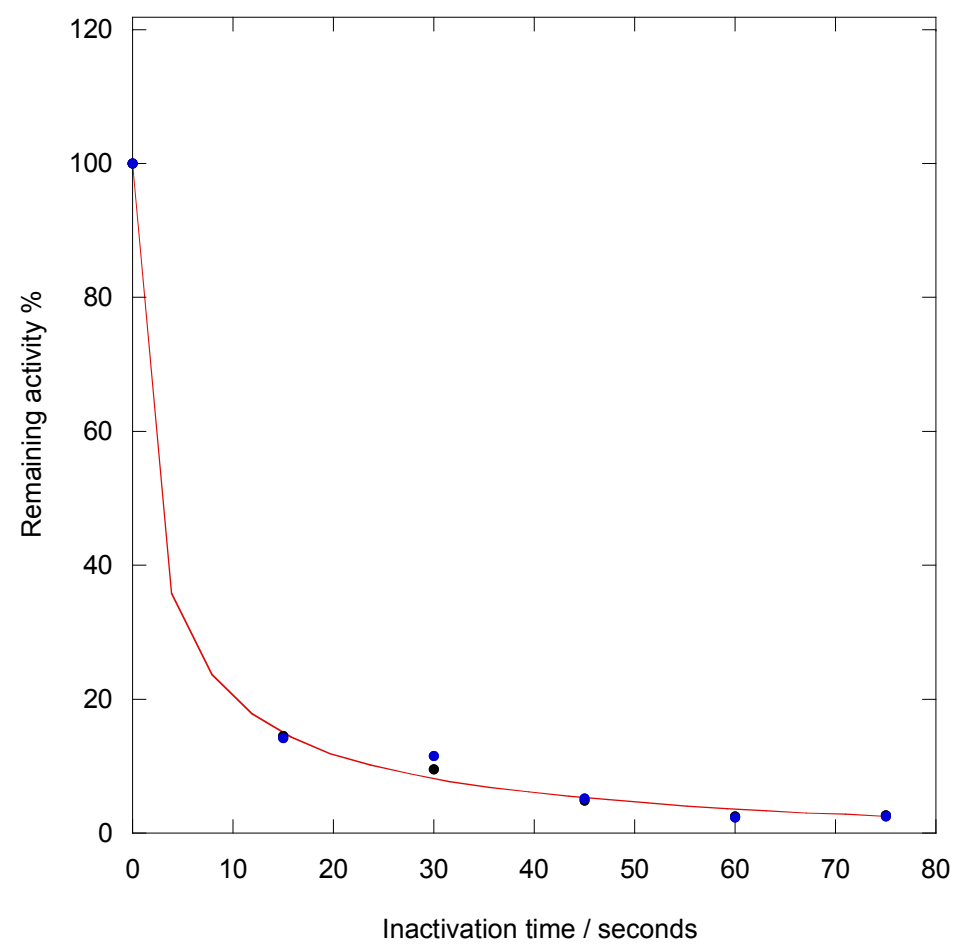

Figure 25. Inactivation of QueF upon treatment with hydrogen peroxide.

To reduce the enzyme and rescue activity the oxidized enzyme was treated with DTT but this only restored $10 \%$ of the initial activity after $60 \mathrm{~min}$ (Data not shown). However, when the wild-type QueF enzyme was treated with 
thioredoxin, which is a redox protein present in all organisms, significant reactivation of the enzyme ( $\sim 50 \%$ of initial activity) was observed (Figure 26$)$.

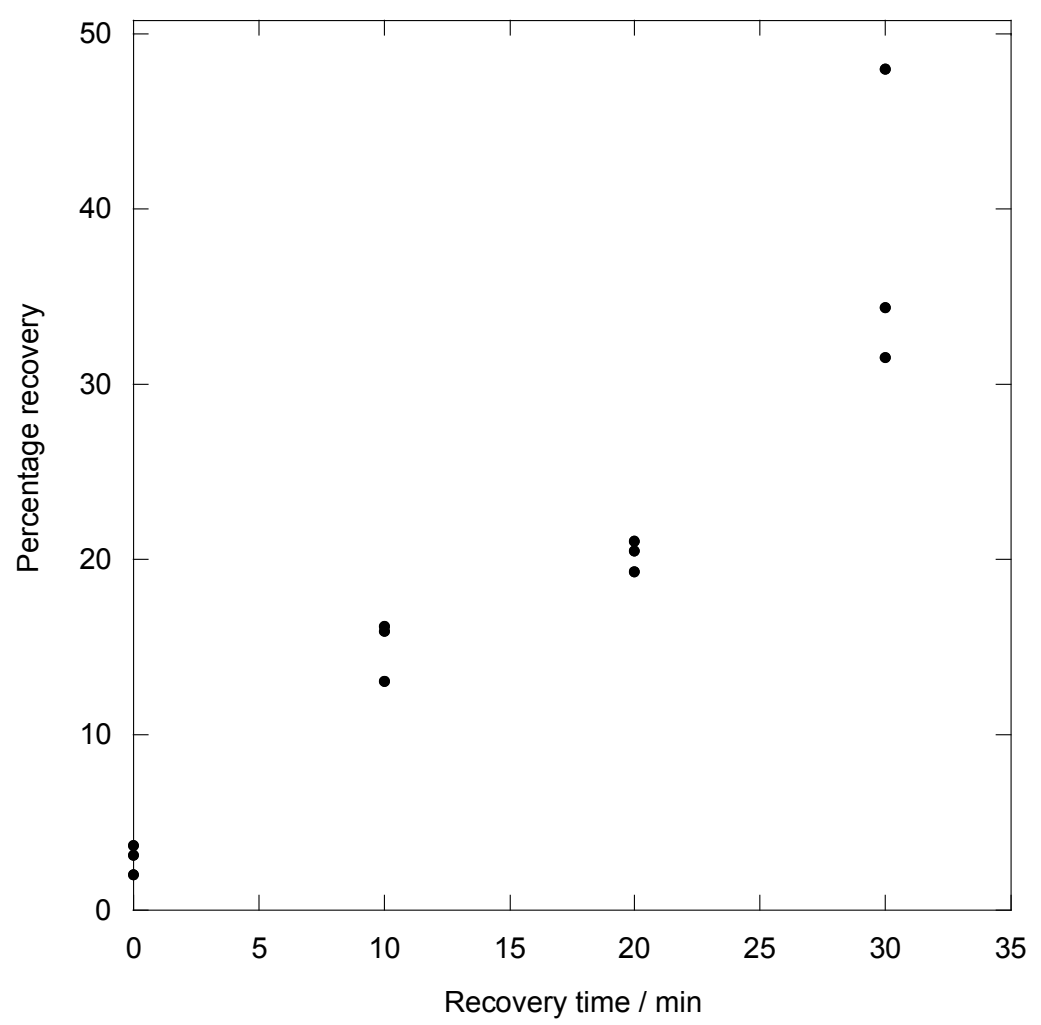

Figure 26. Recovery of oxidized wild-type enzyme activity upon treatment with thioredoxin. The percentage recovery achieved is shown as a function of thioredoxin treatment time.

If the recovery of activity is made possible because the enzyme is oxidized to a Cys55-Cys99 disulfide bond and not sulfenic and sulfonic acids, then QueF enzymes missing Cys99 should be unable to recover activity. To test this, mutants C99A and C99S were tested in the same manner as the wild-type. 
An example of the results is shown in Figure 27 where activity is shown as the loss of absorbance of the cofactor (NADPH) at $340 \mathrm{~nm}$ over time. Activity of the wild type enzyme (orange) can be recovered to about $50 \%$ of the initial activity (WT control, black) upon treatment with thioredoxin. However, both mutant enzymes C99A (blue) and C99S (red) remained inactive even after 60 min of treatment with thioredoxin.

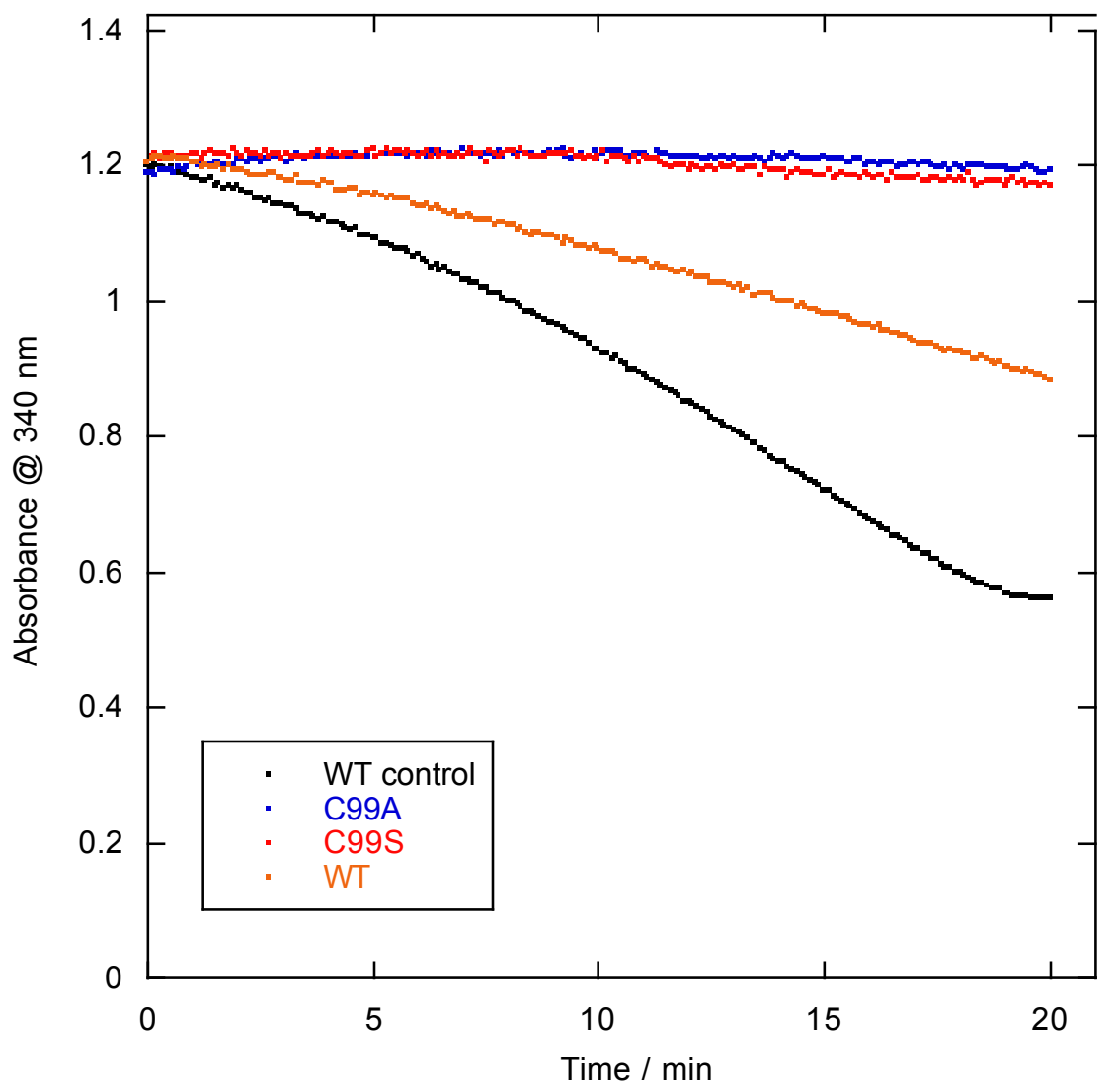

Figure 27. Activity recovery after 60 min treatment with thioredoxin. 


\subsection{Conclusions}

The role of residues $\mathrm{K} 80, \mathrm{~K} 83$ and $\mathrm{R} 125$ in catalysis was evaluated by mutating them to K80A, K83A, R125A and R125K. All mutant enzymes were capable of binding the substrate pre $_{0}$ and forming the thioimide intermediate, demonstrating that the native structure was intact.

When mutations $\mathrm{K} 80 \mathrm{~A}, \mathrm{~K} 83 \mathrm{~A}$ or $\mathrm{R} 125 \mathrm{~A}$ were introduced the resulting enzyme was inactive. Since substrate binding was still possible in these cases and both residues are shown in close proximity to NADPH in the binding model, it is likely that these residues are required to bind the cofactor. Whether they are involved in direct binding of the cofactor or retaining the correct structural configuration of the active site is unknown. Further investigation will be necessary to ascertain the exact role of these residues.

The mutant $\mathrm{R} 125 \mathrm{~K}$ was found to have significant activity with a $\mathrm{k}_{c a t} / \mathrm{K}_{\mathrm{M}}$ approximately $10 x$ less that of the wild-type enzyme. The docking model for NADPH shows two Arg125 from two different subunits come together in the active site and are in close proximity to the negatively charged phosphates of $\mathrm{NADPH}$. The results obtained are indicative of the need for a positively charged residue at this position, which can form an ion pair with negatively charged phosphate. Further analysis will be required to definitively establish the role of this arginine in catalysis. 
Analysis of dihedral angles of the disulfide linkage between Cys55-Cys99 along with the results obtained in the oxidation experiments indicate a functional role for the disulfide bond in preventing the enzyme from being inactivated under oxidative stress conditions.

While DTT was not effective at rescuing activity, significant recovery was observed when the biological redox protein thioredoxin was used. It is reasonable to believe that full recovery is not possible as treatment with hydrogen peroxide unselectively damages amino acids in the enzyme that can't be rescued by the addition of reducing agents.

Lack of recovery in the C99A and C99S mutants further highlights the need for Cys99 in order to effectively prevent irreversible oxidation of Cys55, which could potentially render the enzyme unable to turnover. 


\section{Chapter 4. QueF-like}

\section{1 introduction}

\subsubsection{Archaeosine biosynthesis}

Archaeosine is one of the rare tRNA modifications conserved quasiuniversally in Archaea.52,126 This hypermodification is found at position 15 of all tRNAs in every sequenced Archaea with the exception of Haloqadratum walsbyi. ${ }^{127}$ This degree of conservation is also observed for ArcTGT, the enzyme that catalyzes the exchange of guanine for preQo at position 15 of archaeal tRNAs. The gene encoding for $\operatorname{arcTGT}, \operatorname{tgt} A$, is in fact used as a signature gene family for Archaea.

All Euryarchaeota and four Crenarchaeota (Sulfolobus tokodaii, Sulfolobus solfataricus, Ignococcus hospitalis, and Hyperthermus butylicus) sequenced to date contain the gene that encodes for Archaeosine synthase (arcS), the enzyme that catalyzes the conversion of preQo-tRNA to archaeosine-tRNA in the last step of the archaeosine biosynthetic pathway ${ }^{128}$ (Figure 28). This conversion is not ATP dependent and therefore does not require hydrolysis of the nitrile to an amide. Instead $\mathrm{NH}_{3}$ is added directly from glutamine (or asparagine) hydrolysis. ${ }^{73}$ 

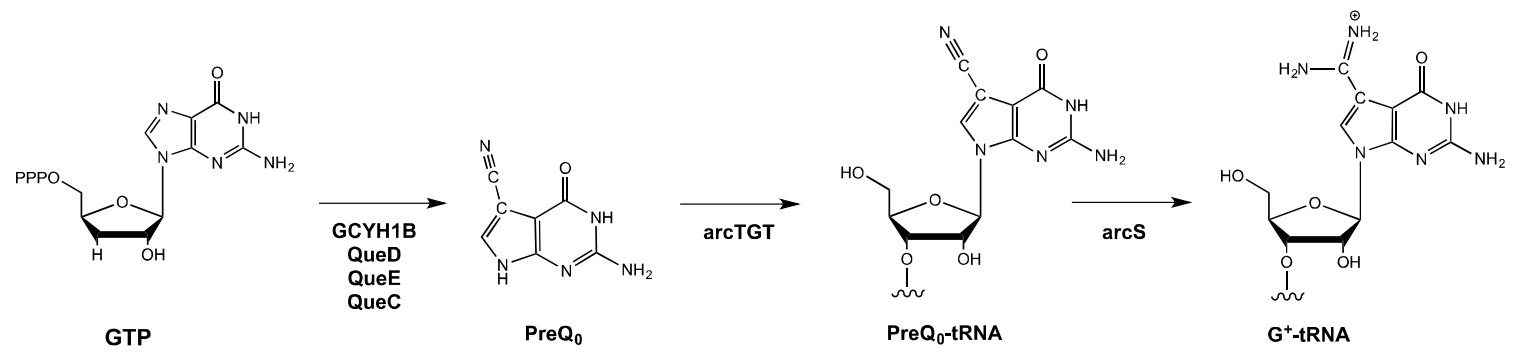

Figure 28. Archaeosine-tRNA biosynthetic pathway.

\subsubsection{Amidotransferases}

Glutamine amidotransferases (GATs) catalyze the removal of the ammonia group from glutamine and the transfer of this group to a new substrate, forming a new carbon-nitrogen bond. ${ }^{129}$ The GAT domain can exist as a separate unit or part of a larger polypeptide fused to a synthase domain. In the latter case, hydrolysis of glutamine in the glutaminase domain yields ammonia and this is subsequently channeled through a tunnel 10 to $40 \AA$ long into the synthase domain ${ }^{130}$. The substrate differs for each GAT ${ }^{129}$.

GAT enzymes are further classified based on the catalytic residues used to perform the chemistry. Class I or triad class use histidine, cysteine and glutamate to activate the cysteine thiol group. In Class II or N-terminal nucleophile (Ntn) the catalytic cysteine is at the $\mathrm{N}$-terminus and its thiol is activated by the alpha-amino group. Structurally, class I GATs have a common open alpha/beta fold whereas class II are composed of antiparallel beta sheets $^{130}$. 
Another large class of ammonia transferring enzymes are the tRNA dependent amidotransferases. These include the heterotrimeric GatCAB enzymes which catalyze the conversion of the misacylated Glu-tRNA Gln/AsptRNA $^{\text {Asn }}$ to Gln-tRNA ${ }^{\text {Gln}} / A_{s n-t R N A}{ }^{\text {Asn }}$ utilizing glutamine or asparagine as ammonia sources, and the heterodimeric GatDE enzymes which convert GlutRNA $^{\text {Gln }}$ to Glu-tRNA ${ }^{\text {Gln }}$ in archaea and use glutamine as the source of ammonia. Both of these families of enzymes are ATP dependent and they phosphorylate the gamma-carboxyl of the Glu/Asp residue attached to the tRNA prior to amidation.

QueF-L and arcS are both unrelated to all of the class I and II and tRNAdependent amidotransferases.

\subsection{3. $G^{+}$biosynthetic enzymes}

ArcS is not conserved in all Crenarchaeota (Figure 29) and the amidino group of archaeosine must therefore be introduced by other non-homologous enzyme families in these organisms. Comparative genomic analysis showed that QueC proteins from several Crenarchaeal species are much larger than those found in most Archaea (470 residues vs. 270). These enzymes contain an additional $\mathrm{N}$-terminal domain homologous to proteins from the glutamine amidotransferase class-I family. However, GAT-QueC homologs are not found in all Crenarchaeota that lack ArcS. ${ }^{128}$ 


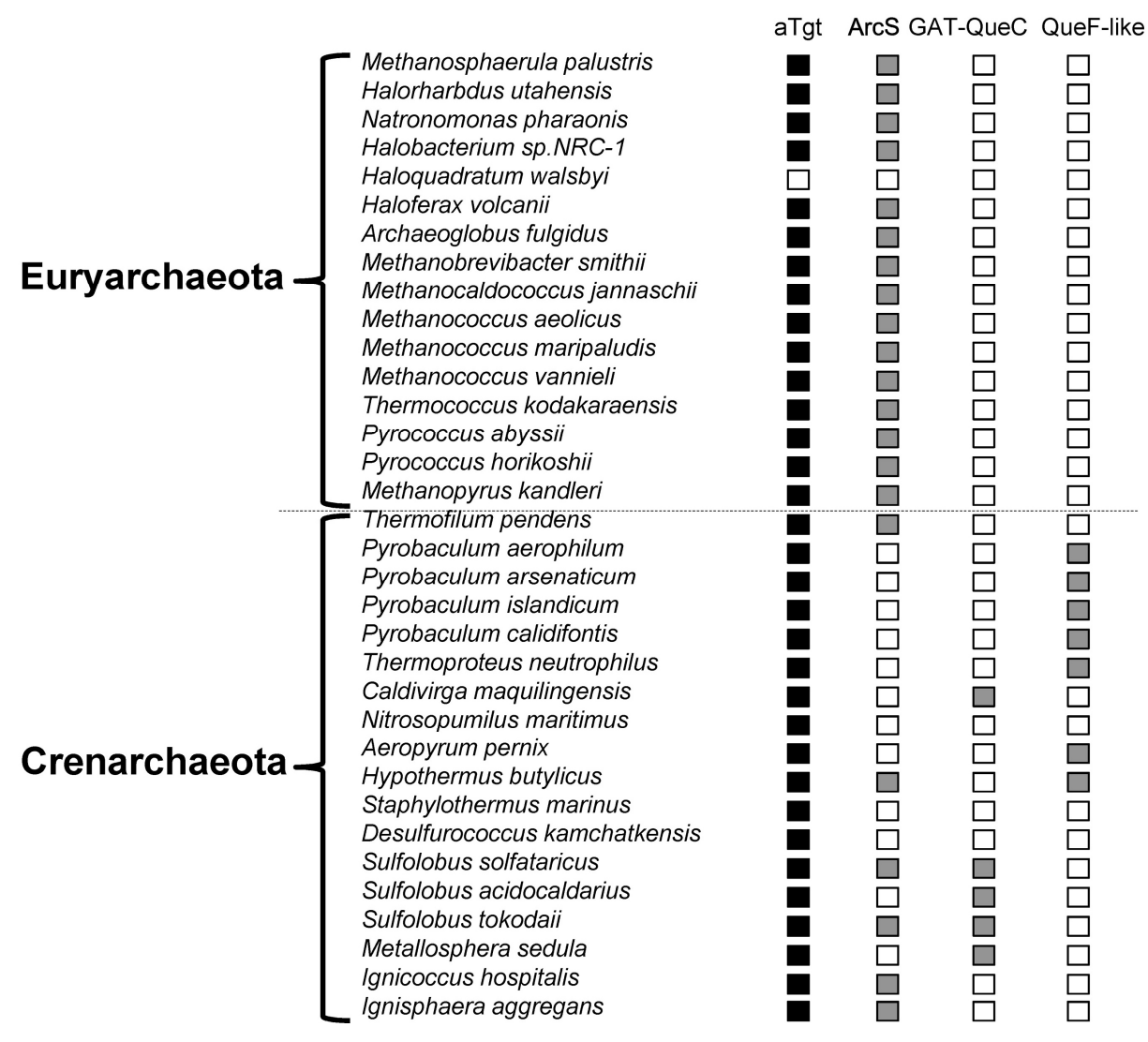

Figure 29. Conservation of archaeosine metabolism enzymes in Archaea. ${ }^{128}$

Another gene family was identified that exhibits a complementary distribution pattern to ArcS and GAT-QueC and contains a member that physically clusters with the queC gene in Aeropyrum pernix. This gene family encodes a protein family homologous to QueF, and was annotated as QueF-like (QueFL). 
To test the hypothesis that GAT-QueC and QueF-like enzymes are functionally analogous to ArcS in the archaeosine pathway, the genes encoding for these proteins from Sulfolobus todokaii and Pyrobacculum calidifontis respectively were introduced into E. coli. The bulk tRNA produced by both strains was then analyzed and found to contain archaeosine at position 34 of the tRNA, consistent with both enzymes functioning as ArcS analogs.

Bacterial TGT can utilize preQo as a substrate and therefore it is possible that GAT-QueC and QueF-L enzymes modify preQo-tRNA in the same manner as arcS even though preQ $Q_{0}$ in the E.coli tRNA is present at position 34 instead of position 15. However, given the homology of QueF-like to QueF, it's also

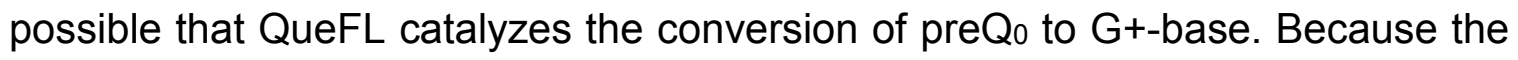
bacterial Tgt has evolved to utilize preQ ${ }_{1}$ as the substrate, which like $\mathrm{G}^{+}$-base possesses a positively charged nitrogen group, it might be capable of utilizing $\mathrm{G}^{+}$-base as a substrate.

While the canonical arcTGT cannot utilize archaeosine base as a substrate, structural comparison of this enzyme with the catalytic domains of arcTGT enzymes from Crenarcheota that lack ArcS, reveal differences in their active site. Substrate recognition determinants for preQo, including the recognition feature for the cyano group, that are present in the canonical arcTGT, are missing in crenarchaeal organisms. These include Met102 (Leu in all crenarcheal arcTGT), and Val198 (Thr in crenarchaeal arcTGT), which are located in the helix that harbors the major antideterminants against recognition of preQ $_{1}$. The modified active site could allow for accommodation of archaeosine, 
making preQo a possible substrate for the QueFL enzyme. Therefore both preQ0 and preQo-tRNA could be considered substrates for QueFL (Figure 30).



Figure 30. Possible biosynthetic routes from PreQ $Q_{0}$ to archaeosine-tRNA.

To gain insight into substrate binding and catalysis, a sequence alignment of QueFL and QueF enzymes was generated to compare both families of enzymes (Figure 31). This revealed that residues of the preQo binding pocket of QueF such as Cys55, Tyr70 and Glu97, as well as Asp62 are strictly conserved in QueFL enzymes. The alignment also shows the absence of the QueF motif, the basis for the annotation as QueFL and not QueF. 


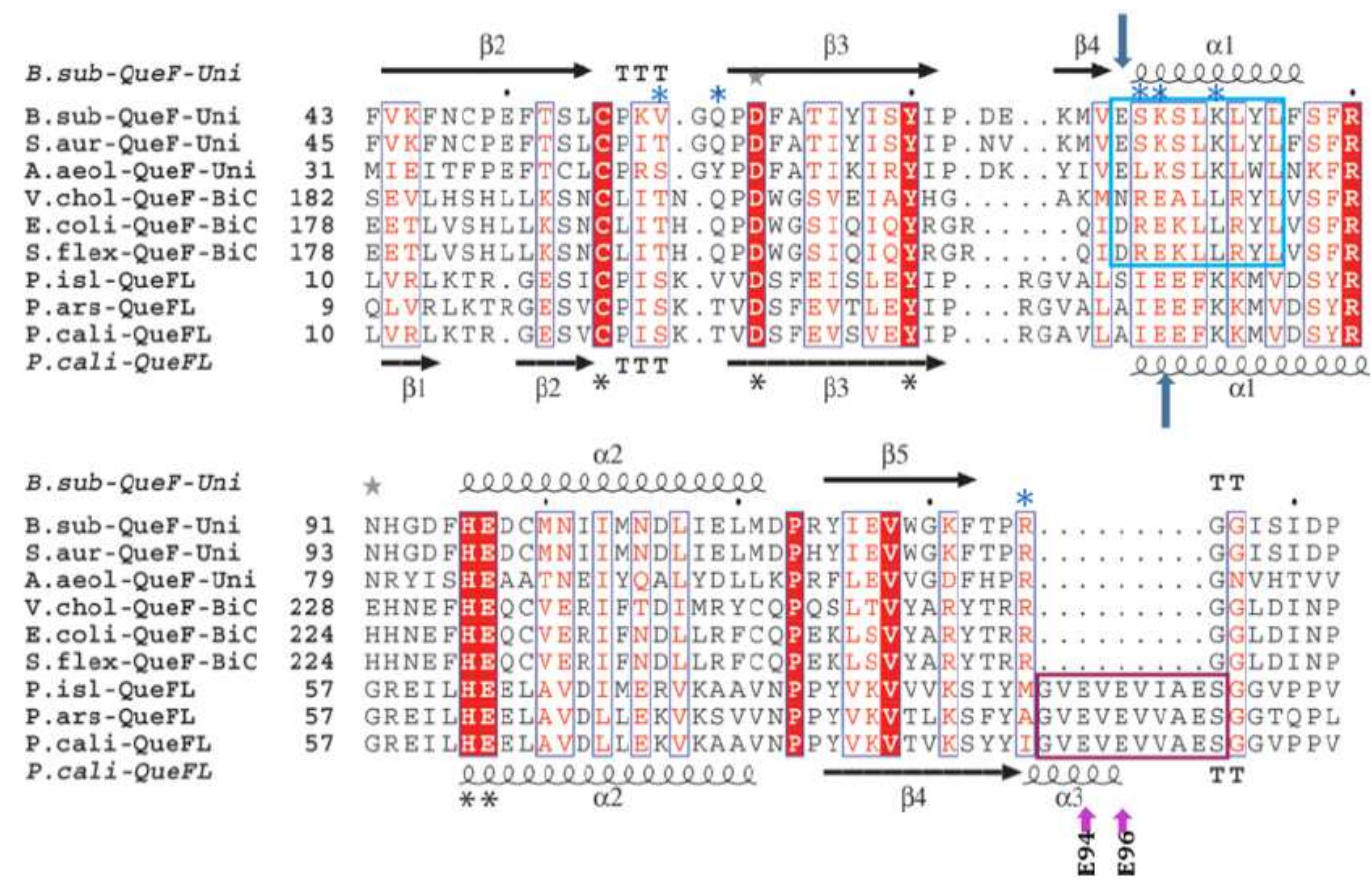

Figure 31. Sequence alignment of Unimodular (uni) and bimodular (BiC) QueF and QueF-like (QueFL). Invariant residues of the substrate binding pocket are highlighted in red. Conserved residues from the QueF and QueF-like binding pockets are marked with a blue and black asterisk respectively. The QueF motif in unimodular QueF is boxed in blue and the QueF-like motif is boxed in pink. Secondary structure elements from the V. cholerae QueF crystal structure and from the P. calidifontis QueF-like homology model are shown above and below the sequences, respectively. ${ }^{128}$

The sequence homology was consistent with QueF-like being a T-fold family member. A homology model was generated based on the crystal structure of Bacillus subtilis QueF ${ }^{27}$ (Manal Swairjo, unpublished data) (Figure 32). 




Figure 32. Modeled QueF-like structure superimposed on QueF B. subtilis structure. QueF is shown in gray and blue, QueF-like is shown in green. Conserved positions are shown in red and QueF motif in blue. Residues are labeled black (QueF) and green (QueF-like).

As expected, the result is a QueF-like structure model that is nearly superimposable with QueF. The QueF-like counterparts to key QueF catalytic residues (Cys21, Asp28, His62, Glu63 and Tyr35) are located at the same position. This model lead to the hypothesis that residues which play a key role on QueF catalysis may function similarly in QueF-like.

\subsubsection{Objective}

The work presented in this chapter aims to characterize the newly discovered enzyme QueF-like. First the substrate for the reaction as well as the nitrogen source required for the formation of archaeosine-tRNA must be determined. As previously discussed, both preQ $_{0}$ and preQo-tRNA are candidate substrates. Many amidotransferases are capable of using several sources of nitrogen and therefore glutamine, asparagine and ammonium chloride must all 
be tested as sources of ammonia. The crystal structure of the enzyme is also elucidated 


\subsection{Results and discussion}

\subsubsection{Expression and purification of QueF-like}

The gene encoding for Pyrobacculum calidifontis QueF was expressed in E. coli and the protein was purified by Ni-NTA affinity chromatography. SDSPAGE analysis of the purification is shown in Figure 33.

No protein was observed in the flowthrough (lane 3) or the $20 \mathrm{mM}$ imidazole fraction (lane 4), indicative of tight binding to the Ni-NTA resin. Cleavage of the tag can be inferred from the molecular weight difference between the $200 \mathrm{mM}$ imidazole fraction (lane 5) and the post Factor Xa cleavage fraction (lane 6), yielding the expected $12 \mathrm{kDa}$ product.

\section{$\begin{array}{llllll}1 & 2 & 3 & 4 & 5 & 6\end{array}$}

40

25

15

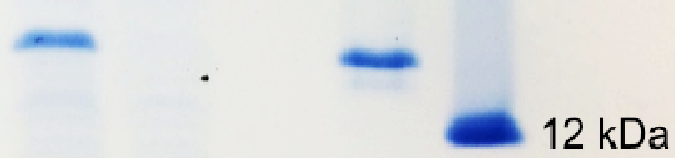

10

4.6

Figure 33. SDS-PAGE analysis of QueF-like purification. Lane 1: molecular weight ladder, lane 2: cell free extract, lane 3: flowthrough, lane 4: $20 \mathrm{mM}$ imidazole fraction, lane 5: $200 \mathrm{mM}$ imidazole fraction, lane 6: QueF-like after Factor Xa cleavage. 


\subsubsection{Expression and purification of Methanococcus janaschii TGT.}

The gene encoding for archaeal tRNA transglycosylase from Methanococcus janaschii (MjTGT) was expressed in E. coli and the protein was purified by Ni-NTA affinity chromatography. ${ }^{72}$ SDS-PAGE analysis of the purification is shown in Figure 34 No significant impurities are found in the purified protein (200 mM imidazole fraction). A fraction of the protein was lost in the $20 \mathrm{mM}$ imidazole fraction, possibly a result of column overloading. The purified protein yielded the expected size of $78 \mathrm{kDa}$



Figure 34. SDS-PAGE analysis of MjTGT purification. From left to right lanes are 1: ladder, 2: cell free extract, 3: flowthrough, 4: $20 \mathrm{mM}$ imidazole fraction, 5: $200 \mathrm{mM}$ imidazole fraction. 


\subsubsection{Production of $M$. thermoautotrophicus preQ0-tRNA ${ }^{\text {Gln }}$}

The tRNA ${ }^{\text {Gln }}$ corresponding to the CTG anticodon for Methanobacterium thermoautotrophicus was produced by T7 RNA polymerase transcription and purified by urea-PAGE gel (Figure 35)

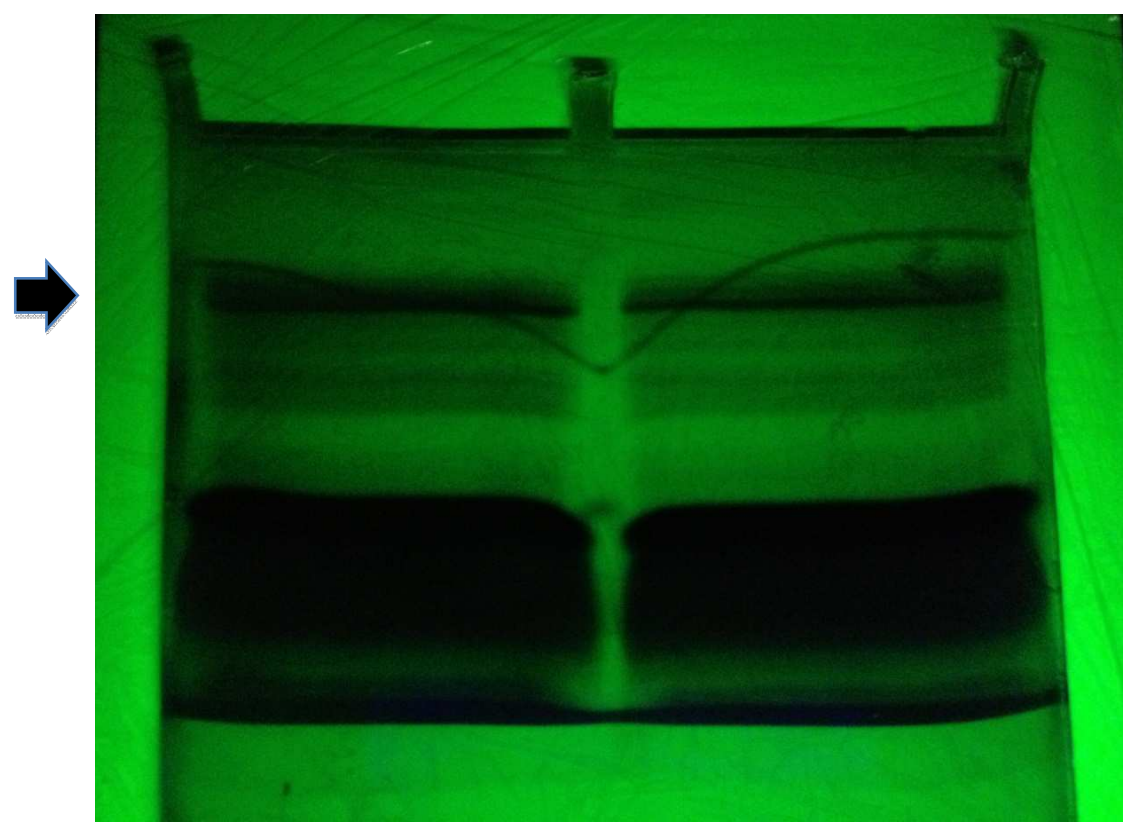

Figure 35. Urea-PAGE purification of in vitro transcribed $M$. Thermoautotrophicus tRNA ${ }^{\text {Gln }}$. Full length tRNA product is indicated with an arrow. Bands underneath show incomplete transcripts and remaining rNTPs.

The product was extracted in ammonium acetate/EDTA buffer overnight and then precipitated with ethanol. The purified product was modified using MjTGT to incorporate preQo at position 15 of the tRNA. Exchange of the unmodified base for preQ $Q_{0}$ can be observed via the guanine exchange assay. In this reaction, radiolabeled guanine is exchanged for cold preQ $Q_{0}$ and the DPM counts of the modified tRNA decrease over time. (Figure 36). 


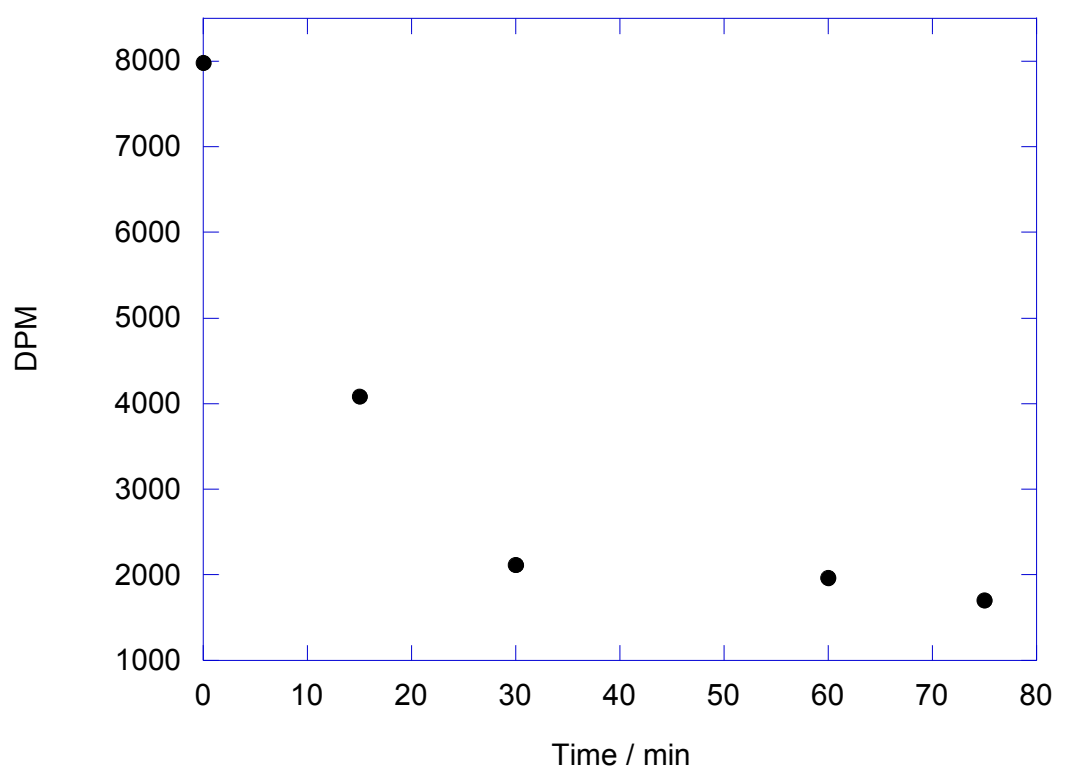

Figure 36. Loss of radiolabeled guanine during the MjTGT exchange reaction.

Incorporation of preQo can then be confirmed by enzymatic digest of the resulting preQo-tRNA and subsequent chromatographic analysis. Figure 37 shows the HPLC trace for the analyzed tRNA digest products.

Peaks correspond to nucleosides cytidine (8 min), uridine (10.2 min), guanosine (17.8 $\mathrm{min})$ and adenosine $(18.2 \mathrm{~min})$ respectively. PreQo nucleoside elutes at a retention time of 24 minutes. 


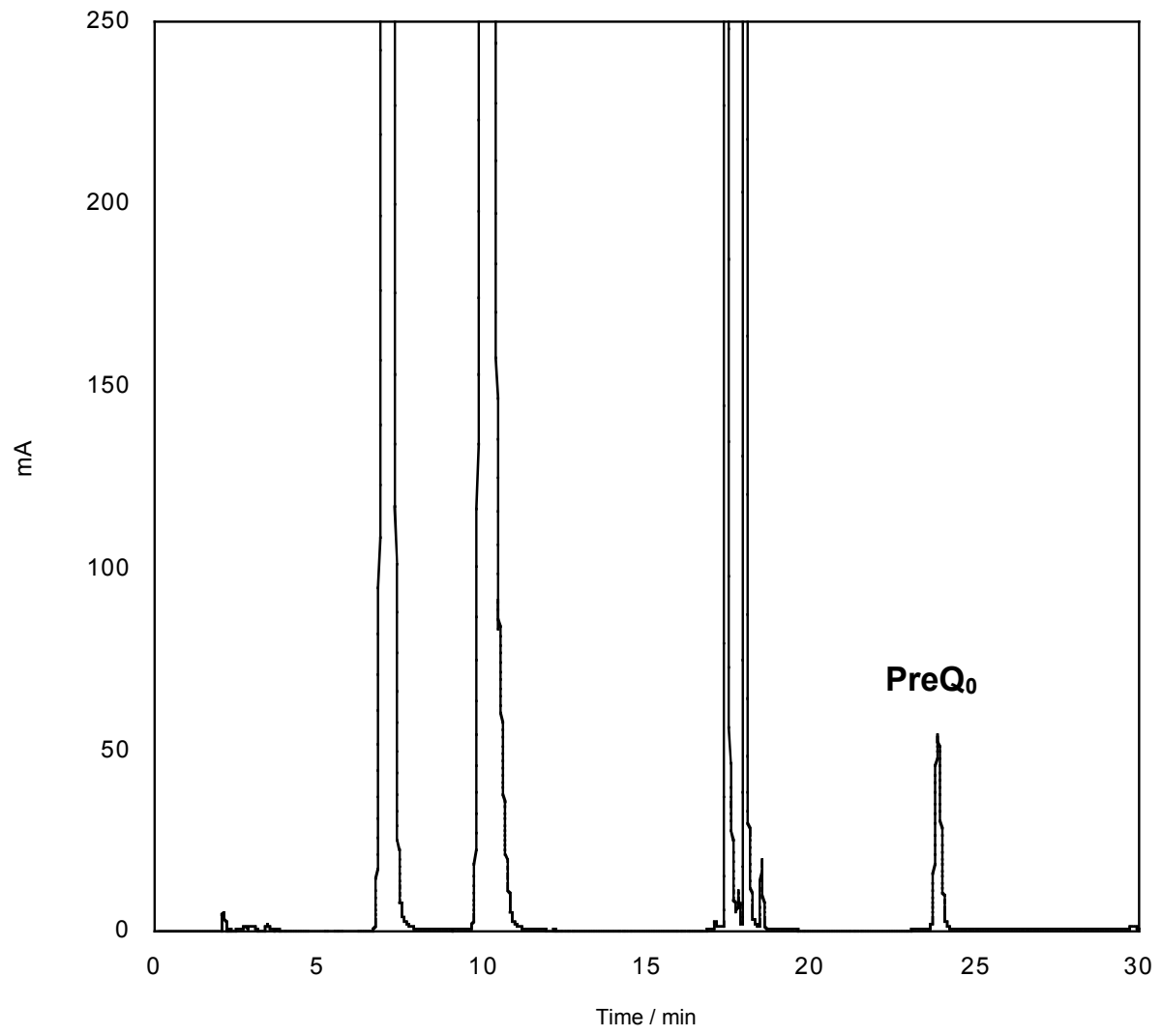

Figure 37. HPLC analysis of digested preQo-tRNA. Peaks correspond to cytidine, uridine, guanosine, adenosine and preQo nucleoside.

\subsubsection{QueF-like substrate identification}

In the homology model QueF-like Cys21 is located at a structurally equivalent position to Cys55 in QueF. This led to the hypothesis that Cys21 could form a thioimide intermediate with $\mathrm{preQ}_{0}$ and/or preQo-tRNA. To test the hypothesis, each candidate substrate was titrated into the enzyme under appropriate buffer conditions and changes in absorbance around the thioimide absorbance maxima (376 nm) were monitored by UV-Vis spectroscopy (Figure 38). 
An increase in absorbance around the $376 \mathrm{~nm}$ region is observed upon subsequent additions of substrate indicating preQo is capable of binding and reacting to form the covalent thioimide intermediate. The figure inset shows this region expanded for clarity.

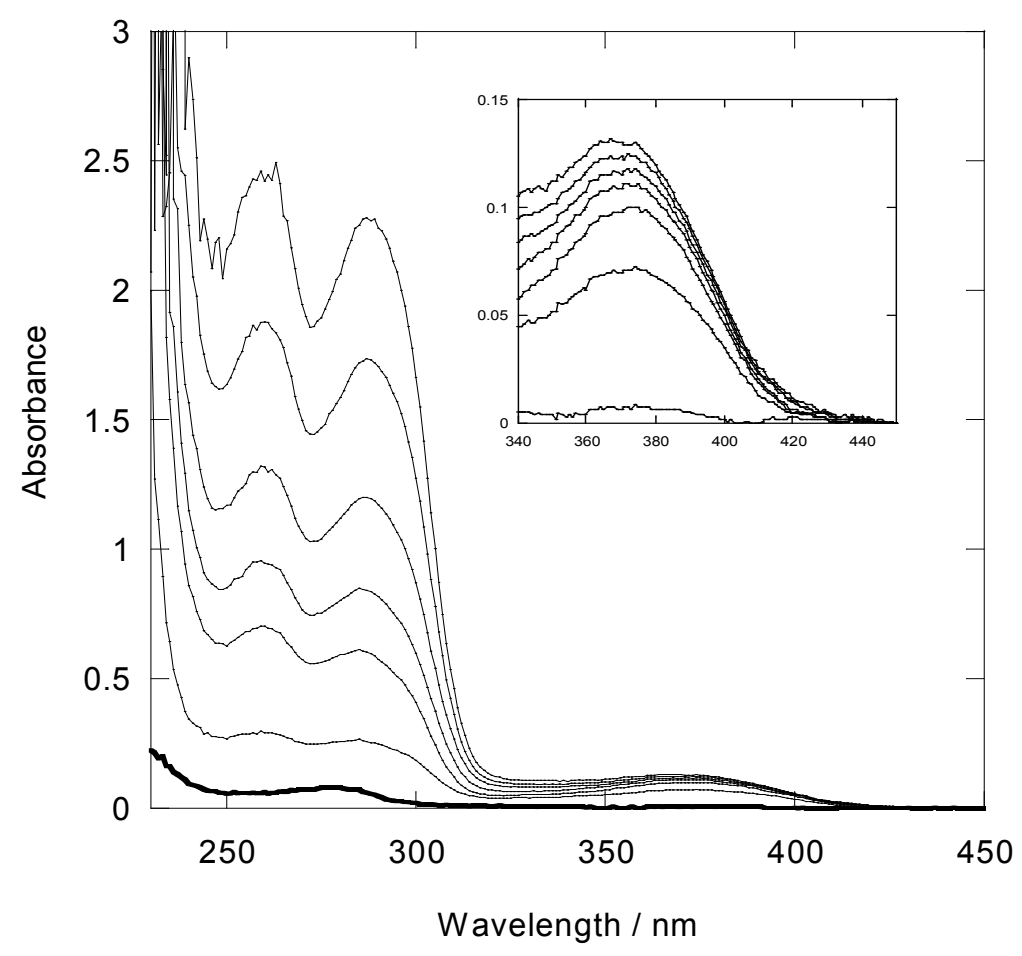

Figure 38. UV-Vis spectroscopy of $\mathrm{preQ}_{0}$ addition to QueF-like. The thicker lower trace corresponds to the protein $(20 \mu \mathrm{M})$ absorbance prior to substrate addition. The finer traces correspond, from bottom to top, to preQ concentrations of $10,20,40,60,80$, and $120 \mu \mathrm{M}$ respectively. 
Figure 39 is a summary plot of the increase in absorbance as a function of preQ concentration.

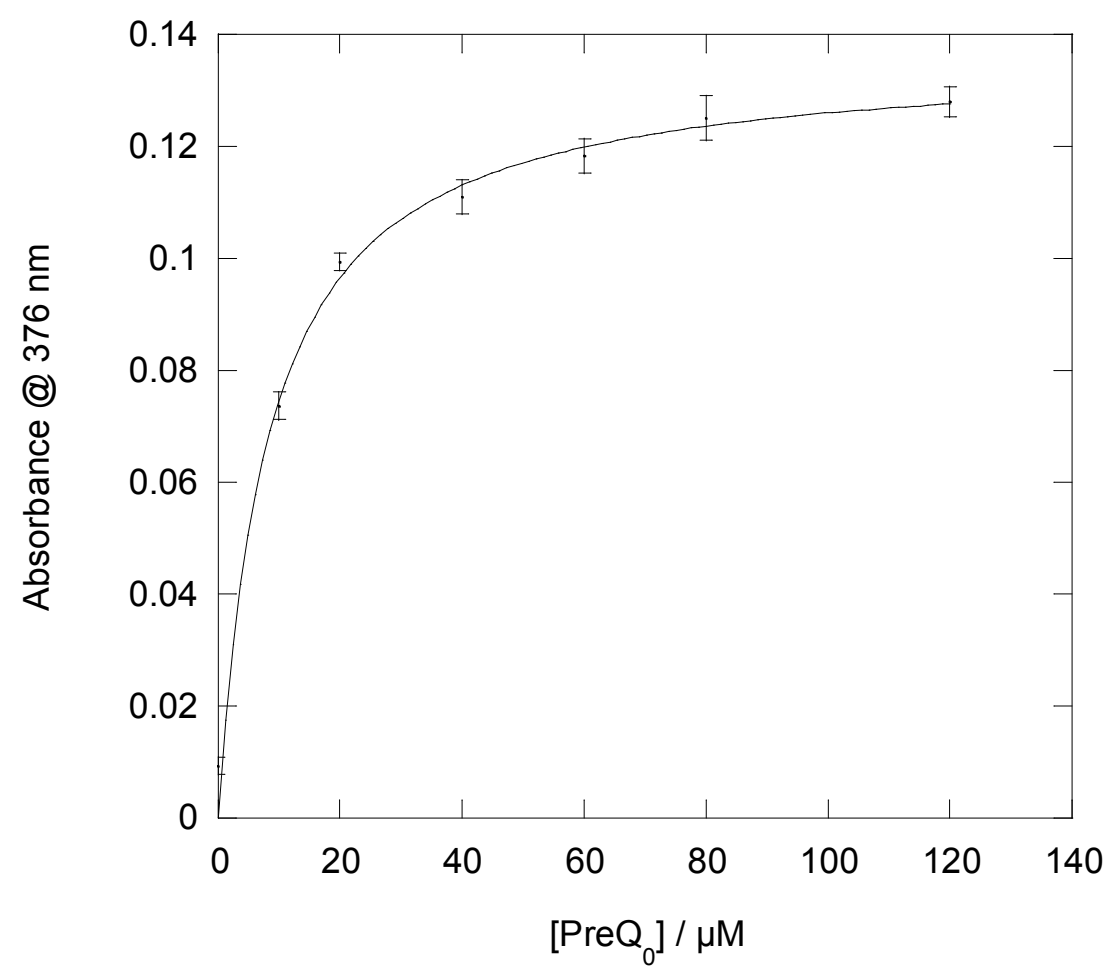

Figure 39. Increase in $376 \mathrm{~nm}$ absorbance as a function of PreQo concentration. 
To test if preQo-tRNA was also capable of binding to QueF-like and forming the thioimide intermediate, QueFL was titrated with preQo-tRNA to probe for thioimide formation. The results of this experiment are presented in Figure 40. As shown, an increase in absorbance was also observed in this case, indicating the ability of the enzyme to bind both the preQo base and the preQo modified tRNA.

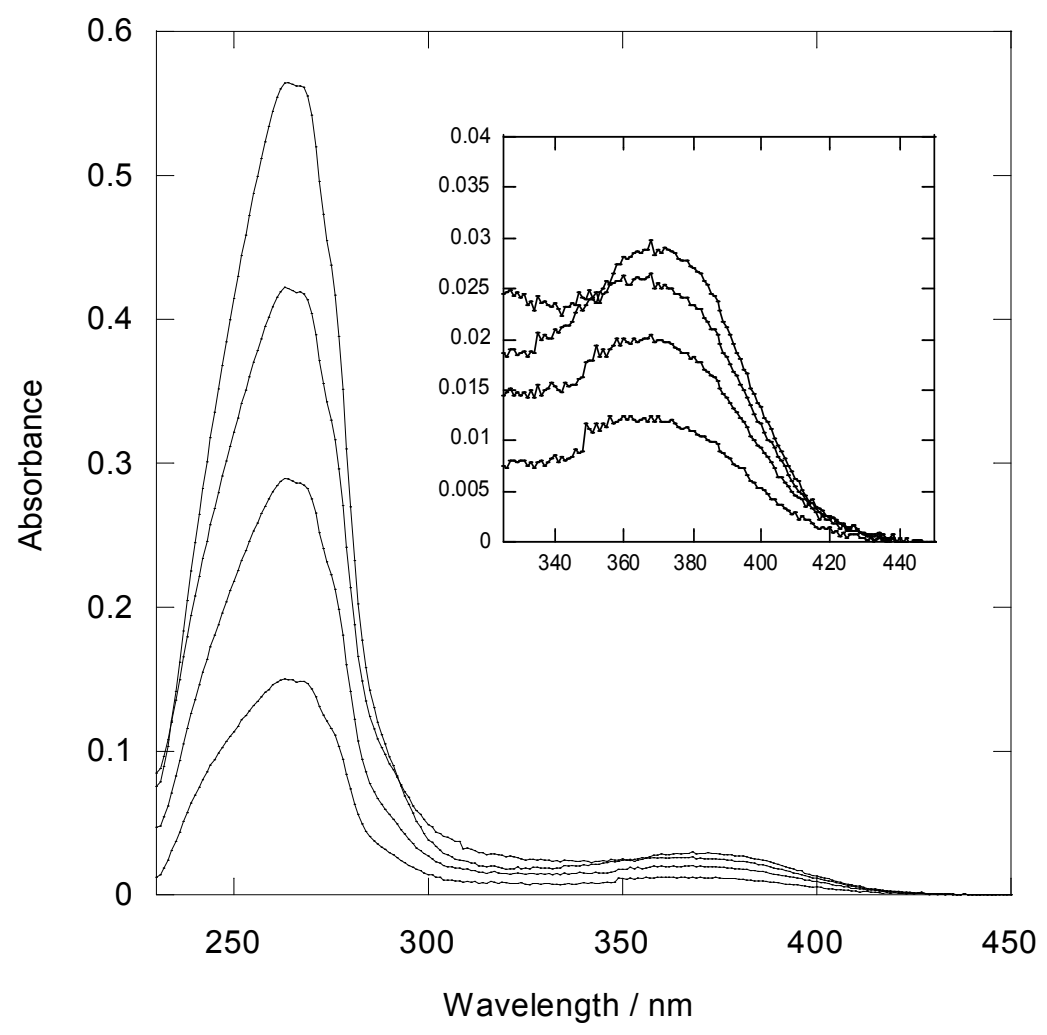

Figure 40. UV-Vis spectroscopy of preQo-tRNA addition to QueF-like. Inset shows the region around $376 \mathrm{~nm}$ expanded for clarity. 
Determining whether preQo or preQ0-tRNA can be turned over by QueFL was somewhat problematic as archaeosine base readily deaminates in water, reverting back to preQ, making it difficult to monitor in enzyme assays.

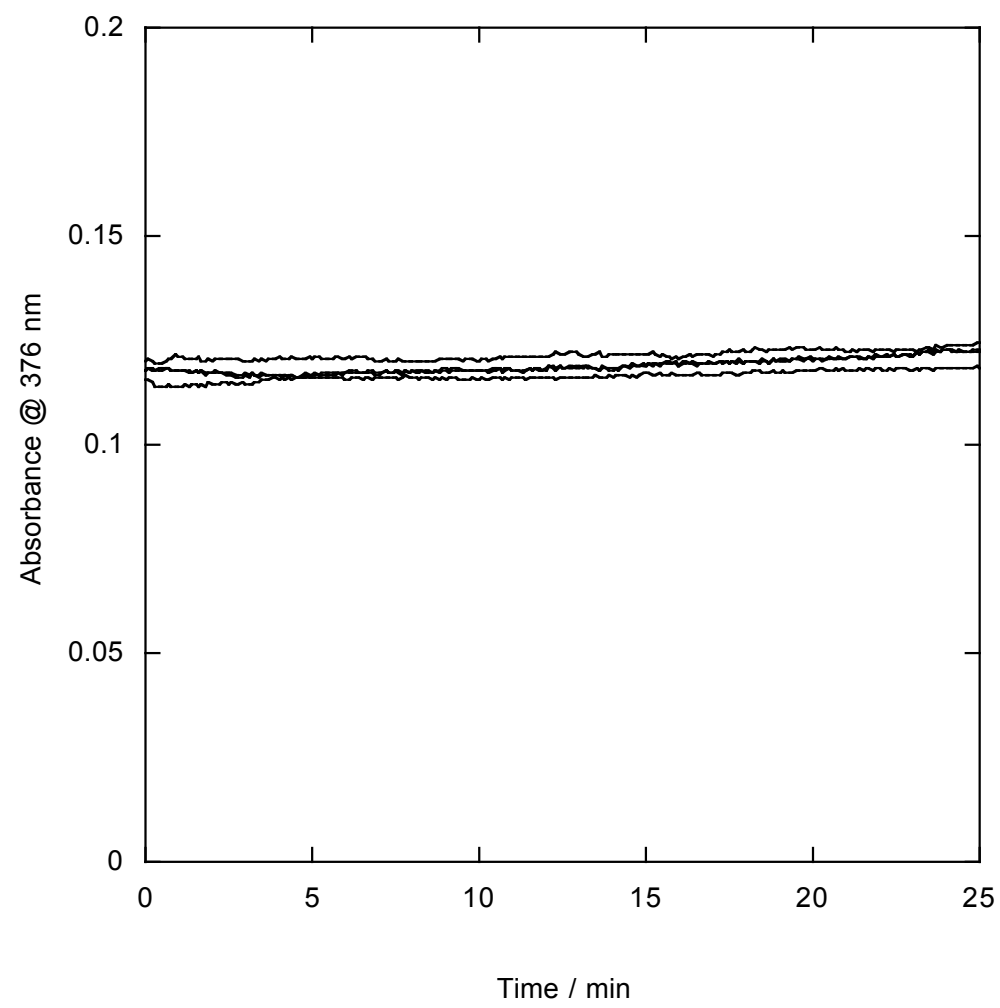

Figure 41. Loss of thioimide intermediate absorbance as a function of reaction time. Ammonium chloride, control reaction, glutamine and asparagine absorbance at $376 \mathrm{~nm}$ are plotted from top to bottom as a function of time.

However, the disappearance of the thioimide bond upon reaction with ammonia in principle can be utilized as a tool to track the fate of the thioimide intermediate. In this experiment the thioimide must be pre-formed followed by removal of excess preQo or preQo-tRNA so new intermediates can't form and then react to form the product. Figure 41 shows the results of this experiment when preQ $Q_{0}$ base is used as a substrate and ammonium chloride, glutamine and asparagine are used as nitrogen sources, respectively. 
Over the course of 25 minutes no difference was observed between the control sample and those containing one of the three nitrogen sources, suggesting that while preQo does react to form the thioimide intermediate, it does not turnover.

To test if preQo-tRNA is the substrate for the production of $\mathrm{G}^{+}$-tRNA, the thioimide intermediate was also similarly monitored using ammonium chloride, glutamine or asparagine as nitrogen donors (Figure 42).

Similar to the case with preQ, when asparagine (dotted line) or glutamine (dashed line) was used as a substrate, no changes in absorbance quickly decreased, consistent with turnover to form $\mathrm{G}^{+}$-modified tRNA.

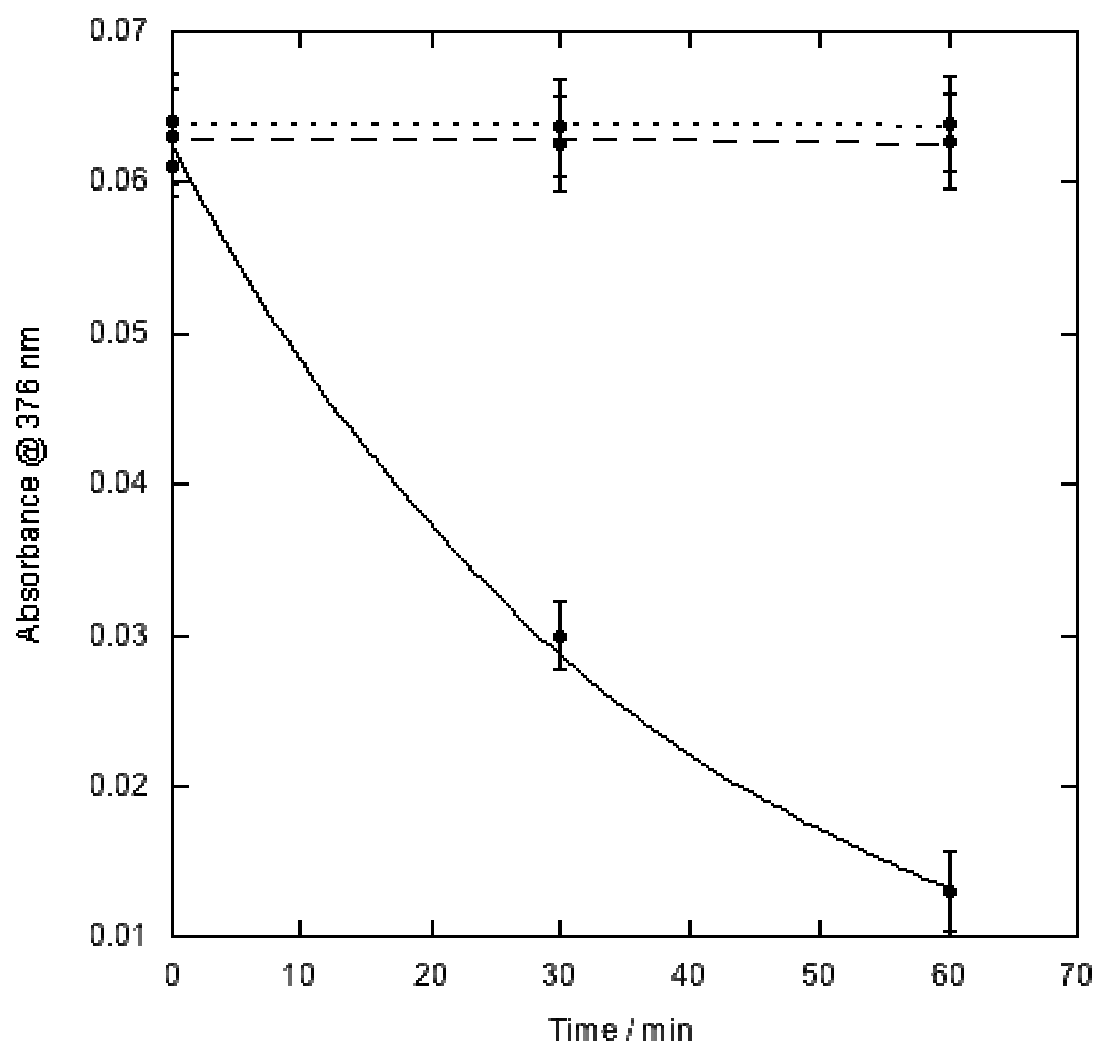

Figure 42. Loss of thioimide absorbance at $376 \mathrm{~nm}$ for the reaction of QueF-like with preQo-tRNA and ammonium chloride (solid), glutamine (dashed) and asparagine (dotted) respectively. 
Figure 43 shows absorbance scans between $300-460 \mathrm{~nm}$ at 0,30 and 60 minutes when the nitrogen source is ammonium chloride.

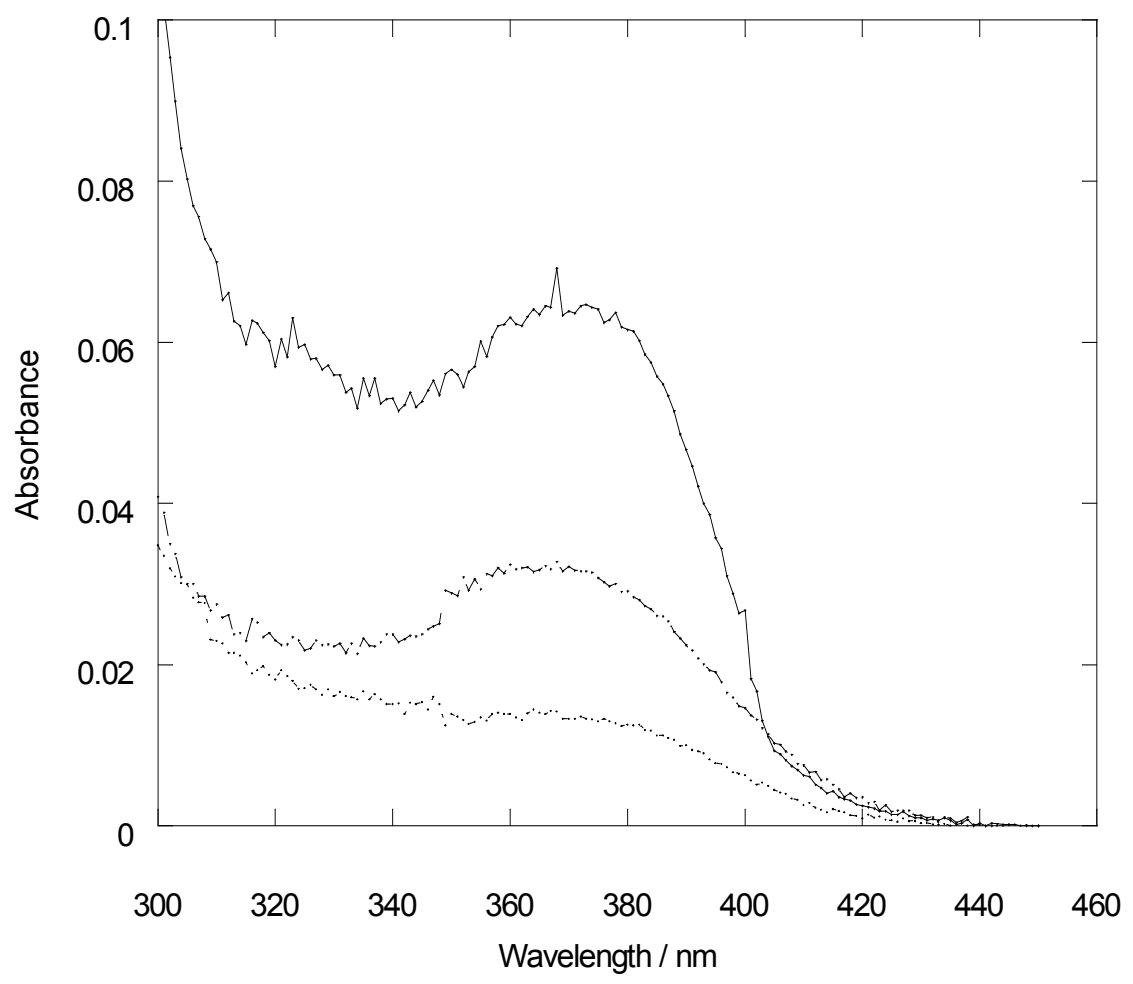

Figure 43. Loss of thioimide absorbance when preQo-tRNA and ammonium chloride are used as substrates for archaeosine formation. Top trace corresponds to 0 min, middle trace to $30 \mathrm{~min}$ and bottom trace to $60 \mathrm{~min}$.

To confirm that G+-modified tRNA was being formed in the reaction with ammonium chloride, and to probe whether GIn and Asn were indeed incapable of supporting turnover, QueFL was allowed to react with preQo-tRNA and one of the three sources of nitrogen followed by LCMS analysis of product tRNA. The tRNA product was first isolated and digested down to nucleosides using nuclease P1 (endonuclease), snake venom phosphodiesterase (5' exonuclease), and alkaline phosphatase. 
Preliminary HPLC analysis from the ammonium chloride reaction was found to contain products with retention times consistent with preQ0 $(31 \mathrm{~min})$ and archaeosine (32 $\mathrm{min})$, as well as the canonical nucleosides cytosine (8 min), uridine (10 min), guanosine (18 $\mathrm{min}$ ) and adenosine (24 min). (Figures 44 and 45).

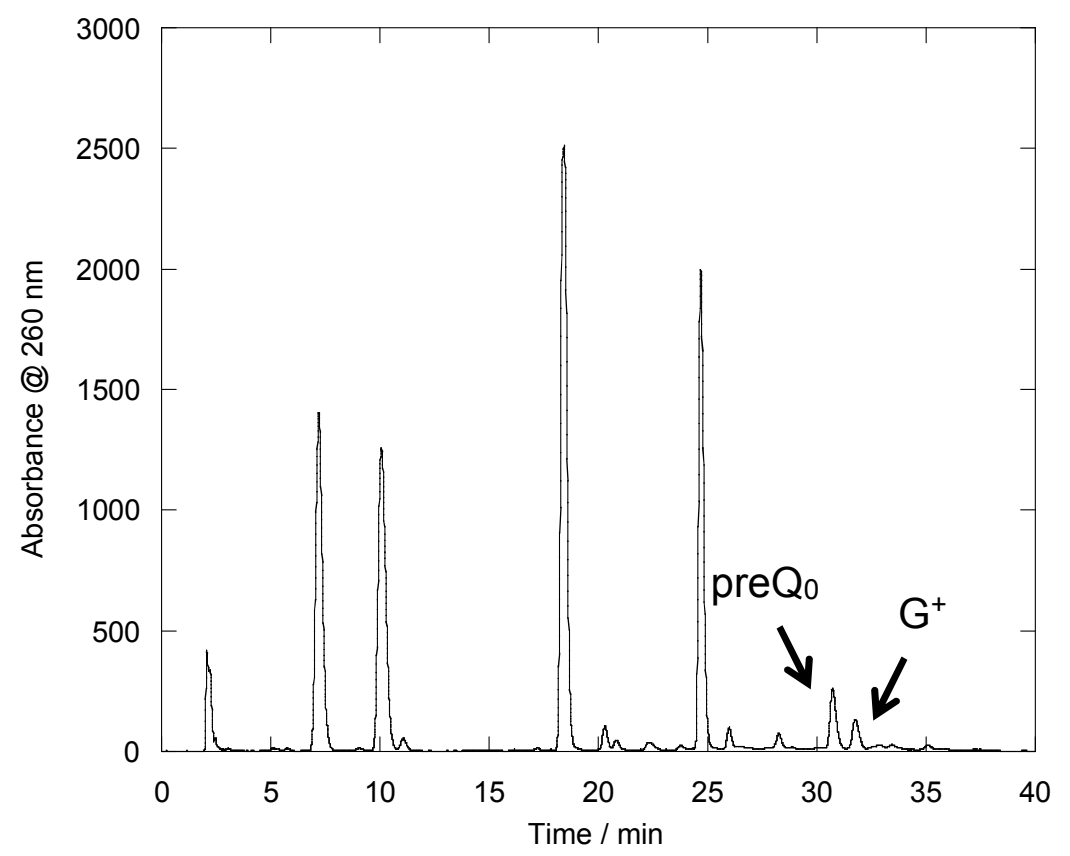

Figure 44. HPLC of digested tRNA from the reaction between QueFL, preQo-tRNA and ammonium chloride. 



Figure 45. Absorbance spectrum of HPLC peaks at $31 \mathrm{~min}$ (left) and $32 \mathrm{~min}$ (right) for the product of the reaction between QueFL, preQo-tRNA and $\mathrm{NH}_{4} \mathrm{Cl}$.

Subsequent, HPLC coupled with positive mode ESI-mass spectrometry was performed. The $\mathrm{m} / \mathrm{z}$ ratios for the 18.4 minute peak are shown on the top portion of Figure 46, where the main ion is 325.12 . This ratio is consistent with the predicted values for archaeosine nucleoside shown at the bottom of the figure. No archaeosine was found in the digests corresponding to reactions where glutamine or asparagine had been used as nitrogen sources. 




Figure 46. ESI-MS analysis of the digested tRNA product from the reaction between QueF-like, preQo-tRNA ${ }^{G I n}$ and ammonium chloride. Top shows the mass of products that elute at 32 minutes. Bottom corresponds to the predicted $\mathrm{m} / \mathrm{z}$ for archaeosine nucleoside. 


\subsubsection{Crystal structure of QueF-like.}

Two crystal structures for Pyrobacculum calidifontis QueF-like were determined by Manal Swairjo (submitted manuscript). The crystal structure of the enzyme with preQo bound was determined using the selenium-multiwavelength anomalous dispersion method. The apo structure was then solved by molecular replacement using a single protein subunit from the preQ0-bound structure (Figure 47). The overall structure is formed by a symmetric tunnel-fold homodecamer of two head-to-head facing pentamers with 10 active sites located at the interface between monomers. Each monomer is a T-fold $\beta 4 \alpha 2$ domain composed of an amphiphatic beta sheet and two antiparallel $\alpha$-helices layered on the concave side.

The central tunnel is $24 \AA$ wide and $58 \AA$ long and is lined by 60 salt bridges protruding from the hydrophilic face of the beta barrel and originating from adjacent beta strands within each subunit and between subunits (Figure 46). These salt bridges presumably confer additional structural stability at high temperatures, which could be required to stabilize QueFL. 

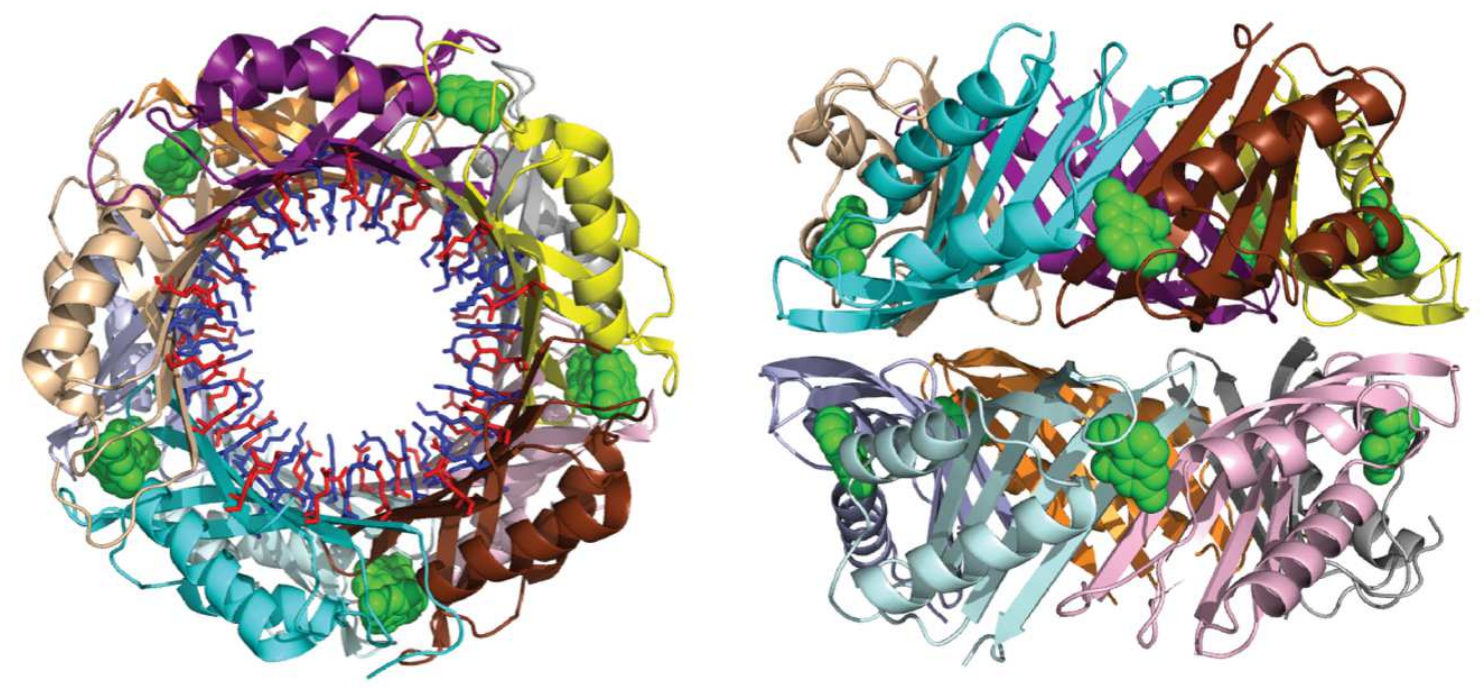

Figure 47. Top (left) and side (right) view of the QueFL homodecamer. Each monomer is colored differently and the preQ 0 bound molecules are depicted in green. Salt bridges are shown in red and blue as stick models.

The cleft between two subunits of the same pentamer forms the preQ0 binding pocket. The left wall is formed by the loops that connect helices $\alpha 1$ and $\alpha 2$ (Ser54-Leu61), strands $\beta 1$ and $\beta 2$ (Cys21-Thr26), and strands $\beta 3$ and $\beta 4$ (Tyr90-Val93), as well as helix $\alpha 2$ (Leu61-Asn78) and strand $\beta 4(V a l 93-G l y 103)$, from the same subunit. The right and back of the cleft are formed by the $\mathrm{N}$ terminal part of strand $\beta 1$ (Val11-Arg16) and helix $\alpha 1$ (Ala44-Lys49) as well as as an N-terminal polypeptide portion from an adjacent subunit (Val4-Ser9). The sulfur atom from the conserved active site Cys21 forms a bond with the nitrile carbon from preQo (Figure 48). As in QueF and other members of the superfamily the binding pocket is at the interface of both subunits. The Glu63 from one of the subunits forms hydrogen bonds with $\mathrm{N} 1$ and $\mathrm{N} 2$ of preQ $\mathrm{Q}_{0}$ and the amine group of 


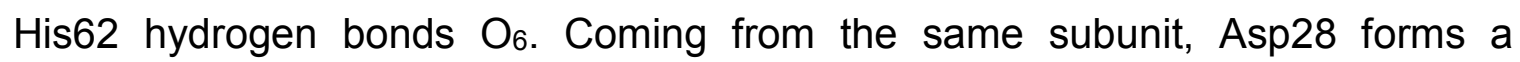
hydrogen bond with the thioimide nitrogen. The side chain oxygen from Glu46 from the adjacent subunit and the carbonyl oxygen from Leu43 hydrogen bond with N9 and N2 of preQ0, respectively. Two hydrophobic patches sandwich the guanidine ring of preQ. One patch is formed by lle23 and Leu61 from one subunit and Leu2 from the next subunit. The other includes Tyr90 from one subunit and lle45 from the neighboring one. The preQo binding pocket of QueFL is very similar to that of QueF.

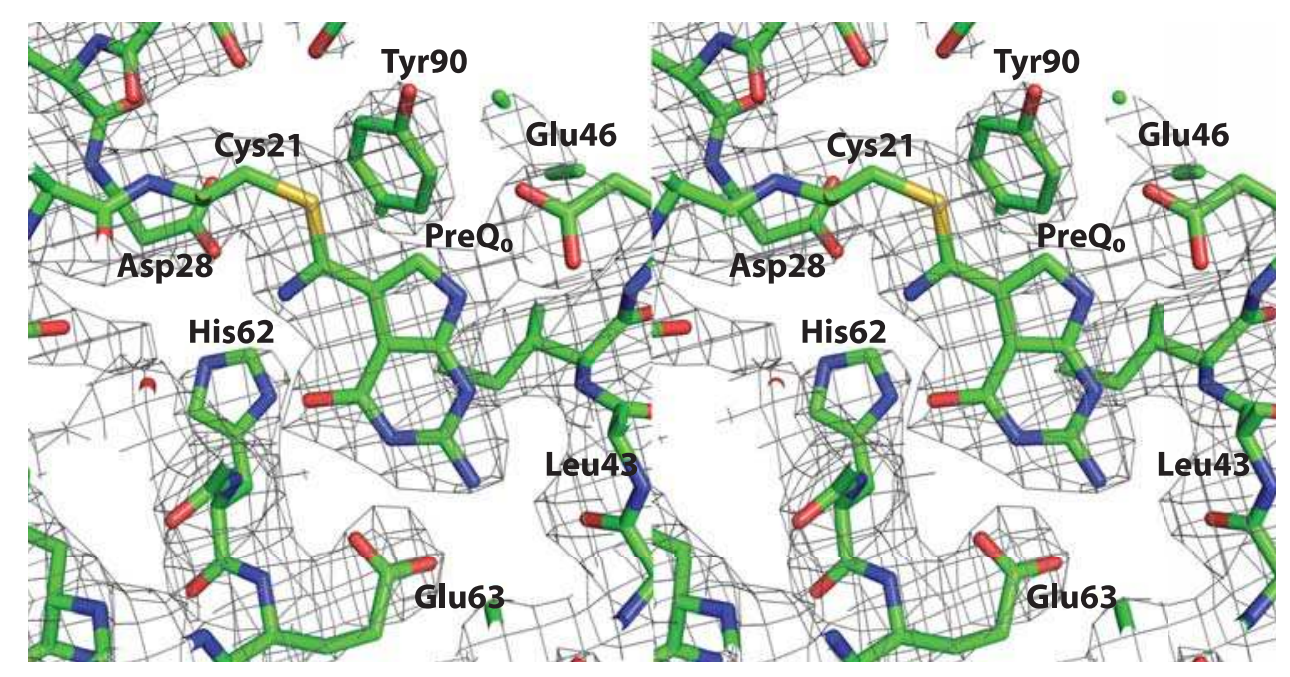

Figure 48. Formation of thioimide intermediate in QueF-like.

QueF-like is the only known tunneling fold enzyme that binds a nucleic acid. To predict the putative tRNA binding site, docking of $P$. horikoshii tRNA ${ }^{\text {Val }}$ was modeled using the Haddock webserver. The resulting model shows the Dloop in an extended conformation with the negatively charged phosphate backbone bound to the positively charged inter-subunit interface and the 
nucleobase at position 15 buried in the active site. The bases of the D-loop point towards the solvent and don't interact with the protein. 


\subsection{Conclusions}

The gene encoding for Pyrobacculum calidifontis QueF-like was successfully expressed in E.coli to produce a $12 \mathrm{kDa}$ protein which can be purified by Ni-NTA affinity chromatography. The expressed protein is capable of binding preQ $Q_{0}$ and forming a covalent thioimide adduct with both preQ $Q_{0}$ and preQo-tRNA.

The thioimide intermediate can be used to monitor the reaction between the enzyme and its possible substrates. No changes in absorbance and therefore no reactivity was observed when preQo was tested as a substrate along with ammonium chloride, glutamine or asparagine as sources of nitrogen. Disappearance of the thioimide bond was observed when the substrate was preQo-tRNA and the source of nitrogen was ammonium chloride, but not glutamine or asparagine. Production of archaeosine-tRNA was confirmed by HPLC-MS of the digested reaction products, indicating that these are indeed the correct substrates for QueF-like. This makes QueF-like the first known Tunneling-fold enzyme that binds a nucleic acid.

The crystal structure of QueF-like was determined to be a dimer of pentamers with a large number of salt bridges pinning the two pentamers together. As it is the case for other members of the superfamily, the preQ0 binding pocket of QueF-like is formed by two subunits and it is very similar to that of QueF. 


\section{Chapter 5: Diverse chemistries in a common fold}

As discussed in Chapter 1, T-fold proteins are present in all kingdoms of life and catalyze an array of chemical reactions: hydrolysis, cleavage of a carboncarbon bond, cleavage of a carbon-oxygen bond, epimerization, oxidation, and as shown in Chapter 4, transfer of an amidino group. Their substrates are different purines and pterins, positioned in the active site by a glutamine or asparagine conserved in all members of the superfamily. ${ }^{26}$

The chemistry performed by these enzymes is diverse and the reaction mechanism utilized by each enzyme of the superfamily is significantly different. GCYH-1B is $\mathrm{Mn}^{2+}$ dependent ${ }^{39}$, QueE is $\mathrm{Mg}^{2+}$ dependent ${ }^{68}$, and PTPS is both $\mathrm{Zn}^{2+}$ and $\mathrm{Mg}^{2+}$ dependent ${ }^{34}$. No metals are required for catalysis by $7,8-$ dihydroneopterin triphosphate epimerase ${ }^{47}$, Urate oxidase ${ }^{48}, \mathrm{QueF}^{27}$, or QueFlike. No common mechanistic steps are shared between the previously discovered T-fold enzymes. However, we now know that both QueF and QueFL form a thioimide intermediate through the reaction of QueF Cys55 and QueFL Cys21 and their respective substrates, preQo and preQ0-tRNA.

In terms of structure, each of these proteins contains a Tunneling-fold domain but the number of subunits required to form a functional enzyme varies ${ }^{47}$. GCYH-1A, unimodular QueF and QueF-like all form decamers (dimers of pentamers). Bimodular $\mathrm{GCYH}-1 \mathrm{~B}$ is a tetramer. 
QueF and QueF-like present the closest degree of structural similarity of all T-fold enzymes. These two enzymes belong to different branches of life, Bacterial and Archaeal respectively. The sequence similarity between these two families is low, with only a few residues universally conserved. However, the shared features between these two families are indicative of a close evolutionary relationship. Existing phylogenetic information is however insufficient to establish this relationship.

The structural similarities between the two enzymes are shown in Figure 49 (submitted manuscript), which depicts the structures of Vibrio cholerae (V. cholerae) QueF (A), Bacillus subtilis (B. subtilis) QueF (B) and Pyrobacculum calidifontis (P. calidifontis) QueF-like (C). In QueF-like over 60 salt bridges pin together the top and bottom pentamer. In B. subtilis QueF, the C-terminal $\mathrm{Mg}^{2+}$ sites contribute to this function. In QueFL the helix that is equivalent to that of the QF motif is shifted to the left. These distinctive structural features make the QueFL pentamer twisted with regards to QF, resulting in a narrower tunnel. 

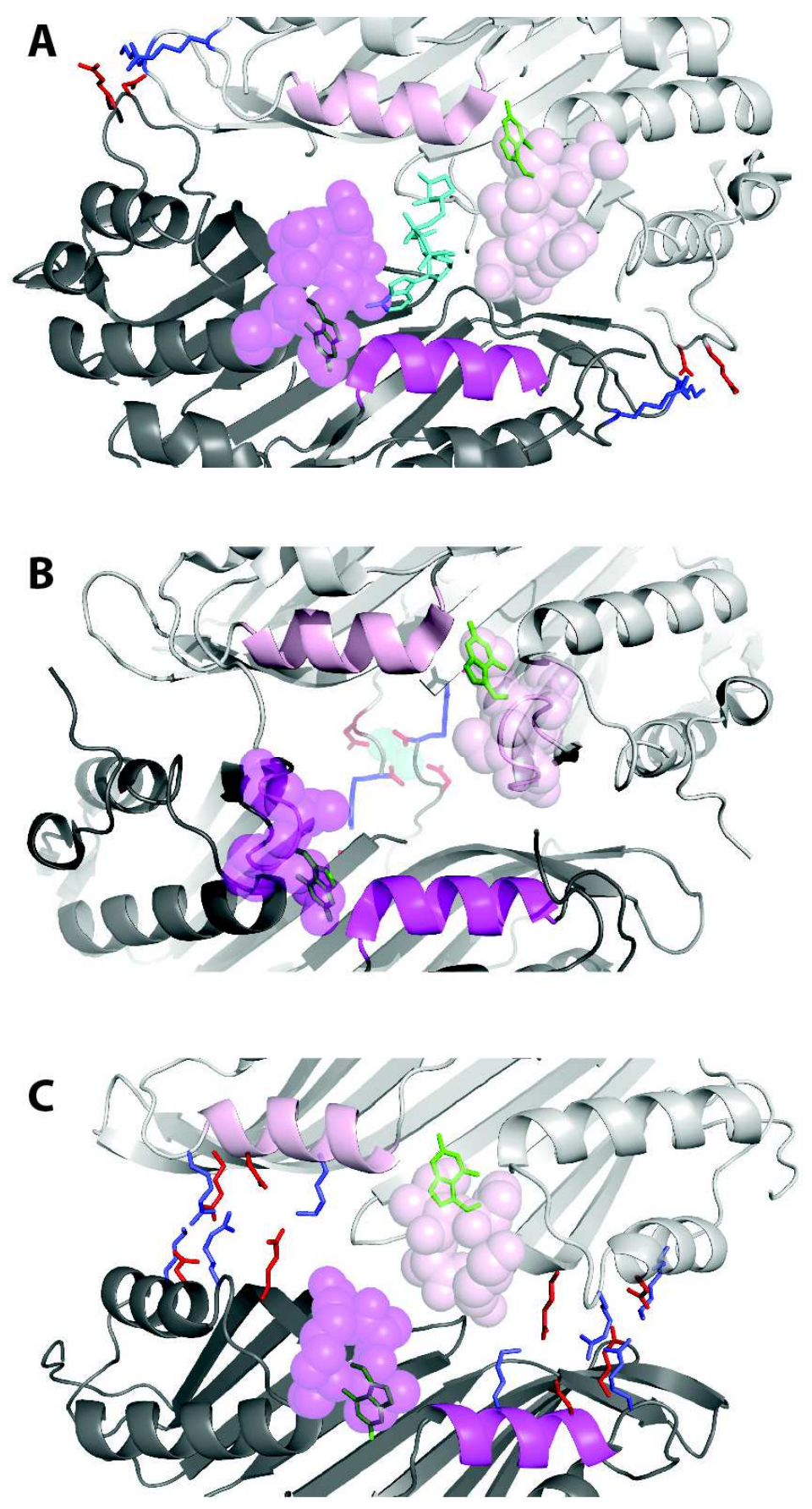

Figure 49. Structural comparison of $V$. chloreae QueF (A), B. subtilis (B), and $P$. calidifontis QueF-like $(C)$. The subunits from different pentamers are depicted in different shades of gray, the helix harboring the QueF motif is shown in purple, and the loops defining the NADPH binding pocket are shown as purple spheres. PreQo is shown in green and NADPH in V. cholerae is shown in cyan. The residues indicated in red and blue form salt bridges that pin together the top and bottom pentamer. 
Based on the shared structural features between QueF and QueFL, a reaction mechanism was proposed for the amidinotransferase (Figure 50). In this mechanism, binding of preQo-tRNA is facilitated by interactions with Glu63 and Glu46. The substrate is anchored in the active site by Glu63 (the conserved Tfold glutamate) through interactions with $\mathrm{N} 1$ and N2 of the preQo whereas Glu46 serves as the proton donor for N9, preventing the delocalization of the lone pair and increasing the electrophilicity of the nitrile carbon to facilitate the nucleophilic attack that produces the thioimide intermediate.

The ammonium cation is bound in a pocket created by Asp28 and the $\pi$ system of Tyr90 and deprotonated by Asp28, which allows ammonia to attack the thioimide carbon from the face of pre $Q_{0}$ that is facing the core of the protein. Proton transfer is then possibly facilitated by a water molecule which is hydrogen bonded to His62 and the thioimide nitrogen. Cleavage of the carbon-sulfur bond results in collapse of the diaminothioorthoester producing archaeosine-modified tRNA. 


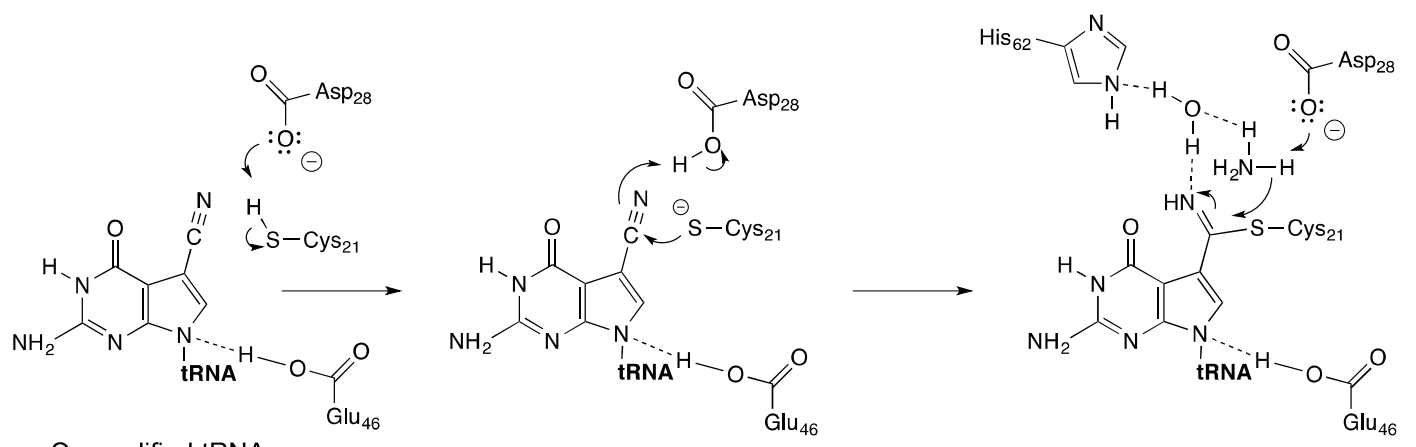

preQ $Q_{0}$-modified tRNA

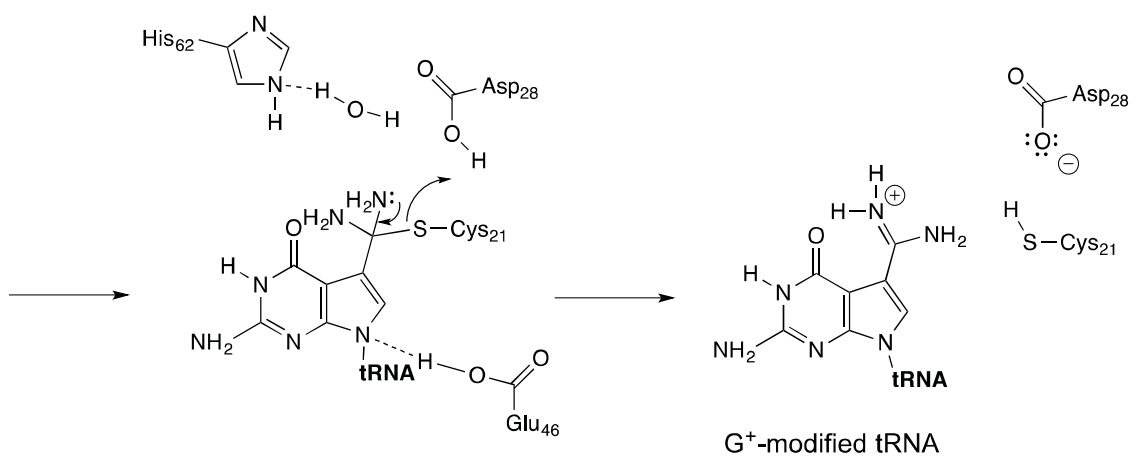

Figure 50. Proposed mechanism for the QueF-like reaction.

The remarkable similarity between QueF and QueF-like in terms of structure and substrate requirements, offer a great opportunity to further understand how enzymes adapt to serve new functions. Determining the full reaction mechanism for each enzyme will allow for further elucidation of the residues which play a key role in catalysis and those that are responsible for the maintenance of the dimer of pentamers quaternary structure. The work presented herein aims to deepen our understanding of the enzymes QueF and QueFL within the context of the Tunneling Fold superfamily and highlights how small differences within a fold can produce catalytic diversity. 


\section{Bibliography}

1. Rentzsch, R. \& Orengo, C. a. Protein function prediction using domain families. BMC Bioinformatics 14 Suppl 3, S5 (2013).

2. Pearl, F. M. G. et al. The CATH database: An extended protein family resource for structural and functional genomics. Nucleic Acids Research 31, 452-455 (2003).

3. Janke, C. The tubulin code: Molecular components, readout mechanisms, functions. J. Cell Biol. 206, 461-472 (2014).

4. Yan, W. et al. The construction of an amino acid network for understanding protein structure and function. Amino Acids 46, 1419-1439 (2014).

5. Mills, C. L., Beuning, P. J. \& Ondrechen, M. J. Biochemical functional predictions for protein structures of unknown or uncertain function. Computational and Structural Biotechnology Journal 13, 182-191 (2015).

6. Chothia, C. \& Lesk, A. M. The relation between the divergence of sequence and structure in proteins. EMBO J. 5, 823-6 (1986).

7. Doolittle, R. F. Similar amino acid sequences: chance or common ancestry? Science 214, 149-159 (1981).

8. Sillitoe, I., Dawson, N., Thornton, J. \& Orengo, C. The history of the CATH structural classification of protein domains. Biochimie 119, 209-217 (2015).

9. Todd, A. E., Marsden, R. L., Thornton, J. M. \& Orengo, C. A. Progress of structural genomics initiatives: an analysis of solved target structures. $J$. Mol. Biol. 348, 1235-60 (2005).

10. CATH: Protein Structure Classification Database at UCL. at $<$ http://www.cathdb.info/>

11. SCOP: Structural Classification of Proteins. at <http://scop.mrcImb.cam.ac.uk/scop/>

12. Glasner, M. E., Gerlt, J. a \& Babbitt, P. C. Mechanisms of protein evolution and their application to protein engineering. Adv Enzym. Relat Areas Mol Biol 75, 193-239, xii-xiii (2007).

13. Todd, a E., Orengo, C. a \& Thornton, J. M. Evolution of function in protein superfamilies, from a structural perspective. J. Mol. Biol. 307, 1113-1143 (2001).

14. Glasner, M. E., Gerlt, J. A. \& Babbitt, P. C. Evolution of enzyme superfamilies. Current Opinion in Chemical Biology 10, 492-497 (2006).

15. Gerlt, J. a \& Babbitt, P. C. Divergent evolution of enzymatic function: 
mechanistically diverse superfamilies and functionally distinct suprafamilies. Annu. Rev. Biochem. 70, 209-246 (2001).

16. Gerlt, J. A. \& Babbitt, P. C. Mechanistically diverse enzyme superfamilies: the importance of chemistry in the evolution of catalysis. Curr. Opin. Chem. Biol. 2, 607-612 (1998).

17. Mildvan, A. S. et al. Structures and mechanisms of Nudix hydrolases. Archives of Biochemistry and Biophysics 433, 129-143 (2005).

18. Seibert, C. M. \& Raushel, F. M. Structural and catalytic diversity within the amidohydrolase superfamily. Biochemistry 44, 6383-6391 (2005).

19. Allen, K. N. \& Dunaway-Mariano, D. Phosphoryl group transfer: Evolution of a catalytic scaffold. Trends in Biochemical Sciences 29, 495-503 (2004).

20. Thornton, J. M., Orengo, C. A., Todd, a E. \& Pearl, F. M. Protein folds, functions and evolution. J. Mol. Biol. 293, 333-42 (1999).

21. Madera, M., Vogel, C., Kummerfeld, S. K., Chothia, C. \& Gough, J. The SUPERFAMILY database in 2004: additions and improvements. Nucleic Acids Res. 32, D235-D239 (2004).

22. Wilson, D., Madera, M., Vogel, C., Chothia, C. \& Gough, J. The SUPERFAMILY database in 2007: Families and functions. Nucleic Acids Res. 35, (2007).

23. Gough, J. The SUPERFAMILY database in structural genomics. in Acta Crystallographica Section D: Biological Crystallography 58, 1897-1900 (2002).

24. Lee, D., Grant, A., Buchan, D. \& Orengo, C. A structural perspective on genome evolution. Current Opinion in Structural Biology 13, 359-369 (2003).

25. Colloc'h, N., Mornon, J.-P. \& Camadro, J.-M. Towards a new T-fold protein?: the coproporphyrinogen III oxidase sequence matches many structural features from urate oxidase. FEBS Lett. 526, 5-10 (2002).

26. Colloc'h, N., Poupon, A. \& Mornon, J. P. Sequence and structural features of the T-fold, an original tunnelling building unit. Proteins Struct. Funct. Genet. 39, 142-154 (2000).

27. Chikwana, V. M. et al. Structural basis of biological nitrile reduction. J. Biol. Chem. 287, 30560-30570 (2012).

28. Kim, Y. et al. High-resolution structure of the nitrile reductase QueF combined with molecular simulations provide insight into enzyme mechanism. J. Mol. Biol. 404, 127-137 (2010). 
29. El Yacoubi, B. et al. Discovery of a new prokaryotic type I GTP cyclohydrolase family. J. Biol. Chem. 281, 37586-37593 (2006).

30. Nar, H. et al. Atomic structure of GTP cyclohydrolase I. Structure 3, 459466 (1995).

31. Cicmil, N. \& Shi, L. Crystallization and preliminary X-ray characterization of queD from Bacillus subtilis, an enzyme involved in queuosine biosynthesis. Acta Crystallogr. Sect. F Struct. Biol. Cryst. Commun. 64, 119-122 (2008).

32. Van Lanen, S. G. et al. From cyclohydrolase to oxidoreductase: discovery of nitrile reductase activity in a common fold. Proc. Natl. Acad. Sci. U. S. A. 102, 4264-4269 (2005).

33. Haussmann, C. et al. Dihydroneopterin triphosphate epimerase of Escherichia coli : purification, genetic cloning, and expression. J. Bacteriol. 179, 949-51 (1997).

34. Ploom, T. et al. Crystallographic and kinetic investigations on the mechanism of 6-pyruvoyl tetrahydropterin synthase. J. Mol. Biol. 286, 851860 (1999).

35. Wu, X. W., Lee, C. C., Muzny, D. M. \& Caskey, C. T. Urate oxidase: primary structure and evolutionary implications. Proc. Natl. Acad. Sci. U. S. A. 86, 9412-9416 (1989).

36. Wang, Y., Li, Y., Wu, Y. \& Yan, H. Mechanism of dihydroneopterin aldolase: NMR, equilibrium and transient kinetic studies of the Staphylococcus aureus and Escherichia coli enzymes. FEBS J. 274, 2240 2252 (2007).

37. Kang, Y. N., Tran, A., White, R. H. \& Ealick, S. E. A novel function for the $\mathrm{N}$-terminal nucleophile hydrolase fold demonstrated by the structure of an archaeal inosine monophosphate cyclohydrolase. Biochemistry 46, 50505062 (2007).

38. Maier, J. et al. Homology cloning of GTP-cyclohydrolase I from various unrelated eukaryotes by reverse-transcription polymerase chain reaction using a general set of degenerate primers. Biochem. Biophys. Res. Commun. 212, 705-711 (1995).

39. Sankaran, B. et al. Zinc-independent folate biosynthesis: Genetic, biochemical, and structural investigations reveal new metal dependence for GTP cyclohydrolase IB. J. Bacteriol. 191, 6936-6949 (2009).

40. Miles, Z. D., Roberts, S. A., McCarty, R. M. \& Bandarian, V. Biochemical and structural studies of 6-carboxy-5,6,7,8-tetrahydropterin synthase reveal the molecular basis of catalytic promiscuity within the tunnel-fold superfamily. J. Biol. Chem. 289, 23641-23652 (2014). 
41. Thöny, B., Auerbach, G. \& Blau, N. Tetrahydrobiopterin biosynthesis, regeneration and functions. Biochem. J. 347 Pt 1, 1-16 (2000).

42. McCarty, R. M., Somogyi, Á. \& Bandarian, V. Escherichia coli QueD Is a 6Carboxy-5,6,7,8-tetrahydropterin synthase. Biochemistry 48, 2301-2303 (2009).

43. Wang, Y., Li, Y. \& Yan, H. Mechanism of dihydroneopterin aldolase: functional roles of the conserved active site glutamate and lysine residues. Biochemistry 45, 15232-9 (2006).

44. Basset, G. et al. Folate synthesis in plants: the first step of the pterin branch is mediated by a unique bimodular GTP cyclohydrolase I. Proc. Natl. Acad. Sci. U. S. A. 99, 12489-94 (2002).

45. Deng, H., Callender, R. \& Dale, G. E. A vibrational structure of 7,8dihydrobiopterin bound to dihydroneopterin aldolase. J. Biol. Chem. 275, 30139-30143 (2000).

46. Bourne, C. Utility of the Biosynthetic Folate Pathway for Targets in Antimicrobial Discovery. Antibiotics 3, 1-28 (2014).

47. Ploom, T. et al. Crystal structure of 7,8-dihydroneopterin triphosphate epimerase. Structure 7, 509-16 (1999).

48. Gabison, L. et al. Structural analysis of urate oxidase in complex with its natural substrate inhibited by cyanide: mechanistic implications. BMC Struct. Biol. 8, 32 (2008).

49. Varela-Echavarría, a, Montes de Oca-Luna, R. \& Barrera-Saldaña, H. a. Uricase protein sequences: conserved during vertebrate evolution but absent in humans. FASEB J. 2, 3092-6 (1988).

50. Hennig, M. et al. Crystal structure and reaction mechanism of 7,8dihydroneopterin aldolase from Staphylococcus aureus. Nat Struct Biol 5, 357-362 (1998).

51. Morris, R. C. \& Elliott, M. S. Queuosine modification of tRNA: a case for convergent evolution. Mol. Genet. Metab. 74, 147-159 (2001).

52. Watanabe, M. et al. Biosynthesis of archaeosine, a novel derivative of 7deazaguanosine specific to archaeal tRNA, proceeds via a pathway involving base replacement on the tRNA polynucleotide chain. J. Biol. Chem. 272, 20146-20151 (1997).

53. Haumont, E., Droogmans, L. \& Grosjean, H. Enzymatic formation of queuosine and of glycosyl queuosine in yeast tRNAs microinjected into Xenopus laevis oocytes. The effect of the anticodon loop sequence. Eur. J. Biochem. 168, 219-225 (1987). 
54. Okada, N., Shindo-Okada, N. \& Nishimura, S. Isolation of mammalian tRNAAsp and tRNATyr by lectin-Sepharose affinity column chromatography. Nucleic Acids Res. 4, 415-423 (1977).

55. Blaise, M. et al. Crystal structure of glutamyl-queuosine tRNAAsp synthetase complexed with L-glutamate: structural elements mediating tRNA-independent activation of glutamate and glutamylation of tRNAAsp anticodon. J. Mol. Biol. 381, 1224-37 (2008).

56. Katze, J. R., Basile, B. \& McCloskey, J. A. Queuine, a modified base incorporated posttranscriptionally into eukaryotic transfer RNA: wide distribution in nature. Science 216, 55-56 (1982).

57. Meier, F., Suter, B., Grosjean, H., Keith, G. \& Kubli, E. Queuosine modification of the wobble base in tRNAHis influences 'in vivo' decoding properties. EMBO J. 4, 823-827 (1985).

58. Meier, F., Suter, B., Grosjean, H., Keith, G. \& Kubli, E. Queuosine modification of the wobble base in tRNAHis influences 'in vivo' decoding properties. EMBO J. 4, 823-827 (1985).

59. Randerath, E., Agrawal, H. P. \& Randerath, K. Specific lack of the hypermodified nucleoside, queuosine, in hepatoma mitochondrial aspartate transfer RNA and its possible biological significance. Cancer Res 44, 1167-1171 (1984).

60. Morris, R. C., Brown, K. G. \& Elliott, M. S. The effect of queuosine on tRNA structure and function. J. Biomol. Struct. Dyn. 16, 757-774 (1999).

61. Gregson, J. M. et al. Structure of the archaeal transfer RNA nucleoside $\mathrm{G}^{*}$ 15 (2-amino-4,7-dihydro- 4-oxo-7-beta-D-ribofuranosyl-1H-pyrrolo[2,3d]pyrimidine-5-carboximi dam ide (archaeosine)). J. Biol. Chem. 268, 10076-10086 (1993).

62. Chawla, M., Abdel-Azeim, S., Oliva, R. \& Cavallo, L. Higher order structural effects stabilizing the reverse watson-crick guanine-cytosine base pair in functional RNAs. Nucleic Acids Res. 42, 714-726 (2014).

63. Dock-Bregeon, A. C., Westhof, E., Giegé, R. \& Moras, D. Solution structure of a tRNA with a large variable region: yeast tRNASer. J. Mol. Biol. 206, 707-722 (1989).

64. Fergus, C., Barnes, D., Alqasem, M. \& Kelly, V. The Queuine Micronutrient: Charting a Course from Microbe to Man. Nutrients 7, (2015).

65. Gündüz, U. \& Katze, J. R. Queuine salvage in mammalian cells. Evidence that queuine is generated from queuosine 5'-phosphate. J. Biol. Chem. 259, 1110-3 (1984). 
66. Vinayak, M. \& Pathak, C. Queuosine modification of tRNA: its divergent role in cellular machinery. Biosci. Rep. 30, 135-48 (2010).

67. Phillips, G. et al. Biosynthesis of 7-deazaguanosine-modified tRNA nucleosides: a new role for GTP cyclohydrolase I. J. Bacteriol. 190, 787684 (2008).

68. Zhu, W. \& Liu, Y. Ring Contraction Catalyzed by the Metal-Dependent Radical SAM Enzyme: 7-Carboxy-7-deazaguanine Synthase from B. multivorans. Theoretical Insights into the Reaction Mechanism and the Influence of Metal lons. ACS Catal. 5, 3953-3965 (2015).

69. Cicmil, N. \& Huang, R. H. Crystal structure of QueC from Bacillus subtilis: An enzyme involved in preQ1 biosynthesis. Proteins Struct. Funct. Bioinforma. 72, 1084-1088 (2008).

70. Sankaran, B. et al. Zinc-independent folate biosynthesis: Genetic, biochemical, and structural investigations reveal new metal dependence for GTP cyclohydrolase IB. J. Bacteriol. 191, 6936-6949 (2009).

71. Miles, Z. D., McCarty, R. M., Molnar, G. \& Bandarian, V. Discovery of epoxyqueuosine $(\mathrm{oQ})$ reductase reveals parallels between halorespiration and tRNA modification. Proc. Natl. Acad. Sci. U. S. A. 108, 7368-7372 (2011).

72. Bai, Y., Fox, D. T., Lacy, J. A., Van Lanen, S. G. \& Iwata-Reuyl, D. Hypermodification of tRNA in thermophilic archaea. Cloning, overexpression, and characterization of tRNA-guanine transglycosylase from Methanococcus jannaschii. J. Biol. Chem. 275, 28731-28738 (2000).

73. Phillips, G. et al. Discovery and characterization of an amidinotransferase involved in the modification of archaeal tRNA. J. Biol. Chem. 285, 1270613 (2010).

74. Rich, A. \& RajBhandary, U. L. Transfer RNA: molecular structure, sequence, and properties. Annu. Rev. Biochem. 45, 805-60 (1976).

75. Schweet, R. \& Heintz, R. Protein Synthesis. Annu. Rev. Biochem. 35, 723 758 (1966).

76. Suzuki, T. Biosynthesis and function of tRNA wobble modifications. Top. Curr. Genet. 12, 23-69 (2005).

77. Beuning, P. J. \& Musier-Forsyth, K. Transfer RNA recognition by aminoacyl-tRNA synthetases. Biopolymers 52, 1-28 (1999).

78. Kirchner, S. \& Ignatova, Z. Emerging roles of tRNA in adaptive translation, signalling dynamics and disease. Nat. Rev. Genet. 16, 98-112 (2014). 
79. Green, N. J., Grundy, F. J. \& Henkin, T. M. The T box mechanism: tRNA as a regulatory molecule. FEBS Lett. 584, 318-324 (2010).

80. Hurto, R. L. Unexpected functions of tRNA and tRNA processing enzymes. Adv. Exp. Med. Biol. 722, 137-155 (2011).

81. Cantara, W. a. et al. The RNA modification database, RNAMDB: 2011 update. Nucleic Acids Res. 39, 195-201 (2011).

82. Grosjean, H. DNA and RNA Modification Enzymes: Structure, Mechanism, Function and Evolution. Evolution (Landes Bioscience, 2009).

83. El Yacoubi, B., Bailly, M. \& de Crécy-Lagard, V. Biosynthesis and Function of Posttranscriptional Modifications of Transfer RNAs. Annu. Rev. Genet. 46, 120820103026000 (2011).

84. Jackman, J. E. \& Alfonzo, J. D. Transfer RNA modifications: nature's combinatorial chemistry playground. Wiley Interdiscip. Rev. RNA 4, 35-48 (2013).

85. Becker, H. F., Motorin, Y., Sissler, M., Florentz, C. \& Grosjean, H. Major identity determinants for enzymatic formation of ribothymidine and pseudouridine in the T psi-loop of yeast tRNAs. J. Mol. Biol. 274, 505-18 (1997).

86. Agris, P. F. Decoding the genome: A modified view. Nucleic Acids Res. 32, 223-238 (2004).

87. Motorin, Y. \& Helm, M. TRNA stabilization by modified nucleotides. Biochemistry 49, 4934-4944 (2010).

88. Phizicky, E. M. \& Alfonzo, J. D. Do all modifications benefit all tRNAs? FEBS Lett. 584, 265-271 (2010).

89. Dalluge, J. J., Hashizume, T., Sopchik, A. E., McCloskey, J. a. \& Davis, D. R. Conformational flexibility in RNA: The role of dihydrouridine. Nucleic Acids Res. 24, 1073-1079 (1996).

90. Noon, K. R. et al. Influence of temperature on tRNA modification in archaea: Methanococcoides burtonii (optimum growth temperature [Topt], 23??C) and Stetteria hydrogenophila (Topt, 95??C). J. Bacteriol. 185, 5483-5490 (2003).

91. Crick, F. H. Codon--anticodon pairing: the wobble hypothesis. J. Mol. Biol. 19, 548-555 (1966).

92. Alkatib, S. et al. The contributions of wobbling and superwobbling to the reading of the genetic code. PLoS Genet. 8, e1003076 (2012).

93. Agris, P. F. Wobble position modified nucleosides evolved to select 
transfer RNA codon recognition: a modified-wobble hypothesis. Biochimie 73, 1345-9 (1991).

94. Agris, P. F., Vendeix, F. a P. \& Graham, W. D. tRNA's Wobble Decoding of the Genome: 40 Years of Modification. J. Mol. Biol. 366, 1-13 (2007).

95. Björk, G. R. et al. Transfer RNA modification: influence on translational frameshifting and metabolism. FEBS Lett. 452, 47-51 (1999).

96. Urbonavicius, J. et al. Transfer RNA modifications that alter +1 frameshifting in general fail to affect -1 frameshifting. RNA 9, 760-768 (2003).

97. Varani, G. \& McClain, W. H. The G.U wobble base pair. EMBO Rep. 1, 1823 (2000).

98. Weissenbach, J. \& Grosjean, H. Effect of threonylcarbamoyl modification (t6A) in yeast tRNA Arg III on codon-anticodon and anticodon-anticodon interactions. A thermodynamic and kinetic evaluation. Eur. J. Biochem. 116, 207-213 (1981).

99. Gu, W. et al. Depletion of Saccharomyces cerevisiae tRNA His Guanylyltransferase Thg1p Leads to Uncharged tRNA His with Additional m 5 C. Mol. Cell. Biol. 25, 8191-8201 (2005).

100. Abbott, J. A., Francklyn, C. S. \& Robey-Bond, S. M. Transfer RNA and human disease. Front. Genet. 5, 158 (2014).

101. Gu, C., Begley, T. J. \& Dedon, P. C. tRNA modifications regulate translation during cellular stress. FEBS Lett. 588, 4287-4296 (2014).

102. Chan, C. T. Y. et al. A quantitative systems approach reveals dynamic control of tRNA modifications during cellular stress. PLoS Genet. 6, 1-9 (2010).

103. Novoa, E. M. \& Ribas de Pouplana, L. Speeding with control: Codon usage, tRNAs, and ribosomes. Trends Genet. 28, 574-581 (2012).

104. Chernyakov, I., Whipple, J. M., Kotelawala, L., Grayhack, E. J. \& Phizicky, E. M. Degradation of several hypomodified mature tRNA species in Saccharomyces cerevisiae is mediated by Met22 and the 5'-3' exonucleases Rat1 and Xrn1. Genes Dev. 22, 1369-1380 (2008).

105. Chernyakov, I., Baker, M. a, Grayhack, E. J. \& Phizicky, E. M. Chapter 11. Identification and analysis of tRNAs that are degraded in Saccharomyces cerevisiae due to lack of modifications. Methods in enzymology 449, (2008).

106. Klepper, F., Gutsmiedl, K. \& Carell, T. A short and efficient synthesis of the 
tRNA nucleosides PreQ0 and archaeosine. Org. Biomol. Chem. 5, 3821 (2007).

107. Klepper, F., Polborn, K. \& Carell, T. Robust Synthesis and Crystal-Structure Analysis of 7-Cyano-7-deazaguanine (PreQ0 Base) and 7-(Aminomethyl)-7-deazaguanine (PreQ1 Base). Helv. Chim. Acta 88, 2610-2616 (2005).

108. Chac??n, K. N. \& Blackburn, N. J. Stable $\mathrm{Cu}(\mathrm{II})$ and $\mathrm{Cu}(\mathrm{I})$ mononuclear intermediates in the assembly of the CuA center of thermus thermophilus cytochrome oxidase. J. Am. Chem. Soc. 134, 16401-16412 (2012).

109. M9 Minimal Media. The lab rat at <http://www.thelabrat.com/protocols/m9minimal.shtml>

110. Sohn, J. \& Rudolph, J. Catalytic and chemical competence of regulation of Cdc25 phosphatase by oxidation/reduction. Biochemistry 42, 10060-10070 (2003).

111. Sherlin, L. D. et al. Chemical and enzymatic synthesis of tRNAs for highthroughput crystallization. RNA 7, 1671-1678 (2001).

112. Bhaskaran, H., Rodriguez-Hernandez, a. \& Perona, J. J. Kinetics of tRNA folding monitored by aminoacylation. Rna 18, 569-580 (2012).

113. Crain, P. F. Preparation and enzymatic hydrolysis of DNA and RNA for mass spectrometry. Methods Enzymol. 193, 782-790 (1990).

114. Feng, L., Sheppard, K., Tumbula-Hansen, D. \& Söll, D. GIn-tRNAGIn formation from Glu-tRNAGIn requires cooperation of an asparaginase and a Glu-tRNAGIn kinase. J. Biol. Chem. 280, 8150-8155 (2005).

115. Banerjee, a, Sharma, R. \& Banerjee, U. C. The nitrile-degrading enzymes: current status and future prospects. Applied microbiology and biotechnology 60, 33-44 (2002).

116. Feingold, D. S. \& Franzen, J. S. Pyridine nucleotide-linked four-electron transfer dehydrogenases. Trends in Biochemical Sciences 6, 103-105 (1981).

117. Egger, S., Chaikuad, A., Kavanagh, K. L., Oppermann, U. \& Nidetzky, B. UDP-glucose dehydrogenase: structure and function of a potential drug target. Biochem. Soc. Trans. 38, 1378-85 (2010).

118. Görisch, H. Steady-state investigations of the mechanism of histidinol dehydrogenase. Biochem. J. 181, 153-7 (1979).

119. Lee, B. W. K., Van Lanen, S. G. \& Iwata-Reuyl, D. Mechanistic studies of Bacillus subtilis QueF, the nitrile oxidoreductase involved in queuosine 
biosynthesis. Biochemistry 46, 12844-12854 (2007).

120. Wong, J. W. H. \& Hogg, P. J. Allosteric disulfide bonds. Protein Rev. 14, 151-182 (2011).

121. Azimi, I., Wong, J. W. H. \& Hogg, P. J. Control of Mature Protein Function by Allosteric Disulfide Bonds. Antioxid. Redox Signal. 14, 113-126 (2011).

122. Wells, J. A. \& Powers, D. B. In vivo formation and stability of engineered disulfide bonds in subtilisin. J. Biol. Chem. 261, 6564-6570 (1986).

123. Zhou, B., Baldus, I. B., Li, W., Edwards, S. A. \& Gr??ter, F. Identification of allosteric disulfides from prestress analysis. Biophys. J. 107, 672-681 (2014).

124. Hogg, P. J. Disulfide bonds as switches for protein function. Trends in Biochemical Sciences 28, 210-214 (2003).

125. Wouters, M. A., Lau, K. K. \& Hogg, P. J. Cross-strand disulphides in cell entry proteins: Poised to act. BioEssays 26, 73-79 (2004).

126. Iwata-Reuyl, D. Biosynthesis of the 7-deazaguanosine hypermodified nucleosides of transfer RNA. Bioorg. Chem. 31, 24-43 (2003).

127. Gao, B. \& Gupta, R. S. Phylogenomic analysis of proteins that are distinctive of Archaea and its main subgroups and the origin of methanogenesis. BMC Genomics 8, 86 (2007).

128. Phillips, G. et al. Diversity of archaeosine synthesis in crenarchaeota. ACS Chem. Biol. 7, 300-305 (2012).

129. Massière, F. \& Badet-Denisot, M. a. The mechanism of glutaminedependent amidotransferases. Cell. Mol. Life Sci. 54, 205-222 (1998).

130. Mouilleron, S. \& Golinelli-Pimpaneau, B. Conformational changes in ammonia-channeling glutamine amidotransferases. Curr. Opin. Struct. Biol. 17, 653-664 (2007). 


\section{Appendix A - QueF: how to measure kinetic constants for preQ0}

The $\mathrm{NADP}^{+}$product of the reaction can be treated with sodium hydroxide to yield a fluorescent decomposition product, the concentration of which can be measured at varying time intervals in order to determine the reaction velocity at different concentrations of substrate. To do so, a standard curve is used to correlate relative fluorescence units to the concentration of $\mathrm{NADP}^{+}$(Figure 1).

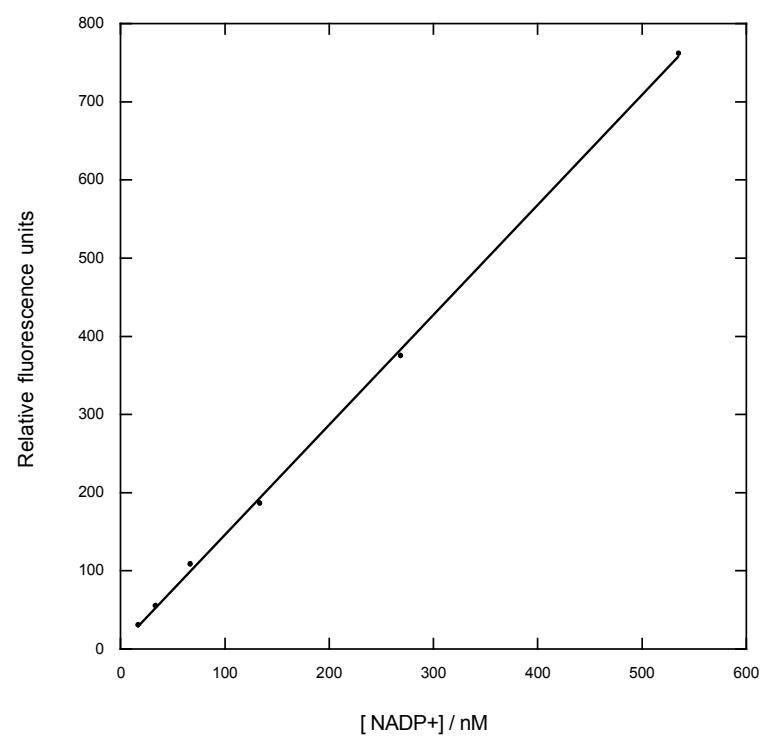

Figure 1. $\mathrm{NADP}^{+}$fluorescence standards. Relative fluorescence units are plotted as a function of NADP + nanomolar concentration.

The data obtained for this assay are summarized in Figure 2. Fitting the data to a Michaelis-Menten equation provides the kinetic values, $V_{\max }=18.8 \pm$ $0.7 \mathrm{nM} / \mathrm{min}, \mathrm{K}_{\mathrm{M}}=0.27 \pm 0.03 \mu \mathrm{M}, \mathrm{K}_{\mathrm{cat}}=0.17 \mathrm{sec}^{-1}$. 


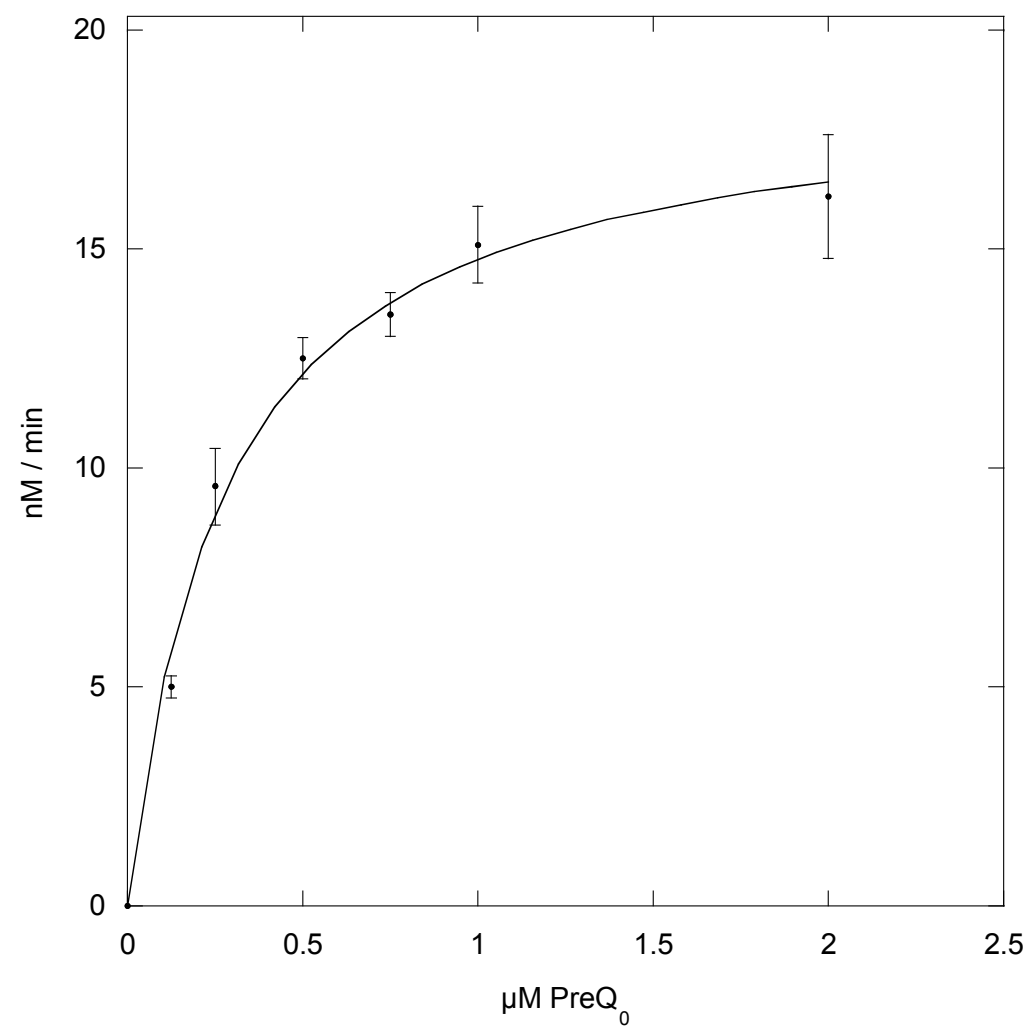

Figure 2. Michaelis-Menten fit of wild-type steady-state kinetics for variable PreQ0 concentrations. Velocity in nanomolar per minute is plotted against PreQ $Q_{0}$ concentrations in micromolar.

Mutant R125K presents a significantly higher NADPH $\mathrm{K}_{\mathrm{M}}$ than that of the wild-type enzyme. In an attempt to be consistent in the way kinetic values for preQ $Q_{0}$ are measured, a reaction was performed at NADPH concentration 10x that of the $\mathrm{K}_{\mathrm{M}}$. However, the background fluorescence that results from the contaminating $\mathrm{NADP}^{+}$was found to be too high to reliably measure nanomolar 
concentration changes in the reaction. When the concentration of NADPH was lowered to $5 \mathrm{x} \mathrm{K}_{\mathrm{M}}$ and $2.5 \mathrm{x} \mathrm{K}_{\mathrm{M}}$, the error was too high to obtain reliable measurements. It was concluded that the changes in preQ $\mathrm{K}_{M}$ that result from the $\mathrm{R} 125 \mathrm{~K}$ mutation will have to be determined by measuring the rate of preQ0 binding to the mutant enzyme as compared to that of the wild-type. As arginine 125 has been predicted to be involved in the binding of NADPH, it is expected that the effect on preQo binding will be minimal. 


\section{Appendix B - QueF-like: Glutamine as a nitrogen source for the QueFL reaction}

To further assess the viability of glutamine as a nitrogen source in the QueFL reaction with PreQo-tRNA, $\left[{ }^{14} \mathrm{C}\right]$-glutamine was used as a substrate, and the reaction was monitored by thin layer chromatography. Appropriate control reactions were also performed. The results are shown in Figure 3 below. The darker TLC spot corresponds to glutamine (by retention factor) and the lighter spot to glutamate. No difference in glutamate formation was observed between the reaction containing all the components and those used as a control. The small amount of glutamate formed in all reactions can be attributed to hydrolysis of glutamine. Glutamine was therefore deemed not a substrate for the reaction.
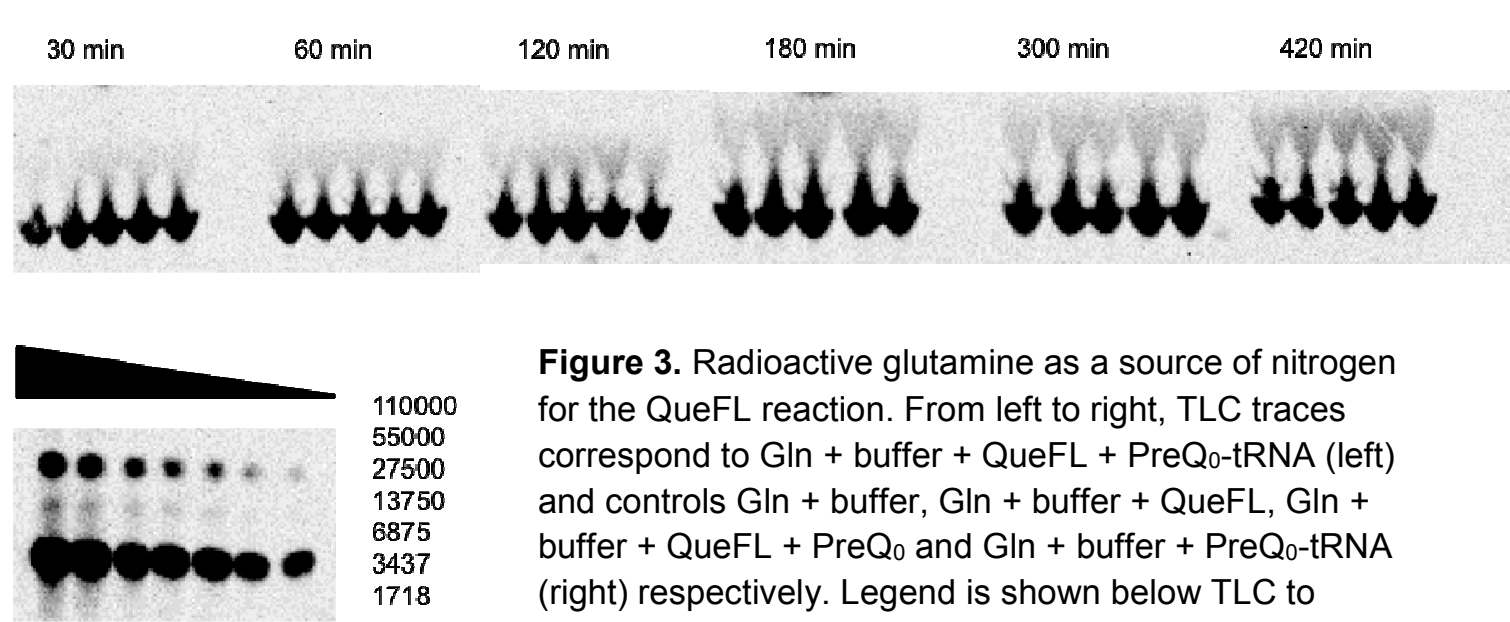

Figure 3. Radioactive glutamine as a source of nitrogen for the QueFL reaction. From left to right, TLC traces correspond to Gln + buffer + QueFL + PreQo-tRNA (left) and controls Gln + buffer, Gln + buffer + QueFL, Gln + buffer + QueFL + PreQ 0 and GIn + buffer + PreQo-tRNA (right) respectively. Legend is shown below TLC to indicate approximate DPM in the reactions.

As previously discussed, glutamine amidotransferases utilize a cysteine in the active site in order to remove nitrogen from glutamine. QueF-like contains a 
single conserved cysteine and it has been shown here that this cysteine binds PreQ 0 and is therefore not available for nitrogen removal.

Radiolabeled asparagine was not available to perform an equivalent experiment as the one described above for glutamine. 